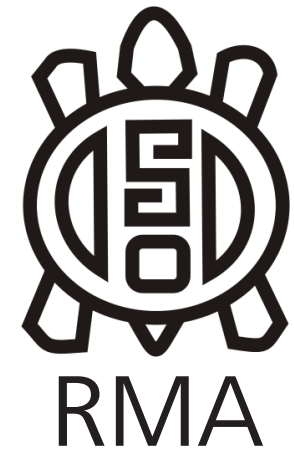

Dossier

Wichí: La palabra

\title{
Los diccionarios matacos de Fr. Esteban Primo de Ayala: Primer registro histórico de la lengua wichí
}

\author{
Friar Esteban Primo de Ayala's Mataco dictionaries: First \\ historical record of the Wichi language \\ Isabelle Combès* y Rodrigo Montani**
}

* Instituto Francés de Estudios Andinos (UMIFRE 17 MAEDI/CNRS USR 3337 - América Latina), y Centro de Investigaciones Históricas y Antropológicas (CIHA). E-mail: kunhati@gmail.com

** CONICET-IDACOR, Argentina; CDE, Universidad de Berna, Suiza, y Centro de Investigaciones Históricas y Antropológicas (CIHA).

E-mail: rodrigomontani@ffyh.unc.edu.ar

\begin{abstract}
Resumen
Se publica por primera vez el manuscrito más antiguo que conocemos de la lengua wichí (familia lingüística mataguaya): el Diccionario y arte de la lengua mataca del franciscano Esteban Primo, confeccionado en la misión de Zenta (actual pronvincia de Salta, Argentina) y fechado en 1795. Asimismo, se contextualiza el documento y se lo compara de forma sistemática con las tres versiones que se preservan del vocabulario conocido como Manuscrito D'Orbigny. La comparación evidencia que este manuscrito, hasta ahora anónimo, es obra del propio Primo.
\end{abstract}

Palabras clave: Wichí/weenhayek; Gran Chaco; Alcide d'Orbigny; Lingüística misionera; Lingüística histórica.

\begin{abstract}
The oldest manuscript known of the Wichi language (Mataguayan linguistic family) is published for the first time: the Diccionario y arte de la lengua mataca by the Franciscan Esteban Primo, compiled in Zenta mission (now province of Salta, Argentina) and dated in 1795. This manuscript is also contextualized and systematically compared with the three preserved copies of the vocabulary known as the Manuscrito D'Orbigny in order to show that this manuscript, so far anonymous, is the work of Primo himself.
\end{abstract}

Keywords: Wichi/Weenhayek; Gran Chaco; Alcide d'Orbigny; Missionary linguistics; Historical linguistics.

El vocabulario manuscrito de la lengua mataca llevado por Alcide d'Orbigny a Francia, que se remonta al siglo XVIII, es considerado el registro más antiguo de la lengua wichí que está hoy a nuestro alcance. Sin embargo, existe en el Archivo Franciscano de Tarija (en adelante, AFT), en Bolivia, un diccionario manuscrito de la lengua mataca, muy poco conocido, de autoría del P. Esteban Primo de Ayala (de ahora en más, Primo), confeccionado en la misión de Zenta (actual provincia argentina de Salta) y fechado de 1795. Aquí publicamos por primera vez este manuscrito de Primo, lo contextualizamos y lo comparamos de manera sistemática con las tres copias del Manuscrito D'Orbigny que hoy están disponibles. La comparación de los documentos permite hacer algunas hipótesis sobre la historia de los documentos y pone en evidencia que el Manuscrito D'Orbigny, de autoría hasta ahora anónima, es obra del mismo autor franciscano.

\section{El Manuscrito D'Orbigny}

Entre los años 1826 y 1834, el afamado naturalista francés
Alcide d'Orbigny recorre gran parte de Sudamérica. Fruto de su viaje es el monumental Viaje a la América meridional, y algo más: en efecto, D’Orbigny se lleva a Francia buena cantidad de manuscritos antiguos que encuentra al azar durante su largo itinerario. Entre ellos, menciona a "un vocabulario manuscrito" de la lengua de los indios "matacos, bejosos y mathaguayos" "escrito por los religiosos de las antiguas misiones de la frontera oriental de Tarija" (Bolivia) en el siglo XVIII (Orbigny, 1839, pp. 234, 236). En una copia parcial de este documento realizada por el propio D'Orbigny, que se conserva en la Biblioteca Nacional de Francia, el autor precisa que estos religiosos eran jesuitas (Orbigny, c. 1830, p. 22); sin embargo, veremos que se equivoca.

Como es sabido, durante la época colonial y buena parte de la republicana, "mataguayos" y "matacos" son nombres aplicados a los grupos indígenas del Chaco occidental actualmente conocidos como wichís. Lo mismo sucede con "vejoz" (los "bejosos" de D'Orbigny), que era el nombre dado especialmente a una "parcialidad" 
de los wichís del actual Chaco salteño y jujeño (Montani y Combès, 2019). Aunque con variaciones dialectales, todos los grupos wichís hablan una misma lengua, perteneciente a la familia lingüística mataguaya o mataco-mataguaya (cf., p. ej., Fabre, 2005). El manuscrito recogido por D'Orbigny, en efecto, empieza afirmando que la lengua que registra es común a las "naciones" de los matacos, bejosos y mataguayos ${ }^{1}$.

La importancia de este documento, al que por comodidad de aquí en adelante llamaremos Manuscrito D'Orbigny, radica ante todo en la fecha temprana en la que fue confeccionado. De hecho, aunque se tienen noticias de que el padre jesuita Juan Nicolás Araoz redactó alrededor de 1744 un arte y vocabulario mataguayo (Hervás, 1800, p. 164), lo cierto es que este manuscrito está extraviado o quizá ha sido destruido. De esta manera, hasta el momento el Manuscrito D'Orbigny es el registro más antiguo de la lengua wichí que tenemos a nuestro alcance.

Este documento fue escrito por misioneros de Tarija que, según D'Orbigny, eran padres jesuitas. Como adelantamos, acá el francés se equivoca². Además de varias misiones inestables que mantuvieron entre indígenas chiriguanos, de lengua guaraní, los jesuitas de Tarija mantuvieron una sola misión (media misión, mejor dicho) entre "mataguayos": la de Nuestra Señora del Rosario de Salinas (Lozano, 1733, pp. 276ss, 302-303). Tanto en los escritos jesuitas como en los posteriores, estos indígenas siempre son llamados "mataguayos", nunca "vejoces" -ni "hueshuos", que es como anota este nombre el jesuita Camaño (1955 [c. 1788]). De hecho, el nombre de parentela "vejoces" se aplicaba a gente que vivía más al suroeste, desde la margen izquierda del río Bermejo hasta la cuenca del Itiyuro, y tal como señaló el franciscano Doroteo Giannecchini al lingüista Samuel Lafone Quevedo, "nunca ni en ningún tiempo ha pertenecido al territorio boliviano"3.

Más aún, si bien no podemos afirmar que no lo hicieron, no tenemos noticias ni registros de que los jesuitas de Salinas hayan trabajado en aprender la lengua de sus mataguayos. Es que estos indígenas eran minoría en la misión, que compartían con indígenas chiriguanos e incluso con mestizos andinos. Concretamente, en 1767, cuando la Compañía de Jesús fue expulsada, en Salinas vivían 268 chiriguanos y apenas 56 mataguayos;

\footnotetext{
${ }^{1}$ No hay que olvidar que los jesuitas ya habían dicho más o menos lo mismo: Camaño (1955 [c. 1788]) señaló que los "matacos" y los "hueshuos" eran "parcialidades" o "tribus" de los "mataguayos", y Lorenzo Hervás, informado por el padre Juan Araoz, sostuvo que "Todas las tribus [mataguayas] hablan un mismo idioma con pequeña diferencia" (1800, p. 164)

2 Probablemente encandilado por la fama alcanzada por las reducciones jesuitas del Paraguay, D'Orbigny no es el único viajero en confundir jesuitas y franciscanos. Poco más tarde, Hugues Weddell (2018 [1851]) también se equivoca constantemente entre ambas órdenes religiosas.

${ }^{3}$ Carta de Doroteo Giannecchini a Lafone, 18.02.1895, reproducida con modicaciones en Lafone Quevedo, 1896b, p. 7.
}

una mujer mataguaya estaba casada con un mestizo de apellido Quispe (de origen andino); dos otras tenían cónyugues mulatos, y un mataguayo también estaba casado con una mulata 4 . En estas circunstancias, lo más probable es que la evangelización de los mataguayos de Salinas se haya hecho en castellano o, a lo sumo, en el guaraní de los chiriguanos.

La expulsión de los jesuitas conllevó el traspaso de la misión de Salinas al Colegio franciscano de Propaganda Fide de Tarija, que precisamente hacia ese fin de siglo se encontraba en plena expansión. Hasta 1800, este colegio llegó a fundar más de 20 misiones entre indígenas chanés y chiriguanos en los confines occidentales del Chaco boreal, y una en Zenta (o Centa), en plena selva pedemontana del actual Noroeste Argentino. Nuestra Señora de las Angustias de Zenta se fundó en 1779 muy cerca del paraje donde, pocos años después, el intendente de Salta fundaría el pueblo de Orán. Sus neófitos eran "mataguayos" y "bejoses", tal vez también "matacos", aunque este nombre genérico parece más bien haber sido un sinónimo (más despectivo) del también genérico mataguayos: de hecho, según el padre Mingo de la Concepción (1981 [1791], p. 377), "matacos" era el nombre dado a los mataguayos en la provincia de Jujuy ${ }^{5}$. Por entonces, según Doroteo Giannecchini, en esta región los mataguayos vivían en el margen derecha del río Bermejo y los vejoces en el izquierdo ${ }^{6}$. Los sempiternos conflictos entre indígenas y colonizadores suscitados por la fundación de la Orán en 1794, sumado a los problemas de convivencia entre mataguayos y vejoces, obligó a fundar otras dos misiones. Primero, Zaldúa, hacia el sureste, donde se trasladaron los vejoces, que duró menos de un año (1799-1800) y terminó con un pronto reintegro de esos vejoces a Zenta. Segundo, San Esteban de Río Seco, hacia el noreste, donde se trasladaron exclusivamente los mataguayos; pero la misión no tuvo más que dos años de vida (1802-1804) y, una vez cerrada, los mataguayos también volvieron a Zenta (Comajuncosa, 1884 [1810], p. 179) ${ }^{7}$. Estas tres misiones son importantes para la historia del pueblo wichí, porque testimonian un tiempo en el que todavía ocupaban también los valles selváticos del piedemonte.

El gentilicio "bejoses", "bejosos" o, más comúnmente, "vejoces" es la notación castellana, y en plural, de un conocido nombre de parentela wichí: wej-wos 'agentes

\footnotetext{
${ }^{4}$ Lista o padrón de la gente o almas de chiriguanos y mataguayos, que tenía la misión de Salinas cuando fue entregada a los misioneros franciscanos de Tarija en septiembre de 1767 (AFT 1-1017).

5 Sobre Zenta, cf. Mingo de la Concepción (1981 [1791], cap. XXIII) y Comajuncosa (1884 [1810], cap. XI). Para un ejemplo de un toba llamando "mataco" como insulto a un mataguayo, cf. la carta del jesuita Román Arto [1756-1762], en Maeder et al., 2016, pp. 189190. Para más información sobre el gentilicio "mataco", cf. Montani y Combès, 2019

6 Carta de Doroteo Giannecchini a Lafone Quevedo, 18.02.1895, reproducida en Lafone Quevedo 1896b, p. 7.

7 En su carta a Lafone, el padre Giannecchini se equivoca y dice que Río Seco se fundó para los vejoces (en Lafone Quevedo, 1896b, p. 8).
} 
del trasero'8. En cuanto a los "mataguayos" de Zenta, al menos parte de ellos llegaron desde la antigua misión de Salinas, huyendo de la difícil convivencia con los chiriguanos9. La inequívoca mención de los "bejosos" en el Manuscrito D'Orbigny indica sin lugar a dudas que fue escrito en Zenta por un misionero franciscano de la misión. Así como constatan los frailes de Zenta que "la lengua de ellos [los vejoces] es la misma que la de los mataguayos"10, las copias que conocemos del Manuscrito D’Orbigny empiezan afirmando que esta lengua es común a las tres "naciones" de los "bejosos", "mataguayos" y "matacos" (Lafone Quevedo, 1896b, p. 15; Orbigny, c. 1830, p. 23). Lo mismo indica el otro manuscrito escrito en Zenta en 1795, que es el que examinamos a continuación.

\section{El diccionario de Primo de Ayala}

El misionero franciscano que más tiempo trabajó en Zenta evangelizando vejoces y mataguayos fue fray Esteban Primo de Ayala, fundador, además, de la efímera reducción de Río Seco (Comajuncosa, 1884 [1810], p. 180).

Nacido en 1765 en Villasesmil (Palencia, España), Esteban Primo se trasladó a América en 1787. Desde 1788 hasta 1801 fue conversor en la misión de Zenta. En 1801 fue nombrado "prefecto de misiones" del Colegio de Tarija y en 1804, "padre guardián" del mismo Colegio. En 1811-1812, durante las guerras de Independencia, volvió a Zenta y fue tomado preso por el bando patriota, que lo liberó poco después. En 1813 regresó a Tarija donde ejerció nuevamente de guardián. Falleció en 1834 (Necrología, 2004 [1834]). Se trata de uno de los pocos frailes que permanecieron en Tarija durante los sombríos años de las guerras de Independencia. En 1802, el comandante del fuerte de Pizarro, Diego José de Puyrredon, y el subdelegado y comandante de la ciudad de Orán, lo califican de "conversor de la Nación Bejosa" e, incluso, de "oráculo de los indios del Chaco"11.

Más importante para nosotros, fray Esteban dedicó largas horas a aprender la lengua de sus neófitos vejoces y mataguayos. Como adelantamos, existe en el AFT un manuscrito de su autoría y de su puño y letra ${ }^{12}$, titulado

\footnotetext{
${ }^{8}$ Las palabras wichís en cursivas son las del wichí que conocemos hoy, escritas en el alfabeto unificado por los anglicanos (cf. Lunt, 2016). Las comillas simples encierran las glosas o traducciones literales. Los signos menor y mayor $(<>)$ encierran las palabras wichís en su ortografía original. Entre barras (//) aparecen las notaciones fonológicas.

${ }^{9}$ Lista de indios mataguayos bautizados en Salinas que se fueron a vivir a Centa antes de ser reducción, 20.11.1789 (AFT 1-1095); Mingo de la Concepción, 1981 [1791], p. 378.

${ }^{10}$ Carta del P. Benvenuto Vidal al P. Mingo de la Concepción, Zenta, 30.12.1789 (AFT 1-1098).

${ }^{11}$ Testimonios de Diego José de Puyrredon, comandante del fuerte de Pizarro, y de Rafael Bachir, subdelegado y comandante de la ciudad de Orán, 1802 (AFT 1-1115: 1v-2).

12 La comparación de este documento con cartas de Primo conservadas en el mismo AFT demuestra que efectivamente fue escrito por él.
}

Diccionario y arte de la lengua mataca compuesto por el P. Fr. Esteban Primo, conversor de la reducción de Nuestra Señora de las Angustias, de indios mataguayos, bejoses y matacos en el valle de Centa, año de 1795 (AFT 1-1834). Se trata de un cuaderno de 26 folios (más la carátula), organizado en tres partes. La primera es un vocabulario español-mataco, dividido en dos columnas, una para nombres y otra para verbos (ff. 1-23) (FIGURA 1); la segunda es un suplemento con más nombres y verbos (ff. 24-24v) (en Tabla 4); la tercera es una doctrina bilingüe (en Tabla 3), que incluye además el Padre Nuestro y el Ave María "en lengua mataca o mataguaya" (ff. 2626v). El documento no presenta el "arte" anunciado, es decir, la gramática, a excepción de la siguiente nota en la contra-carátula:

En esta lengua mataca, mataguaya o bejosa, que es lo mismo, los nombres son indeclinables, y sólo por alguna proposición o letra que se les antepone o pospone se distingue el singular del plural y una persona de otra. Lo mismo digo de los verbos, aunque no es regla general, porque muchas veces el singular no se distingue en nada del plural, ni una persona de otra. También es muy común en esta lengua el sincopizar las primeras dicciones de los nombres y verbos, cuando se juntan con otros.

Si bien esta observación general es acertada (en wichí no hay casos, los nombres inalienables llevan obligatoriamente prefijo posesivo, el plural verbal es a veces facultativo y la aféresis es frecuente; cf. Nercesian, 2014; Terraza, 2009; Viñas Urquiza, 1974), es un hecho que, contrariamente a lo que ocurriría luego durante la época republicana, durante el período colonial los franciscanos de Tarija no destacaron por sus habilidades lingüísticas. A partir de la fundación de su primera misión entre los chanés de Pilipili en 1767, los prefectos de misiones y los padres guardianes del Colegio insisten en la necesidad de aprender la lengua guaraní hablada por la inmensa mayoría de sus neófitos. Así, por ejemplo, en 1788, fray Manuel Parra envía una circular a los misioneros, donde ve "conveniente" el aprendizaje de la lengua chiriguana (AFT 1-1039); en 1810 el prefecto de misiones, fray Benito Izquierdo, reitera que los padres "deben aplicarse con diligencia" en aprender el chiriguano (AFT 1-489). Pero en este aspecto, los logros son magros y el panorama es más bien desalentador. Aunque mucho después los padres Santiago Romano y Hermán Cattunar escriban que "desde que, en 1755, se fundó este Colegio Franciscano de Santa María de los Ángeles de Tarija, con el fin principal de llevar la luz de la fe y de la civilización a las tribus salvajes del Chaco y de otras regiones, nuestros misioneros pusieron todo su conato en dominar las lenguas de esas mismas tribus, para obtener así el trato apetecible del apostolado" (1916, p. iii), lo cierto es que en los inicios de la evangelización los franciscanos de Tarija no parecen haber cumplido sus promesas (Combès y Oliva, en prensa). Los misioneros no dominan el idioma chiriguano, ni siquiera lo habla bien el abnegado Francisco 


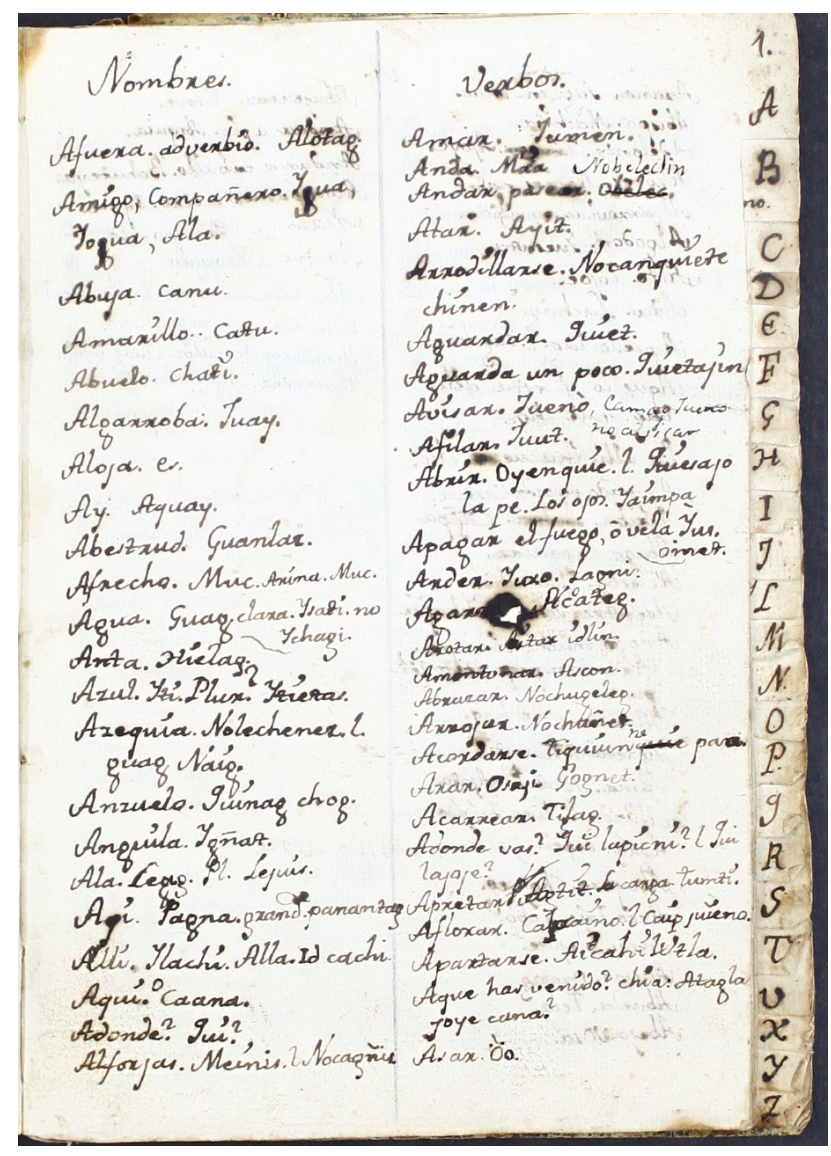

Figura 1. Primer folio del Diccionario y arte de la lengua mataca de Primo, 1795 (AFT 1-1834).

Figure 1. First page of Diccionario y arte de la lengua mataca by Primo, 1795 (AFT 1-1834)

del Pilar, fundador de la mayor parte de las misiones (Saignes, 1984, pp. 28-29). Podemos imaginar que la situación era aún peor en lo que concierne a la lengua de los vejoces y mataguayos, integrantes de una sola misión y un grupo minoritario entre los neófitos de Tarija. Esteban Primo de Ayala fue una notoria excepción franciscana en el aprendizaje lingüístico, pues pensamos que, además del mencionado Diccionario y arte de la lengua mataca, fue también el autor del Manuscrito D'Orbigny, redactado en la misma misión, como lo confirma plenamente la comparación de ambos vocabularios (Tabla 4).

\section{Los manuscritos de fray Esteban}

Si bien recorrió buena parte del territorio boliviano, Alcide d'Orbigny nunca estuvo en Tarija. En su descripción de los mataguayos, basada sobre "todo lo que se ha escrito sobre el Chaco", menciona haber encontrado (no dice donde) a "un habitante de Tarija" que vivió entre ellos por mucho tiempo (Orbigny, 1839, p. 236.). ¿Este tarijeño le habría entregado el manuscrito franciscano que se llevó a Francia? No lo sabemos. Otra posibilidad es que D'Orbigny lo haya conseguido en los colegios franciscanos de Sucre, La Paz o Tarata, a los que sí visitó.
Sea lo que fuere, y aunque según Lafone el Manuscrito D'Orbigny estaría resguardado en la Biblioteca Nacional de Francia (BNF), no logramos ubicarlo. Hoy sólo lo conocemos por tres transcripciones. La primera es, en la misma BNF, una traducción y transcripción parcial hecha por el propio D'Orbigny (c. 1830). Abarca el "Vocabulario" hasta los inicios de la letra "e". En esta transcripción, que llamaremos Copia D'Orbigny, el naturalista divide las entradas en tres columnas: español, mataco y francés (FIGURA 2).

Otras dos transcripciones del Manuscrito D'Orbigny fueron publicadas, respectivamente, en 1896 y en 1913, por Lafone. El autor explica que, a finales del siglo XIX, el lingüista francés Lucien Adam le entregó una copia del manuscrito original (Lafone Quevedo, 1896b, p. 14; y en Hunt, 1913, p. 8) ${ }^{13}$. Este documento contenía "un regular vocabulario y cinco carillas de apuntes gramaticales". Estos apuntes, que inician en el folio 55 del documento, fueron transcritos y comentados por Lafone y publicados junto con el vocabulario en 1896, como artículo del Boletín del Instituto Geográfico Argentino $y$, en ese mismo año, como un libro independiente. Ambas publicaciones son idénticas. A esta transcripción la llamaremos Copia Lafone. Lafone atribuye la autoría del manuscrito, correctamente, a los misioneros franciscanos de Río Seco y/o Zenta (Lafone Quevedo, 1896b, p. 15.), y llama al documento "manuscrito vejoz", asumiendo que se trata de un registro del dialecto vejoz de la lengua wichí o, como él dice, "mataca". Sin embargo, si creemos en la Copia D'Orbigny, el documento es un vocabulario de la lengua que hablan los matacos, mataguayos y vejoces, sin distinción; y, de hecho, tampoco aparecen en el cuerpo de la Copia Lafone (ni en ninguna de las copias) marcas que indiquen variantes dialectales propias de "los vejoces".

Es el momento de dejar algo bien en claro. Desde la Colonia hasta casi la actualidad, la sociología de los wichís y la dialectología de su lengua se han basado sobre conceptos equivocados. Concretamente, la idea es siempre que los wichís están divididos en grupos bien delimitados y localizados, con nombres específicos y que hablan cada uno de ellos variedades geolectales de la lengua, dialectos. Las objeciones a esta idea son tres. Primero, aunque desde la colonia los no wichís han visto a los wichís como un conglomerado de subconjuntos sociales autocontenidos y localizados ("naciones", "parcialidades", "tribus", "bandas", etc.), los análisis sociológicos más rigurosos muestran que los wichís son más bien un entretejido de parentelas bilateras abiertas, geográficamente superpuestas (p. ej., Montani, 2017a; Palmer, 2005). Segundo, entre los gentilicios que se han usado para clasificar internamente a los wichís, algunos son exógenos ("mayaguayos", "matacos") y otros son endógenos: los nombres de parentela, los gentilicios

\footnotetext{
${ }^{13}$ Consultado al respecto Máximo Farro, responsable del fondo Lafone Quevedo en el Museo de La Plata, nos comunicó que esta copia no se ha conservado.
} 
topológicos y los gentilicios ecológicos (Montani, 2017a, pp. 91ss; Montani y Combès, 2019). Aunque los nombres de parentelas tienen una función de identificación subjetiva -algo así como un apellido, pero de transmisión más compleja (Palmer, 2005, p. 118ss)-, tienen sobre todo una función de clasificación intraétnica; y en esta función, son fundamentalmente motes burlescos, o incluso insultantes, que sirven para nombrar a los grupos vecinos grosso modo y en un movimiento centrífugo que parte de la propia comunidad; es decir, no son nombres de grupos ni claramente localizados ni bien definidos. Por último, teniendo en cuenta la dinámica sociológica de los wichís, desde el punto de vista dialectológico debemos esperar variaciones graduales en distintos planos de la lengua a lo largo del territorio, con algunas dislocaciones acá y allá por trayectorias históricas específicas; para decirlo llanamente: la lengua wichí no es una bolsa de dialectos y esos dialectos, menos aún, se corresponden de manera biunívoca con grupos que presuntamente identificarían los nombres de parentela ${ }^{14}$.

Todo esto es en parte para decir que más que de un "dialecto vejoz", como dijo Lafone, se trata de una variante geolectal de la lengua wichí, hablada por la gente que se dio encuentro en la misión de Zenta. El propio diccionario de Primo nos da la pauta de que su o sus informantes realmente no se identificaban con ninguno de los nombres que figuran en el título del manuscrito -con "mataguayo" y "mataco" es predecible que no lo hiciesen, porque son nombres exógenos, pero tampoco "vejoz" (wej-wos) parece ser un nombre que ellos se estén aplicando a sí mismos. Concretamente, el diccionario traduce "Mataguayo" por <Taglele> pl. <Tagleleleis>, es decir, tahyi-Ihelhey 'habitantes del bosque/montaraces'; "Mataco" por <Aanal> pl. <Aanaleis>, es decir, änällhais 'vizcacha', un nombre de parentela -hoy, aplicado generalmente a la gente que vive más al sudoeste que los wej-wos-, y "Bejoso" [vejoces], llamativamente, no por wej-wos, sino por <Tacho> pl. <Tachones>, es decir, tachonhay 'frentones' - un nombre de parentela hoy asignado, generalmente, a grupos del interior del Chaco salteño (cf. Montani, 2017a, pp. 101-102).

Volviendo al Manuscrito D'Orbigny, la historia de las copias se cierra en 1913, cuando Lafone vuelve a publicar el "vocabulario vejoz", esta vez con una revisión del misionero y lingüista anglicano Richard Hunt. Entre las columnas en castellano y en wichí original, Hunt intercala una columna suya, el "wichí revisado", donde traslitera a lo que podríamos Ilamar el "primer alfabeto Hunt"

\footnotetext{
${ }^{14}$ Como uno de nosotros dijo en otra ocasión, hasta ahora los lingüistas han subrepresentado la diversidad y la complejidad dialectal del wichí, al menos por tres razones: a) las comparaciones han sido en el nivel fonético-fonológico y escasamente en el léxico, pero poco o nada en el morfosintáctico; b) no se han hecho encuestas sociolingüísticas amplias y bien contextualizadas; c) no se ha comprendido bien la organización sociopolítica wichí ni la historia regional (Montani, 2017a, p. 128). El trabajo de Nercesian en este dossier es un primer intento por resolver al menos las dos primeras dificultades.
}

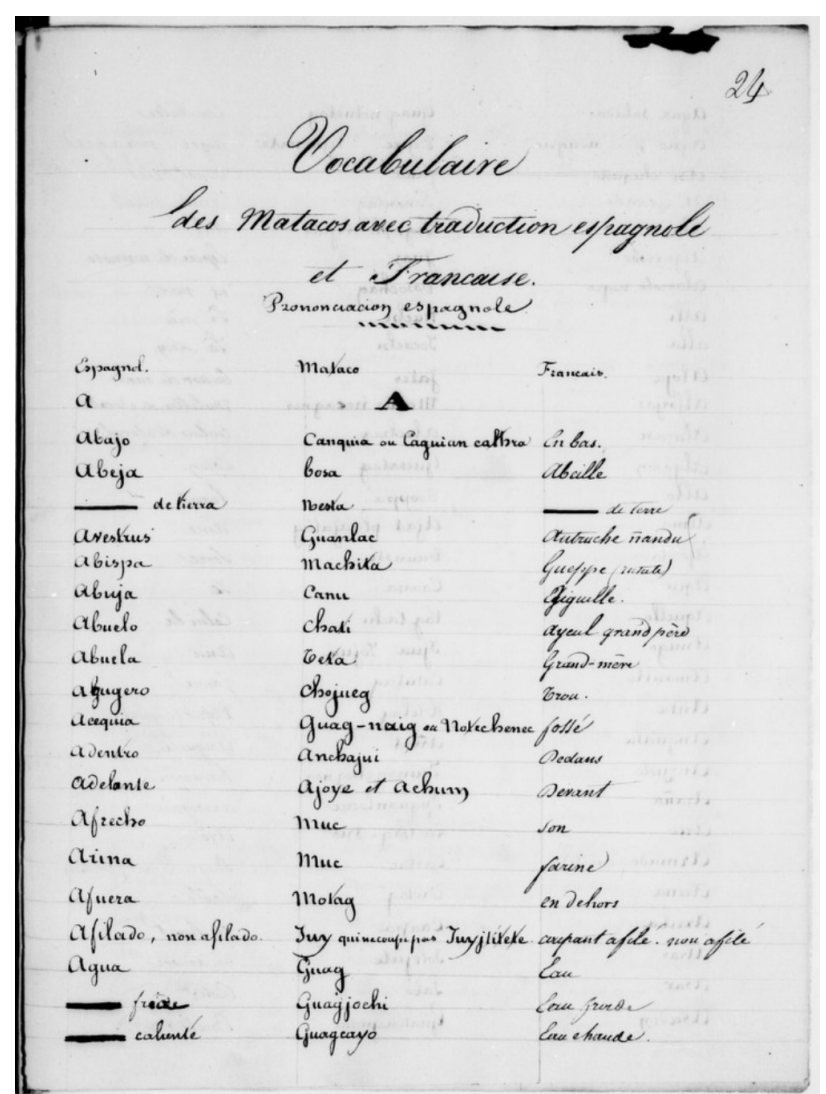

Figura 2. Primera página de la Copia D'Orbigny (c. 1830, BNF, Manuscrits Américains 26, f. 24).

Figure 2. First page of Copia D'Orbigny (c. 1830, BNF, Manuscrits Américains 26, f. 24).

e intenta acomodar las expresiones wichí a lo que él conoce. El anglicano es el único de nuestros tres copistas que efectivamente conoce la lengua wichí y, más aún, la conoce en una variante occidental del continuum dialectal wichí, como también había sido una variante occidental la que conoció Primo. Cabe destacar, sin embargo, que se trata de un Hunt que todavía está aprendido la lengua (la estudia desde hace casi dos años), y no de un Hunt que la conoce a la perfección como sí lo evidencian sus últimos trabajos (cf. Montani, 2015). Llamaremos a esta copia del Manuscrito D’Orbigny, la Copia Hunt.

En la Tabla 4 ofrecemos entonces una comparación entre, por una parte, el manuscrito original de Primo conservado en el AFT y, por otra, las tres copias que sí conocemos del inhallable Manuscrito D'Orbigny. Las similitudes no dejan lugar a dudas, y confirman que Primo fue el autor de ambos documentos. Resumamos brevemente lo que nos muestra la comparación.

En primer lugar, es asombrosa la similitud de las entradas en español y, en particular, de la ortografía de estas entradas. Para facilitar la lectura del cuadro hemos modernizado la ortografía del español, pero debemos resaltar que en los diversos documentos se advierte 
la misma manera de escribir el castellano. Más allá de grafías corrientes en la época como "baca" por "vaca", tanto Primo como el autor hasta ahora anónimo del Manuscrito D'Orbigny escriben, por ejemplo, "abujero" y "abuja" para "agujero" y "aguja". Además, la gran mayoría de las entradas castellanas del diccionario se corresponden estrechamente $y$, convendremos, por ejemplo, que no es tan frecuente que un misionero ofrezca una traducción para "hijo de puta". Otras entradas de ambos documentos, muy singulares, también obligan a pensar que son fruto de una misma cabeza: "componer los reñidos", por ejemplo, o "cortarse el pelo, cortar hasta la frente, cortar hasta las orejas". Va en el mismo sentido la elección en ambos documentos de palabras como "galápago" para "tortuga", o del quechuismo "gualca" (en el quechua de hoy, walqa) por "collar".

En segundo lugar, la prueba más contundente de que ambos manuscritos son producto de una misma persona está en que en ambos documentos nombres y verbos se presentan en dos columnas separadas $y$, sobre todo, en que las palabras wichís de ambos documentos son mayormente las mismas y siguen la misma ortografía. Cuando aparece una diferencia otrográfica, en muchísimos de los casos ella se debe evidentemente a errores del copista.

En ausencia del original del Manuscrito D'Orbigny, estamos reducidos a trabajar con las copias, con los consiguientes posibles errores de transcripción. Pero comparando las palabras de Primo con las de las copias a la luz del wichí actual, pudimos detectar muchísimos casos que deben atribuirse a errores de los copistas. Las equivocaciones más frecuentes se deben a malas lecturas de letras, a veces muchas en una misma entrada. En la Tabla 1 damos unos pocos ejemplos de esos errores, tomados un poco al azar. Las confusiones más frecuentes, aunque de ningún modo las únicas, son entre $g, y$ y $q$, entre e y $c, y$, especialmente en la Copia D'Orbigny, entre $t$ y l. Creemos poder garantizar que nosotros hemos distinguido bien entre todas estas letras en la caligrafía de Primo. Otras diferencias entre las ortografías de los documentos, como la pérdida o reemplazo de la $g$ en las palabras wichís para "acarrear", "ají" o "cavar", o como la enmienda de la $z$ de Primo en la palabra wichí para "armado", dejan en claro que el diccionario de Primo no es exactamente el mismo documento que el Manuscrito D'Orbigny, y apuntan incluso a la existencia de una cuarta copia, que podría haber hecho Adam y habría mediado entre el Manuscrito D'Orbigny y las copias de Lafone y Hunt. En suma, las conclusiones más importantes que permite sacar la comparación de las entradas coincidentes son que (a) la ortografía de Primo se ajusta muchísimo más a la fonología del wichí actual que la ortografía de las copias -o, lo que es lo mismo, que estas se equivocan muchísimo más que aquel, lo que las confirma en su carácter de copia-y b) que aunque las tres copias se asemejan entre sí en su ortografía y se diferencian del diccionario de Primo, la Copia D'Orbigny se equivoca mucho más que las otras dos copias, lo que -repetimos- hace pensar que estas son copias de una hipotética cuarta copia más fiel, o incluso del Manuscrito D'Orbigny original.

Desde el punto de vista cuantitativo, el Manuscrito D’Orbigny, con más de 1.000 entradas, es algo más extenso que el diccionario de Primo, que tiene solo 804 (Tabla 4). Además, a veces las copias nos permiten deducir que el Manuscrito D'Orbigny tenía con respecto al diccionario de Primo algunas enmiendas lexicográficas. Por ejemplo: Primo traduce erróneamente "Cubrirse o ponerse el sombrero" por <Tipa letec> tiphä lhetek 'alzar la cabeza', mientras que las copias, acertadamente, lo trasladan por <Tipo cabona> tiphä lakawona 'ponerse el sombrero'. Otro ejemplo: Primo traduce "Alto" por $<$ Tojoc $>$, que parece ser un error por thaläkw /tha'lakw/ 'ser adulto' (cf. <talac> en "maduro"), mientras que las copias lo trasladan por <Tooppa>, hoy -tofwphä / tox ${ }^{w} \mathrm{p}^{\mathrm{h}} \mathrm{a} /$ 'estar alto'. A veces, además, las copias del Manuscrito D'Orbigny agregan sinónimos que no figuran en Primo, como en "amigo", donde Lafone y Hunt suman <Jumenec> humenek /hume 'nek/ 'amado'. Finalmente, el Manuscrito D'Orbigny tiene una gramática que el manuscrito de Tarija no ofrece, pese a su título. Todos estos indicios hacen pensar que el documento llevado por D’Orbigny era una versión posterior, más completa y mejorada del que está conservado en Tarija o, lo que es lo mismo, que este es una primera versión, o un borrador, del Manuscrito D'Orbigny ${ }^{15}$. Uno no puede dejar de preguntarse, sin embargo, por qué en el diccionario de Primo figuran a veces aciertos que se pierden en el Manuscrito D'Orbigny, como en "cuchillo", que Primo traslada por <Cognet> (tsonhat 'cuchillo/ puñal') y <Catnet $>$ (katnhat 'cuchillo'), pero que las copias traducen sólo con el primer término.

La autoría de Primo del Manuscrito D'Orbigny se apoya también en un criterio cuantitativo. En total, la Tabla 4 ofrece 1.094 entradas en castellano seguidas por su traducción en wichí. El diccionario de Tarija posee 804 entradas castellanas; la Copia D'Orbigny (incompleta), sólo 366. La Copia Lafone tiene 1005 entradas y la Copia Hunt, 1037. Puede parecer extraño que el número de entradas varíe entre Lafone y Hunt, que supuestamente transcriben un mismo documento; pero lo más probable es que Hunt -el único que hablaba wichí- haya agregado o cambiado entradas en busca de una mayor profundidad de análisis. Así, por ejemplo, la Copia Hunt es la única copia que registra una entrada para "animal, insecto": $<$ locue >-creemos que como resultado de un análisis fallido del término wichí que en el Manuscrtito D'Orbigny

\footnotetext{
15 Esto es algo que en el mismo AFT sucede también con otros documentos, de los que existen tres o más borradores, como es el caso del diccionario de la lengua chiriguana del padre Doroteo Giannecchini.
} 
Tabla 1. Algunos ejemplos de los errores más frecuentes que se deducen de la comparación de los documentos a la luz del wichí actual. Referencias: $\mathrm{H}$ Copia Hunt, L Copia Lafone, O Copia D’Orbigny, P diccionario Primo.

Table 1. Some examples of the most frequent errors that can be deduced from the comparison of the documents under the light of current Wichi language. References: H Hunt's Copy, L Lafone's Copy, O D'Orbigny's Copy, P Primo's dictionary.

\begin{tabular}{|c|c|c|c|}
\hline $\begin{array}{l}\text { Castellano } \\
\text { original }\end{array}$ & Correcto & Errado & Wichí actual /fonologia/ 'glosa' \\
\hline \multicolumn{4}{|c|}{ Equivoca el orden de una letra } \\
\hline bolsa, tabaquera & \begin{tabular}{|l|} 
no cagni $(\mathrm{P})$ \\
nocagni $(\mathrm{L})$ \\
no-cagni $(\mathrm{H})$ \\
\end{tabular} & noacgni (O) & nokäy-hi/nokaj'fi// 'su bolsa' \\
\hline \multicolumn{4}{|c|}{ No pone una letra } \\
\hline acarrear & tiglag $(\mathrm{P})$ & tilag $(\mathrm{O}, \mathrm{L}, \mathrm{H})$ & tilhäj/ti'łax/'acarrea/carga y lleva' \\
\hline ají & pagna $(\mathrm{P})$ & pana $(\mathrm{O}, \mathrm{L}, \mathrm{H})$ & pänhän/pa'naan/'ají del monte' \\
\hline \multicolumn{4}{|l|}{ Confunde letras } \\
\hline anguila & igñat (P) & añat $(\mathrm{O}, \mathrm{L}, \mathrm{H})$ & ihya /i'h ${ }^{\mathrm{j}} \mathrm{a} /$ 'anguila' \\
\hline caldo & tobeg ii $(\mathrm{P})$ & \begin{tabular}{|l|} 
tobebii $(\mathrm{O})$, \\
tobobii $(\mathrm{L}, \mathrm{H})$ \\
\end{tabular} & towej-t' $i$ /towex't ${ }^{2} \mathrm{i}$ / 'líquido de la olla' \\
\hline anta & hielag $(\mathrm{P})$ & $\operatorname{hiclag}(\mathrm{O}, \mathrm{L}, \mathrm{H})$ & yel'a /ye $\mathrm{e}^{12} \mathrm{la} /$ 'tapir' \\
\hline agrio & tepei $(\mathrm{P}, \mathrm{L}, \mathrm{H})$ & tepec $(\mathrm{O})$ & tapay/ta'paj/'ser amargo' \\
\hline caballo & $\operatorname{latag}(\mathrm{P})$ & $\operatorname{letag}(\mathrm{O})$ & (y'e)lataj /je ela'tax/'caballo' \\
\hline $\begin{array}{l}\text { patos negros } \\
\text { chiquititos }\end{array}$ & yeleni $(\mathrm{P})$ & ycleni $(\mathrm{L}, \mathrm{H})$ & yelen' $i / \mathrm{yele} \mathrm{e}^{12} \mathrm{ni} /$ 'patillo' (varias $s p p$.) \\
\hline camisa & sacal (P) & $\operatorname{sagal}(\mathrm{O}, \mathrm{L}, \mathrm{H})$ & sak'al/sa'k'al/'tela delicada' \\
\hline acompañar... & iquie $(\mathrm{P})$ & $\begin{array}{l}\text { ignie/iguie }(\mathrm{O}) \\
\text { iguic }(\mathrm{L}, \mathrm{H})\end{array}$ & iche /'ik $\mathrm{k}^{\mathrm{j}} \mathrm{e}$ ' existir afuera' \\
\hline cabeza & letec $(\mathrm{P})$ & litec $(\mathrm{O}, \mathrm{L}, \mathrm{H})$ & lhetek/le'tek/'su cabeza' \\
\hline afilado & yui $(\mathrm{P}, \mathrm{O}, \mathrm{H})$ & iui (L) & $y^{\prime} u y / \mathbf{j}^{2} u \mathrm{j} /$ 'está afilado' \\
\hline abrir los ojos & yainpa $(\mathrm{O}, \mathrm{H})$ & yaimpa $(\mathrm{P}, \mathrm{L})$ & yahinphä/ja'finp ${ }^{\mathrm{h}} \mathrm{a} /$ 'alza la vista' \\
\hline cavar & gognet (P) & gotnet $(\mathrm{O}, \mathrm{L}, \mathrm{H})$ & honhat/fo'nat/ 'tierra' \\
\hline abeja de tierra & nesla $(\mathrm{L}, \mathrm{H})$ & nesta $(\mathrm{O})$ & neslä/nes'la/ 'abeja alpamiske' \\
\hline abuela & (no)tela $(\mathrm{P}, \mathrm{L}, \mathrm{H})$ & teta $(\mathrm{O})$ & (no)tela /note'la/'(su) abuela' \\
\hline algarroba & iuay $(\mathrm{P})$ & yuay $(\mathrm{O}, \mathrm{L}, \mathrm{H})$ & fwa'ay / $\mathbf{x}^{\mathbf{w}} \mathrm{a}^{21} \mathrm{aj} /$ 'algarrobas' \\
\hline armado, pescado & $\operatorname{castac}(\mathrm{O}, \mathrm{L}, \mathrm{H})$ & castaz $(\mathrm{P})$ & kastak/kas'tak/'armado (pez)' \\
\hline \multicolumn{4}{|l|}{ Errores múltiples } \\
\hline no afilado & yui-nite $(\mathrm{P})$ & $\begin{array}{l}\text { yuyititete }(\mathrm{O}) \\
\text { yui(-)gite, } \\
\text { yui(-)iutetc }(\mathrm{L}, \mathrm{H})\end{array}$ & $y^{\prime} u y h i t$ 'e $^{\prime} \mathrm{j}^{2} u j \mathrm{fi}^{\prime} \mathrm{t}^{2} \mathrm{e}$ / 'no está afilado' \\
\hline agua salada & $\begin{array}{l}\text { guag nosoitag } \\
(\mathrm{P})\end{array}$ & $\begin{array}{l}\text { guag nolnetag }(\mathrm{O}) \\
\text { nanitag }(\mathrm{L}) \\
\text { nanitag }(\mathrm{H})\end{array}$ & $\begin{array}{l}\text { Waj nosoytaj/wax nosoj'tax/'el agua } \\
\text { es muy salada' }\end{array}$ \\
\hline
\end{tabular}

filas, todas las celdas con datos, están en azul);

traducía "araña"16 - o es la Copia Hunt la que rectifica un error al sacar el término <no-tolile> de "caja" y ponerlo en "ceja"17. En el mismo orden de cosas, las palabras wichís varían entre las copias, particularmente en la inserción de espacios o guiones. Las más de las veces Hunt, que ya conocía bastante bien la morfología de la lengua, introduce espacios o guiones en la transcripción original, con ánimo de racionalizar la ortografía. Pero a veces, además, Hunt elimina espacios y guiones que figuran innecesariamente en las copias de D'Orbigny y Lafone, pero que no están en la ortografía de Primo (como en el término wichí para "abrazar").

Del total de 1.094 entradas (Tabla 4), entonces, tenemos:

- $\quad 739$ entradas y su traducción al wichí que se corresponden entre el diccionario de Primo y las copias del Manuscrito D'Orbigny (en esas filas, todas las celdas con datos, están pintadas de amarillo);

\section{- $\quad 17$ entradas que no se corresponden (en esas}

\footnotetext{
${ }^{16}$ Vale notar, sin embargo, que la Copia Hunt traduce "araña" por <suguan-locuc>, menos correcta que la forma que registra Primo: <suguan-locue> suwanlhokwe 'tarántula'. Esto hace pensar que el error de $c$ por $e$ puede haber sido de los editores, no de Hunt. Decimos que el análisis de Hunt es erróneo porque <locue> lhokwe, no significa lo que dice el anglicano, sino 'su mayor/principal'.

${ }^{17}$ Hunt no rectifica sin embargo la ortografía. La correcta parece ser la de Primo, porque en <notelile> reconocemos note-Ihile 'su hueso del ojo'. Esto indica probablemente que el error de o por $e$ estaba ya en el original que Hunt copiaba.
}

- $\quad$ cinco entradas que son casos extraños: un poco extraños (tres), porque algunas de las copias no coinciden con Primo (en estas filas, algunas de las celdas con datos que coinciden están en amarillo y los que no coinciden en violeta), o muy extraños (dos), porque ninguna de las copias coincide con Primo (en esas filas, todas las celdas con datos están en violeta);

46 entradas castellanas que figuran en el diccionario de Primo, pero no en las copias del Manuscrito $D^{\prime}$ Orbigny (en estas filas, todas las celdas con datos, en rojo);

- $\quad 266$ entradas que sólo existen en dos o más copias del Manuscrito D'Orbigny, pero no en Primo (en estas filas, todas las celdas con datos, en verde);

y, por último, 21 entradas sólo existen en una de las tres copias del Manuscrito D'Orbigny (toda la fila sin pintar): cuatro en la Copia D'Orbigny, una en la Copia Lafone y 17 en la Copia Hunt (que, dijimos, probablemente dividió entradas).

La Tabla 2 resume en términos porcentuales esta misma comparación de los documentos. En la Tabla 4 hemos explicado en notas los casos que no se corresponden, los casos extraños y varios de los casos de palabras que existen en las copias pero no en Primo. De todos modos, hemos intentado limitar las notas a las mínimas 
Tabla 2. Resumen en términos porcentuales de la comparación del diccionario de Primo con las copias del Manuscrito D’Orbigny.

Table 2. Percentual summary of the comparison of the Primo's dictionary with the copies of the Manuscrito D'Orbigny.

\begin{tabular}{|l|r|}
\hline \multicolumn{2}{|l|}{ Porcentaje de entradas que } \\
\hline coinciden & $67.55 \%$ \\
\hline no coinciden & $1.55 \%$ \\
\hline son raras & $0.46 \%$ \\
\hline están sólo en Primo & $4.20 \%$ \\
\hline están sólo en las copias del Manuscrito D'Orbigny & $24.31 \%$ \\
\hline aisladas & $1.92 \%$ \\
\hline TOTAL & $100.00 \%$ \\
\hline
\end{tabular}

e indispensables.

\section{Palabras finales}

El documento conocido como Manuscrito D'Orbigny fue publicado dos veces en la Argentina y, por supuesto, es más conocido que el Diccionario y arte de la lengua mataca de Primo de Ayala que resguarda el AFT. Pareciese que la fama del naturalista francés, o el desconocimiento de la historia, llevó a ciertos abusos a lo largo del tiempo, pues no faltaron investigadores que atribuyeron directamente la autoría del primer documento al mismísimo D'Orbigny, que sin embargo no hablaba ni una palabra de wichí ( $p$. ej., Alvarsson y Claesson, 2014; Nercesian 2014, pp. 16, 19; Vidal \& Nercesian, 2009). En ocasiones, la confusión ha tomado dimensiones inimaginables: se ha llegado a afirmar que el "Padre D'Orbigny" (Vidal y Nercesian, 2009a, p. 143)

based on the data provided by his contemporary, Father Doroteo Giannecchini in Tarija (Bolivia), focuses on the Vejoz dialect located in the province of Salta (Argentina) from the Orán River to the Seco River, quite near the Noctén group. Using sources from other missionaries and his own information, D'Orbigny proposes to develop a grammar of this Wichí dialect. (Vidal y Nercesian, 2009b, p. 1019)

Los errores saltan a la vista: D'Orbigny no era sacerdote, no escribió el Manuscrito D'Orbigny y, además, no recibió nada de Giannechini. Cuando el viajero francés regresó de su gran gira sudamericana, jel misionero italiano ni siquiera había nacido!

En fin, lo que importa es que la comparación del diccionario de Primo con las copias del hoy extraviado Manuscrito D'Orbigny permite deducir que el primero es una suerte de borrador del segundo, que es más extenso y con ciertas enmiendas lexicográficas. Pero al mismo tiempo, una comparación minuciosa de todos los documentos con el wichí actual (que aquí no desarrollamos más que con algunos ejemplos, por falta de espacio) muestra que los copistas han introducido muchos errores ortográficos, "de lectura", errores que el diccionario de Primo, precisamente, permite subsanar.

Aunque aquí no podemos entrar en detalles, es necesario remarcar que el valor del diccionario de Primo como documento lingüístico, histórico y cultural es grande. En primer lugar, porque es el primer documento de la lengua wichí que hoy disponemos. Queda por determinar

Tabla 3. "Doctrina en lengua mataco o mataguaya" de Primo. P: Pregunta que hace el misionero; R. Respuesta del neófito.

Table 3. "Doctrina en lengua mataco o mataguaya" by Primo. P: Question asked by the missionary; R. Answer given by the neophyte.

\begin{tabular}{|l|l|}
\hline P. Decidme hijos, ¿hay Dios? & P. Les jueno Tupa yguen? \\
R. Sí Padre, Dios hay. & R. Ee Padre Tupa yguen. \\
P. ¿Cuántos Dioses hay? & P. Qui jate Tupa yguen? \\
R. Un solo Dios no más. & R. Befacla Tupa Maic. \\
P. ¿Dónde está Dios? & P. Qui Tupa? \\
R. En el cielo y en la tierra y en toda parte y lugar. & R. Pule, Gognet, inucuecho, el inucuecho. \\
P. ¿Quién es Dios? & P. Achi Tupa? \\
R. La santísima trinidad. & R. Tacuiya santísima. \\
P. ¿Quién es la santísima trinidad? & P. Achi tacuiya santisima? \\
R. Es el Padre, es el Hijo y es el Espíritu Santo, tres personas & R. Ydquia, Yas, Espiritu santo, tacuiya Tupa, \\
distintas y un solo Dios. & Tupa befagla. \\
P. ¿Cuál de las tres personas se hizo hombre por nosotros? & P. Achi tacuiya santisima Nolas Ala? \\
R. El hijo. & R. Yas. \\
P. ¿Por qué se hizo hombre? & P. Chia Yas Nolas Ala? \\
R. Para enseñarnos y librarnos del cautiverio del demonio. & R. Chajuenlin Nolas Nolay Ajatag. \\
P. ¿Qué hizo Jesucristo por nosotros? & P. Qui chunglin Jesucristo Nólas? \\
R. Padeció y murió en una cruz. & R. Aytas ilan, cagquia la. \\
[26v] P. ¿Dónde van los indios buenos cuando mueren? & R. Qui yapicni Nolastag, il? \\
P. Al cielo, para ver y gozar de Dios para siempre. & R. Pule, iguen Tupa nequianis loos. \\
P. ¿Dónde van los malos? & P. Qui yapicni Nolastag cächia il? \\
R. Al infierno ha[n] de ser quemados para siempre. & R. Itag yecanquia, nequianis loos no-yo. \\
\hline
\end{tabular}


el valor real que el documento tiene para un estudio diacrónico y dialectal de la lengua, aunque ya a simple vista se observan ciertas limitaciones para el estudio fonético/fonológico: Primo anotó el wichí con un alfabeto demasiado simple, pasando por alto muchos sonidos que sin duda tenían en el wichí de antaño (como tienen aún en el wichí de hoy) un valor distintitvo. Cualquier uso lingüístico de los datos de Primo requiere, obviamente, una exégesis y una hermenéutica previas. Sin embargo, es fácil ver en los manuscritos del franciscano indicios importantes de la historia lingüística, social y cultural de los wichís. Veamos sólo unos ejemplos. Las entradas "acequia", "cedro" o el etnónimo <juit vote> para los indígenas andinos -un etnónimo que hoy (hasta donde sabemos) ya nadie conoce, pero que Hunt (1913, pp. 36, 141) lo reencontró más tarde como <fuiyet-wotes $>$ - dan cuenta de una época donde los wichís también vivian en la zona montañosa. La sola existencia de entradas como "azotar", "azotes", "cepo", "pedir licencia" o "castigar" dan cuenta de que los wichís fueron victimas de la violencia fronteriza y misional. El empecinamiento por traducir "Santísima Trinidad" (TABLA 3) o el hecho de que Primo traduzca "alma" por <ajat> ahät 'alma postuma' -un error en el que los franciscanos del siglo XIX seguirán insistiendo (Montani, 2017b)-, revelan que los franciscanos entendieron poco y nada de la cosmología wichí.

Además de dar a conocer el manuscrito de Primo de Ayala de 1795, nuestra intención en estas páginas ha sido devolver su verdadera autoría al llamado Manuscrito D’Orbigny. Los dos diccionarios "matacos" estudiados aquí son, pues, los documentos más antiguos de la lengua wichí que tenemos hoy a nuestra disposición. Su autor, el humilde fray Esteban, merece ser arrancado del olvido.

\section{Anexo. Doctrina en lengua mataca o mataguaya}

Las últimas páginas del Diccionario de Primo (ff. 26-26v) ofrecen la doctrina cristiana en versión bilingüe (Tabla 3), así como los dos rezos más importantes del catolicismo: el Padre Nuestro y el Ave María.

\section{Padre Nuestro}

Padre nuestro que estás en los cielos

Ygquia lemil, papà cue pule

Santificado sea tu nombre

Nolèi Ysis

Venga a nos tu reino

Jogla Lemil nè

Hágase tu voluntad

Enlin no juenentag [dañado, podría ser también una $m$ ]

Así en la tierra como en el cielo

Ate gognet, ate pule

El pan nuestro de cada día

Tenten lemil chagiac

Dánoslo hoy

Guenojo tag

Perdónanos nuestras deudas, etc. [así como también perdonamos a nuestros deudores]

Lemil Yein leig ate Lemil Yem leig

No nos dejes caer en la tentación

Amageg site lemil

Mas libramos de todo mal

Yeg alogue nequieg

Amén Jesús

Amen Jesus

\section{Ave María}

Dios te salve María

Anne negi María

Llena eres de gracia

Gracia tepóye

El Señor es contigo

Tupa igléni

Bendita tú eres entre las mujeres

Agùe nequieg quileis isis

Y bendito es el fruto de tu vientre, Jesús

As isís Jesus

Santa María, madre de Dios

Santa María Tupa coo

Ruega por nosotros, pecadores

Alat nemil lichas

Ahora y en la hora de nuestra muerte

Tájua-jà, Teil-lája

Amén Jesús

Amen Jesus

\section{Agradecimientos}

Queremos dar las gracias a Marie Morel, Diego Oliva, Alain Fabre, Cristobal Wallis, John Palmer y Dora Fernández por sus ayudas y sus comentarios, y a Karen Buseman, responsable de Field Linguist's Toolbox, SIL, que nos reparó nuestra base de datos en Toolbox. En parte, este artículo fue financiado por el Consolidator Grant INCLUDE 681518, proyecto "Indigenous Communities, Land Use and Tropical Deforestation" del European Research Council.

\section{Referencias bibliograficas}

Alvarsson, J-Å, y Claesson, K. (2014) 'Weenhayek. En M. Crevels y P. Muysken (Eds.), Lenguas de Bolivia, tomo 3: Oriente (pp. 415-465). La Paz: Embajada de los Países Bajos/ MUSEF/Plural.

Camaño, J. (1955 [circa 1788]) Noticias del Gran Chaco. En G. Furlong: Joaquín Camaño SJ y su 'Noticia del Gran Chaco' (1778) (pp. 109-182). Buenos Aires: Librería del Plata.

Claesson, K. (2008) Notas sobre el vocabulario 'weenhayek. Cochabamba: SBB.

Comajuncosa, A. (1884 [1810]) Manifiesto histórico.... En A. Comajuncosa y A. Corrado: El Colegio franciscano de Tarija y sus misiones. Noticias históricas recogidas por dos misioneros del mismo Colegio (pp. 75-275). Quaracchi: Tipográfica del Colegio de San Buenaventura. 
Combès, I., y Oliva, D. (en prensa) Las lenguas chaqueñas en el archivo franciscano de Tarija (Bolivia), Revista del Museo de La Plata (Argentina).

Fabre, A. (2005) Los pueblos del Gran Chaco y sus lenguas, segunda parte: Los Mataguayo. Suplemento antropológico, 40, 313-435. Versión actualizada en www. ling.fi/Entradas\%20diccionario/Dic=Mataguayo.pdf

Giannecchini, D., Romano, S. y Cattunar, H. (1916) Diccionario chiriguanolespañol y español/chiriguano. Tarija: Colegio de Propaganda Fide.

Hervás, L. (1800) Catálogo de las lenguas conocidas y numeración, división y clases de éstas según la diversidad de sus idiomas y dialectos. Vol. 1: lenguas y naciones americanas. Madrid: Imprenta de la Administración del Real Árbitro de Beneficencia,

Hunt, R. (1913) El vejoz ó aiyo. Revista del Museo de la Plata, 22(9), 7-215.

Hunt, R. (1937) Mataco-English and English-Mataco Dictionary. Gotemburgo: Etnologiska Studier, vol. 5.

Lafone Quevedo, S. (1896a) Dialecto Vejoz. Vocabulario y Apuntes Ms. D'Orbigny. Introducción y notas de Samuel Lafone Quevedo. Boletín del Instituto Geográfico Argentino $17,121-181$.

Lafone Quevedo, S. (1896b) Lenguas Argentinas. Grupo Mataco-Mataguayo del Chaco: Dialecto Vejoz. Vocabulario y Apuntes Ms. D'Orbigny. Buenos Aires: Imprenta Roma.

Lozano, P. (1733) Descripción chorográfica [...] del Gran Chaco Gualamba. Córdoba: Colegio de la Asunción.

Lunt, R. (2016) Diccionario de la lengua wichí: WichiEspañol. Buenos Aires: SBA.

Mingo de la Concepción, M. (1981 [1791]) Historia de las misiones franciscanas de Tarija entre Chiriguanos. Tarija: Universidad boliviana "Juan Misael Saracho".

Maeder, E., Salinas, M. L., Folkenand, J., y Braunstein, J. (2016) Entre los jesuitas del Gran Chaco: Compilación de Joaquin Camaño S. J. y otras fuentes documentales del siglo XVIII. Buenos Aires: Academia Nacional de Ciencias de Buenos Aires.

Montani, R. (2015) Una etnolingüística oculta. Notas sobre la etnografía y la lingüística wichís de los misioneros anglicano. Boletín americanista, 70, 73-94.

Montani, R. (2017a) El mundo de las cosas entre los wichís del Gran Chaco: Un ensayo etnolingüístico. Cochabamba: Itinerarios. wichí: La traducción de la terminología cristiana por los misioneros anglicanos, En C. Ceriani (Ed.), Los evangelios chaqueños: Misiones y estrategias indígenas en el siglo $X X$, (pp. 145-172). Buenos Aires: Rumbo Sur.

Montani, R., y Combès, I. (2019) Etnonimia wichí: cien hipótesis para mil y un nombres. Revista andina, 56, 227269.

Necrología (2004 [1834]) Padre Esteban Primo de Ayala [necrología]. En L. Calzavarini (Ed.), Presencia franciscana y formación intercultural en el sudeste de Bolivia según documentos del archivo franciscano de Tarija, 16061936, tomo 3 (pp. 1459-1460). Tarija: Centro Eclesial de Documentación.

Nercesian, V. (2014) Wichi Ihomtes: Estudio de la gramática y la interacción fonología-morfología-sintaxis- semantica. Múnich: LINCOM.

Orbigny, A. d' (circa 1830) Copia d'Orbigny, Biblioteca Nacional de Francia (BNF), Manuscrits Américains 26, ff. 22-30.

Orbigny, A. d' (1839) L'Homme Américain (de l'Amérique méridionale), considéré sous ses rapports physiologiques et moraux. Estrasburgo: imprimerie Berger-Levrault.

Orbigny, A. d' (2002 [1835-1847]) Viaje a la América meridional (realizado de 1826 a 1833), 4 tomos. La Paz: IFEA/Plural.

Saignes, T. (1984) L'ethnographie missionnaire des sauvages. La première description franciscaine des Chiriguano (1782), Journal de la Société des Américanistes, $70,21-42$

Terraza, J. (2001) Grammaire du wichí: Phonologie et morphosyntaxe, Tesis de doctorado, Universidad de Québec à Montréal.

Vida, A., y Nercesian, V. (2009a) Estudio del léxico wichí (mataco-mataguaya): Aportes al conocimiento de algunas situaciones de contacto y desplazamiento lingüístico en el Chaco argentino, Cuadernos Interculturales, 7(12), 141-158.

Vida, A., y Nercesian, V. (2009b) Loanwords in Wichí, a Mataco-Mataguayan language of Argentina. En M. Haspelmath y U. Tadmor (Eds.), Loanwords in the World's Languages: A Comparative Handbook of Loanword Typology (pp. 1015-1034). La Haya: Mouton de Gruyter.

Viñas Urquiza, M. T. (1974) Lengua mataca, 2 tomos. Buenos Aires: Facultad de Filosofía y Letras, UBA.

Weddell, H. A. (2018 [1851]) Viaje en el sur de Bolivia (1845-1846). Santa Cruz: El País/CIHA.

Montani, R. (2017b) Las verdaderas palabras de Dios en 
Tabla 4. El Diccionario y arte de la lengua mataca de Primo comparado con las tres copias que se conservan del Manuscrito D'Orbigny ("ch" después de " $c$ "). Como se publican por primera vez el diccionario de Primo y la Copia D'Orbigny, se señalan los números de folio. Referencias: * préstamo del quechua, ${ }^{* *}$ p. del castellano, ${ }^{* *}$ p. del guaraní (chiriguano), H Copia Hunt, L Copia Lafone, O Copia D'Orbigny, mismas traducciones, traducciones diferentes,

entradas sólo en Manuscrito D'Orbigny, entradas aisladas (sin pintar).

Table 4. Diccionario y arte de la lengua mataca by Primo compared with the three copies preserved of the Manuscrito 'Orbigny ("ch" after " $c$ "). As Primo's dictionary and the Copia D'Orbigny are published for the first time, the folio numbers are indicated. References: * loanword from Quechua, ** I. from Spanish, *** I. from Guarani (chiriguano), H Hunt's Copy, L Lafone's Copy, O D'Orbigny Copy, same translations; different translations

Manuscrito D'Orbigny, isolated entries (unpainted).

\begin{tabular}{|c|c|c|c|c|c|}
\hline \multicolumn{2}{|c|}{ Primo (AFT, 1795) } & \multicolumn{4}{|c|}{ Copias del Manuscrito $D^{\prime} O_{\text {RbiGnY }}$} \\
\hline Castellano & Mataco & Castellano & O'Orbigny & LAFONE 1896 & Hunt 1913 \\
\hline abajo & cagquia (1v) & abajo & $\begin{array}{l}\text { canquia; } \\
\text { caguian cathra } \\
\text { (24) }\end{array}$ & $\begin{array}{l}\text { canquia; } \\
\text { cagguian; catha }\end{array}$ & $\begin{array}{l}\text { canquia; } \\
\text { cagguian; catha }\end{array}$ \\
\hline abandonar & $\begin{array}{l}\text { leyeg; mantegi } \\
\text { (1v) }\end{array}$ & & & & \\
\hline \multirow[t]{4}{*}{ abeja } & $\operatorname{vos} a(1 \mathrm{v})$ & abeja & bosa (24) & vosa & vosa \\
\hline & & abeja de tierra & nesta (24) & nesla & nesla \\
\hline & & ablandar & guiquit (25v) & guicquic & guiquic \\
\hline & & abortar & liecheiel (25v) & licheiel & licheiel \\
\hline aborrecer & nijumenni (1v) & & & & \\
\hline $\begin{array}{l}\text { abrasarse con } \\
\text { fuego }^{1}\end{array}$ & $y u x o(1 \mathrm{v})$ & & & & \\
\hline $\begin{array}{l}\text { abrasarse de } \\
\text { calor }\end{array}$ & chiug ilan (1v) & & & & \\
\hline abrazar & nochugeleg (1) & abrazar & $\begin{array}{l}\text { nochug eleg } \\
\text { (25) }\end{array}$ & nochug-eleg & nochugeleg \\
\hline \multirow[t]{3}{*}{ abrir } & $\begin{array}{l}\text { oyenquie; } \\
\text { quiesajo la pe } \\
\text { (1) }\end{array}$ & abrir & oyenquic (25) & oyenquic & oyenquic \\
\hline & & abrir la boca & quiczajaji (27) & quiczajaji & quiczajaji \\
\hline & & abrir la puerta ${ }^{2}$ & & qui-gajo nope & quisajo-nope \\
\hline abrir los ojos & yaimpa (1) & abrir los ojos & yainpa (25) & yaimpa & yainpa \\
\hline abuela & tela (1v) & abuela & teta (24) & no-tela & no-tela \\
\hline abuelo & chati (1) & abuelo & chati (24) & chati & chati \\
\hline acarrear & tiglag (1) & acarrear & tilag (25) & tilag & tilag \\
\hline \multirow[t]{3}{*}{ acequia } & $\begin{array}{l}\text { nolechenec; } \\
\text { guag naig (1) }\end{array}$ & acequia & $\begin{array}{l}\text { guag-naig; } \\
\text { notechenec } \\
\text { (24) }\end{array}$ & $\begin{array}{l}\text { guagnaig; } \\
\text { nolechenec }\end{array}$ & $\begin{array}{l}\text { guag-naig; no-le- } \\
\text { che-nec }\end{array}$ \\
\hline & & acercarse & $\begin{array}{l}\text { amme alojo } \\
(25 \mathrm{v})\end{array}$ & amme & amme \\
\hline & & acertar tirando & isom (25v) & ysom & isom \\
\hline
\end{tabular}

1 Cf. "arder".

${ }^{2}$ Cf. "abrir". 


\begin{tabular}{|c|c|c|c|c|c|}
\hline \multicolumn{2}{|c|}{ Primo (AFT, 1795) } & \multicolumn{4}{|c|}{ Copias del ManusCrito $D^{\prime} O_{\text {RBIGNY }}$} \\
\hline Castellano & Mataco & Castellano & O'ORBIGNY & LAFone 1896 & Hunt 1913 \\
\hline & & $\begin{array}{l}\text { aclararse el } \\
\text { tiempo }(\mathrm{O}, \mathrm{L}) \text {; } \\
\text { aclarar el tiempo } \\
(\mathrm{H})\end{array}$ & $\begin{array}{l}\text { ijuala nagni } \\
(25 \mathrm{v})\end{array}$ & yjuela nagni & ijuala nagni \\
\hline & & acocear; cocear & & $\begin{array}{l}\text { asec; cocear: } \\
\text { asei }\end{array}$ & asec; cocear: asei \\
\hline & & acometer & la itamiel (25v) & la ilameel & lai lameel \\
\hline $\begin{array}{l}\text { acompañar a } \\
\text { otro }\end{array}$ & iquie (1v) & $\begin{array}{l}\text { acompañar o } \\
\text { ir con otro }(O) \text {; } \\
\text { acompañar }(L, H)\end{array}$ & \begin{tabular}{|l|} 
ignie/iguie \\
moque (25)
\end{tabular} & $\begin{array}{l}\text { iguic; moque; } \\
\text { tapuas }\end{array}$ & $\begin{array}{l}\text { iguic; moque; } \\
\text { tapuas }\end{array}$ \\
\hline \multirow[t]{5}{*}{ acordarse } & $\begin{array}{l}\text { tiquiunquiene } \\
\text { pana[?] (1) }\end{array}$ & acordarse & $\begin{array}{l}\text { tiquinnquie } \\
\text { liebay (25) }\end{array}$ & $\begin{array}{l}\text { tiquiunque- } \\
\text { liebay }\end{array}$ & tiquiunque liebay \\
\hline & & $\begin{array}{l}\text { acordarse de } \\
\text { cosas tristes }\end{array}$ & $\begin{array}{l}\text { tiquinnquie } \\
\text { paan (25) }\end{array}$ & $\begin{array}{l}\text { tiquiunque pana } \\
\text { nolitag }\end{array}$ & $\begin{array}{l}\text { tiquiunque pana } \\
\text { nolitag }\end{array}$ \\
\hline & & acostarse & $\begin{array}{l}\text { caina casquie } \\
(25 \mathrm{v})\end{array}$ & cainacasquie & caina-casquie \\
\hline & & acostumbrarse & ajuit (26v) & ajuit & ajuit \\
\hline & & no acostumbrarse & & no ajuitninitc & no-ajuit-ninitc \\
\hline \multirow[t]{3}{*}{ adelante } & ajoye (1v) & adelante & $\begin{array}{l}\text { ajoye; achum } \\
(24)\end{array}$ & agoye; achum & agoye; achum \\
\hline & & adelantarse & achium (25v) & achium & achium \\
\hline & & adelgazar & yajasquie (25v) & yajasquie & yajasquie \\
\hline \multirow[t]{4}{*}{ adentro } & $\begin{array}{l}\text { ych[dañado]; } \\
\text { ichajùi (1v) }\end{array}$ & adentro & anchajui (24) & $\begin{array}{l}\text { anchajui; } \\
\text { inchajui }\end{array}$ & $\begin{array}{l}\text { an-chajui; in- } \\
\text { chajui }\end{array}$ \\
\hline & & adobe & & yñat, nogomné & no-gomne; iñat \\
\hline & & $\begin{array}{l}\text { adobes }(O) \text {; } \\
\text { adobes hacen }(L \text {, } \\
\text { H) }\end{array}$ & yenta iñat (25v) & yenta, yñat & yenta iñat \\
\hline & & adobera & iñat-is (26) & & iñatis \\
\hline \multirow[t]{2}{*}{ ¿adónde? } & qui? (1) & $\begin{array}{l}\text { ¿adónde, de } \\
\text { dónde? }(L, H)\end{array}$ & & qui? & qui? \\
\hline & & ¿a dónde está? & & quic? & quic? \\
\hline \multirow[t]{4}{*}{ ¿a dónde vas? } & $\begin{array}{l}\text { qui lapicni? qui } \\
\text { lajoje? (1); qui } \\
\text { lajoge? (20) }\end{array}$ & ¿a dónde vas? & & $\begin{array}{l}\text { quilajoje? } \\
\text { chilajoje? }\end{array}$ & $\begin{array}{l}\text { qui lajoje? chi } \\
\text { lajoje? }\end{array}$ \\
\hline & & adonde quiera & inucuecho (26) & ynucuecho & i-nucuecho \\
\hline & & $\begin{array}{l}\text { adormecer el hijo } \\
\text { (O); adormecer } \\
\text { (L, H) }\end{array}$ & yuug (26) & $\begin{array}{l}\text { laguagua*3; } \\
\text { yuug }\end{array}$ & laguagua; yuug \\
\hline & & adrede & & neneyg & neneyg \\
\hline afilado & yui (1v) & afilado & yui (24) & jui & yui \\
\hline no afilado & yui-nite (1v) & no afilado & yuyjtitete (24) & yuigite; yuijutetc & $\begin{array}{l}\text { yui-gite; yui- } \\
\text { jutetc }\end{array}$ \\
\hline
\end{tabular}

\footnotetext{
${ }^{3}$ Sospechamos que en el Manuscrito D’Orbigny decía "adormecer la guagua", donde "guagua" es un quechuismo por "niño pequeño". De ahí, la Copia D'Orbigny tradujo a "adormecer el hijo", pero Lafone y Hunt leyeron laguagua, como si se tratara de una palabra Wichí.
} 


\begin{tabular}{|c|c|c|c|c|c|}
\hline \multicolumn{2}{|c|}{ PRIMo (AFT, 1795) } & \multicolumn{4}{|c|}{ Copias del ManusCRITO $D^{\prime} O_{\text {RBIGNY }}$} \\
\hline Castellano & Mataco & Castellano & O'Orbigny & LAFONE 1896 & Hunt 1913 \\
\hline \multirow[t]{2}{*}{ afilar } & juut (1) & afilar & yuut (25) & yuict (juict) & juict \\
\hline & & afligirse & yacaileg (26) & yacaileg & yacaileg \\
\hline aflorar & $\begin{array}{l}\text { capcaino; caip } \\
\text { juieno (1) }\end{array}$ & aflojar & cagcaino (25) & $\begin{array}{l}\text { cagcaino; } \\
\text { cagcagno; caig } \\
\text { juieno }\end{array}$ & $\begin{array}{l}\text { cagcaino; } \\
\text { cagcagno; } \\
\text { caigjuieno }\end{array}$ \\
\hline \multirow[t]{2}{*}{ afrecho; harina } & muc (1) & $\begin{array}{l}\text { afrecho, harina } \\
(\mathrm{O}) \text {; afrecho }(L, H)\end{array}$ & muc (24) & muc & muc \\
\hline & & afrentarse $^{4}$ & najuel (26) & najuel & najuel \\
\hline \multirow[t]{2}{*}{ afuera } & $\operatorname{alotag}(1)$ & afuera & motag (24) & motag & motag \\
\hline & & agacharse & upien (26) & upien & upien \\
\hline \multirow[t]{2}{*}{ agarrar } & $\operatorname{acateg}(1)$ & agarrar & acateg (25) & acateg & a-categ \\
\hline & & agotar & upun (26) & upun & upun \\
\hline \multirow[t]{2}{*}{ agrio } & $\begin{array}{l}\text { tepei; picante: } \\
\text { nosoy (1v) }\end{array}$ & agrio & tepec (24v) & tepei & tepei \\
\hline & & no agrio & tepecnite (24v) & tepeinite & tepei-nite \\
\hline agua & guag (1) & agua & guag (24) & guag & guag \\
\hline agua buena & guag is (24) & & & & \\
\hline agua caliente & chayuji (24) & agua caliente & guagcayo (24) & guag-cayo & guag cayo \\
\hline agua clara & isati (1) & & & & \\
\hline agua no clara & ichagi (1) & & & & \\
\hline agua fría & guag jochi (24) & agua fría & guagjochi (24) & $\begin{array}{l}\text { guag jochi; } \\
\text { gochi }\end{array}$ & guag jochi \\
\hline agua salada & $\begin{array}{l}\text { guag nosoitag } \\
(24)\end{array}$ & agua salada & $\begin{array}{l}\text { guag nolnetag } \\
(24 \mathrm{v})\end{array}$ & nanitag & nanitag \\
\hline $\begin{array}{l}\text { aguarda un } \\
\text { poco }\end{array}$ & quietajin (1) & aguarda un poco & quietajin (25) & quietajin & quietajin \\
\hline aguardar & quiet (1) & aguardar & motite (25) & $\begin{array}{l}\text { quieto matitc; } \\
\text { nipinoquioya }\end{array}$ & $\begin{array}{l}\text { quieto matitc; } \\
\text { nipinoquioya }\end{array}$ \\
\hline aguja & canu (1) & aguja & canu (24) & canu & canu \\
\hline agujerear & notoye (1v) & agujerear & $\begin{array}{l}\text { notoyen notijo } \\
\text { (25); toyen (26) }\end{array}$ & $\begin{array}{l}\text { toyen; notoyen; } \\
\text { notijo }\end{array}$ & $\begin{array}{l}\text { toyen; no-toyen; } \\
\text { no-tijo }\end{array}$ \\
\hline \multirow[t]{2}{*}{ agujero } & chojueg (1v) & agujero & chojueg (24) & chojueg & chojueg \\
\hline & & agusanarse $^{5}$ & vos ilam (26) & vosilam & vos-ilam \\
\hline \multirow[t]{4}{*}{ ahí está } & inacachi (1v) & ahí está & macachi (25) & inacachi & ina-cachi \\
\hline & & $\begin{array}{l}\text { ahogarse del } \\
\text { pescuezo }(O) \text {; } \\
\text { ahogar del } \\
\text { pescuezo }(L, H)\end{array}$ & chocoo $(25 \mathrm{v})$ & chocoo & chocoo \\
\hline & & $\begin{array}{l}\text { ahogarse con } \\
\text { agua }\end{array}$ & iquia (25v) & yquia & i-quia \\
\hline & & ahora & & tajuaja-tana & tajuaja-tana \\
\hline
\end{tabular}

${ }^{4}$ Cf. "tener vergüenza".

5 Cf. "gusanos". 


\begin{tabular}{|c|c|c|c|c|c|}
\hline \multicolumn{2}{|c|}{ PrIMo (AFT, 1795) } & \multicolumn{4}{|c|}{ Copias del MANUSCRITO $D^{\prime} O_{\text {RBIGNY }}$} \\
\hline Castellano & Mataco & Castellano & O'OrBigny & Lafone 1896 & Hunt 1913 \\
\hline & & ahorita & $\begin{array}{l}\text { caile guatana } \\
\text { (25) }\end{array}$ & cayle; guatana & cayle; guatana \\
\hline & & ahorrar poquito & & teigjua & teigjua \\
\hline & & ajeno & nocatagite (26) & nocatagitc & no-catagite \\
\hline \multirow[t]{2}{*}{ ají } & pagna (1) & $\begin{array}{l}\text { aji (H); "ágil" }(\mathrm{O}, \\
\mathrm{L})^{6}\end{array}$ & pana (25) & pana & pana \\
\hline & & $\begin{array}{l}\text { ají chiquito }(\mathrm{H}) \text {; } \\
\text { "así chiquito" (O, } \\
\text { L) }\end{array}$ & jana (24v) & fana & fana \\
\hline \multirow[t]{2}{*}{ ají grande } & panantag (1) & $\begin{array}{l}\text { ají grande }(H) \text {; "así } \\
\text { grande" }(\mathrm{O}, \mathrm{L})\end{array}$ & panantag (24v) & panan-tag & panan-tag \\
\hline & & ajuar & & $\begin{array}{l}\text { nocaigies; } \\
\text { nocaies }\end{array}$ & $\begin{array}{l}\text { no-caigies; no- } \\
\text { caies }\end{array}$ \\
\hline \multirow[t]{2}{*}{ ala } & $\begin{array}{l}\text { legug pl. lejuis } \\
\text { (1) }\end{array}$ & ala & $\begin{array}{l}\text { leg pl. lejuis } \\
(24 \mathrm{v})\end{array}$ & leg pl. lejuis & leg pl. lejuis \\
\hline & & alargar & $\begin{array}{l}\text { cochoinuce } \\
\text { (26) }\end{array}$ & cochoinuce & cocho inucc \\
\hline \multirow[t]{5}{*}{ alazán } & alechag (1v) & alazán & alechag (24v) & alechag & alechag \\
\hline & & alcanzar lo caído & $\begin{array}{l}\text { chumina } \\
\text { [dañado] (26) }\end{array}$ & jumin; chumina & jumin; chumina \\
\hline & & alegre, alegrarse & $\begin{array}{l}\text { caylin }(26) \\
\text { caxlin }(26 v)\end{array}$ & caglin; caylin & caglin; caylin \\
\hline & & alentar & agligquie (26) & agtigquié & agtigquie \\
\hline & & alentado & xaxag (26) & & \\
\hline alforjas & $\begin{array}{l}\text { meinis; nocagñis } \\
\text { (1) }\end{array}$ & alforjas & $\begin{array}{l}\text { meinis } \\
\text { nocagnis (24v) }\end{array}$ & neinis; nocagnis & neinis; no-cagnis \\
\hline \multirow[t]{2}{*}{ algarroba } & juay (1) & $\begin{array}{l}\text { algarrobo }(O) ; \\
\text { algarroba }(L, H)\end{array}$ & yuay $(24 v)$ & yuay & yuay \\
\hline & & $\begin{array}{l}\text { algarrobo negro } \\
(O) \text {; algarroba } \\
\text { negra }(L, H)\end{array}$ & vosochag (24v) & vosochag & vosochag \\
\hline algarrobilla ${ }^{7}$ & gua chia (1v) & & & & \\
\hline algodón & $\begin{array}{l}\text { guesata[dañado] } \\
\text { (1v) }\end{array}$ & algodón & guesatag (24v) & guesatag & guesatag \\
\hline alma & $\begin{array}{l}\text { ajat pl. ajatas } \\
\text { (1v) }\end{array}$ & alma & $\begin{array}{l}\text { ajat pl. ajatag } \\
(24 \mathrm{v})\end{array}$ & ajat pl. ajatas & ajat pl. ajat-as \\
\hline aloja & es (1) & aloja & yates (24v) & & \\
\hline \multirow[t]{2}{*}{ alto $^{8}$} & tojoc (1v) & alto & tooppa (24v) & tooppa & tooppa \\
\hline & & alumbrar & utunquie (26v) & utunquie & utunquie \\
\hline alzar & quiaspa (1v) & & & & \\
\hline allá & id cachi (1) & allá & iocachi (24v) & iocachi & iocachi \\
\hline
\end{tabular}

\footnotetext{
${ }^{6}$ Sin duda, D'Orbigny y Lafone leyeron mal el castellano, pues pänhän es 'ají de monte'. Suponemos que el mismo error sucede en "ají chiquito" y "ají grande".

${ }^{7}$ Creemos reconocer wäch'ä 'fruto del guayacán'.

${ }^{8}$ Están anotando cosas diferentes: las copias, -tofwphä 'estar alto', y Primo, quizá, thaläkw 'es adulto' (cf. "madurO").
} 


\begin{tabular}{|c|c|c|c|c|c|}
\hline \multicolumn{2}{|c|}{ PrIMo (AFT, 1795) } & \multicolumn{4}{|c|}{ Copias del ManusCrIto $D^{\prime} O_{R B I G N Y}$} \\
\hline Castellano & Mataco & Castellano & O'ORBIGNY & LAFone 1896 & Hunt 1913 \\
\hline & & allá lejos & & ydycadni & idicadni \\
\hline & & allá no muy lejos & & ydcachi & idcachi \\
\hline allí & ilachi (1) & allí & nachi (24v) & nachi; yllachi & nachi; illachi \\
\hline por allí & inucue cho (1v) & por allí & & yninucucho & yninucucho \\
\hline \multirow[t]{2}{*}{ amar } & jumen (1) & amar & jumien (25) & jumien & jumien \\
\hline & & amar contra & & cachi jumin & cachi jumin \\
\hline \multirow[t]{2}{*}{ amarillo } & catu (1) & amarillo & catutag $(24 \mathrm{v})$ & catutag & catu-tag \\
\hline & & a mí & & yaan & yaan \\
\hline $\begin{array}{l}\text { amigo, } \\
\text { compañero }\end{array}$ & $\begin{array}{l}\text { igjua, yogjua, } \\
\text { ala (1) }\end{array}$ & amigo & $\begin{array}{l}\text { ijua, yojua } \\
(24 v)\end{array}$ & $\begin{array}{l}\text { yjua; yojua; } \\
\text { jumenec }\end{array}$ & $\begin{array}{l}\text { ijua; yojua; } \\
\text { jumenec }\end{array}$ \\
\hline amontonar & $\operatorname{ascon}(1)$ & amontonar & asconluu (25) & ascontúú & ascon tuu \\
\hline \multirow[t]{2}{*}{$\begin{array}{l}\text { anda; anda vete } \\
\text { (9) }\end{array}$} & $\begin{array}{l}\text { maa (1); maa } \\
\text { api; noquien (9) }\end{array}$ & anda vete & $\begin{array}{l}\text { maa, maaopi, } \\
\text { noquien (25) }\end{array}$ & $\begin{array}{l}\text { maa; maa-api; } \\
\text { ma }\end{array}$ & $\begin{array}{l}\text { maa; maa-api, } \\
\text { ma }\end{array}$ \\
\hline & & anda a comer & & mateec & mateec \\
\hline andar, pasear & nobeteclin (1) & andar o caminar & $\begin{array}{l}\text { obelec, obest, } \\
\text { nobeleclin (25) }\end{array}$ & \begin{tabular}{|l|}
$\begin{array}{l}\text { obelec; no- } \\
\text { beleclin; obest }\end{array}$ \\
\end{tabular} & \begin{tabular}{|l|} 
o-belec; no- \\
beleclin; o-best
\end{tabular} \\
\hline andar a caballo & bohuteya (1v) & $\begin{array}{l}\text { andar a caballo } \\
(\mathrm{O}, \mathrm{L}) ; \text { a caballo }(\mathrm{H})\end{array}$ & abute (25) & abuté & a-bute \\
\hline andar a pie & asquia (1v) & andar a pie & $\begin{array}{l}\text { asquia-noig } \\
\text { (25) }\end{array}$ & asquia noig & $\begin{array}{l}\text { asquia noig, } \\
\text { asquia }\end{array}$ \\
\hline \multirow[t]{2}{*}{ anguila } & igñat (1) & anguila & añat (24v) & añat & añat \\
\hline & & animal, insecto & & & locue \\
\hline \multirow[t]{2}{*}{ anta } & hielag (1) & anta & hiclag (24v) & hiclag & hichag \\
\hline & & anteayer ${ }^{9}$ & $\begin{array}{l}\text { aponag agi, } \\
\text { yonag el agi }\end{array}$ & $\begin{array}{l}\text { aponag, agi; } \\
\text { yonag el nagi }\end{array}$ & $\begin{array}{l}\text { ap-onag-agi; } \\
\text { yonag-el-nagi }\end{array}$ \\
\hline anzuelo & quinag chog (1) & anzuelo & $\begin{array}{l}\text { yuinag chog } \\
\text { nog (24v) }\end{array}$ & $\begin{array}{l}\text { quinag-chog- } \\
\text { non }\end{array}$ & quinag-chognon \\
\hline $\begin{array}{l}\text { año o mucho } \\
\text { tiempo }\end{array}$ & nequian $(1 \mathrm{v})^{10}$ & & & & \\
\hline \multirow[t]{2}{*}{$\begin{array}{l}\text { apagar el fuego } \\
\text { o vela }\end{array}$} & yus omet (1) & $\begin{array}{l}\text { apagar el fuego } \\
\text { o vela }\end{array}$ & omet (25v) & omet & omet \\
\hline & & apagarse & yon (25v) & yon & yon \\
\hline \multirow[t]{2}{*}{ apartarse } & aicahi[iu?]tla (1) & apartarse & aiacochis-atla & aiacachis-alta & aiacachis-alta \\
\hline & & apasanca & yag tag (26) & yag-tag & yagtag \\
\hline apretado & tuunti (1v) & apretado & tuunsti (24v) & tuunsti & tuunsti \\
\hline apretar & agtit (1) & apretar & aptit (25) & aptit & aptit \\
\hline \multirow[t]{3}{*}{ apretar la carga } & tunti (1) & apretar la carga & & tuunti; nuunti & tuunti; nuunti \\
\hline & & a propósito [?] & neyeyg (26v) & & \\
\hline & & apurar alguno & caile-ozlin (25v) & cayle-ezlin & cayle-ezlin \\
\hline
\end{tabular}

\footnotetext{
${ }^{9}$ Cf. "por la tarde".

${ }^{10}$ Se trata sin lugar a dudas de nekchäm 'año'.
} 


\begin{tabular}{|c|c|c|c|c|c|}
\hline \multicolumn{2}{|c|}{ PrIMo (AFT, 1795) } & \multicolumn{4}{|c|}{ Copias del MANUSCRITO $D^{\prime} O_{\text {RBIGNY }}$} \\
\hline Castellano & Mataco & Castellano & O'ORBIGNY & LAFONE 1896 & Hunt 1913 \\
\hline \multirow[t]{2}{*}{$\begin{array}{l}\text { ¿a qué has } \\
\text { venido? }\end{array}$} & $\begin{array}{l}\text { chia ataglajoye } \\
\text { cana? (1) }\end{array}$ & & & & \\
\hline & & $\begin{array}{l}\text { aquel, aquellos } \\
(\mathrm{H}) \text {; aquellos (L) }\end{array}$ & & tajoslechi & tag pl. tajos \\
\hline \multirow[t]{3}{*}{ aquello } & tag; tagchi (1v) & $\begin{array}{l}\text { aquello }(\mathrm{O}, \mathrm{L}) ; \\
\text { aquello, ese }(\mathrm{H})\end{array}$ & tag-tachi $(24 v)$ & $\begin{array}{l}\text { tag; tagchi, } \\
\text { macha; } \\
\text { jatalechi }\end{array}$ & $\begin{array}{l}\text { tagchi; a-tagdchi; } \\
\text { macha }\end{array}$ \\
\hline & & aquel es & & japtulechi & $\begin{array}{l}\text { japtulechi; } \\
\text { jatalechi }\end{array}$ \\
\hline & & aquellos son & & $\begin{array}{l}\text { japatuglechi; } \\
\text { japaluglechi }\end{array}$ & $\begin{array}{l}\text { japatuglechi; } \\
\text { tajoslechi }\end{array}$ \\
\hline $\begin{array}{l}\text { aquello, que } \\
\text { está allí }\end{array}$ & $\begin{array}{l}\text { tag-quie-cho } \\
\text { (1v) }\end{array}$ & & & & \\
\hline aquí & caana (1) & aquí & caana (24v) & caana & caana \\
\hline araña & $\begin{array}{l}\text { suguan locue } \\
\text { (1v) }\end{array}$ & araña & $\begin{array}{l}\text { suguanlocue } \\
(24 \mathrm{v})\end{array}$ & suguanlocuc & suguan-locuc \\
\hline arar & osaji gognet (1) & arar & $\begin{array}{l}\text { osaji gognet } \\
(25 \mathrm{v})\end{array}$ & osaji, gognet & o-saji gognet \\
\hline arco & luchag (1v) & arco & $\begin{array}{l}\text { luchag-iris } \\
(24 \mathrm{v})^{11}\end{array}$ & juchag/luchag & luchag \\
\hline arco iris & lobò (1v) & arco iris & & labo & labo \\
\hline arder $^{12}$ & yuxo; lagni (1) & & & & \\
\hline arena & $\operatorname{orotag}(1 \mathrm{v})^{13}$ & arena & orotag (24v) & orotag & olotag \\
\hline \multirow{5}{*}{$\begin{array}{l}\text { armado, } \\
\text { pescado }\end{array}$} & castaz (1v) & armado, pescado & castac $(24 \mathrm{v})$ & castac & castac \\
\hline & & arrear & $\begin{array}{l}\text { si arrean?: } \\
\text { acosta; acoz } \\
\text { (25v) }\end{array}$ & $\begin{array}{l}\text { ocosla; ocoz, si } \\
\text { arrean }\end{array}$ & ocoz; ocoz-la \\
\hline & & arremangarse & aimpa (26) & aimpa & aimpa \\
\hline & & arriba $^{14}$ & caapa $(24 \mathrm{v})$ & caapa, puule & caapa; puule \\
\hline & & arrimar & $\begin{array}{l}\text { ain, amcalojo, } \\
\text { aame ( } 25 \mathrm{v})\end{array}$ & ain, aama & ain; aame \\
\hline arrodillarse & $\begin{array}{l}\text { nocanquiete } \\
\text { chinen (1) }\end{array}$ & arrodillarse & $\begin{array}{l}\text { nocanquiete- } \\
\text { chinen (25v) }\end{array}$ & $\begin{array}{l}\text { nocanquicte- } \\
\text { chinen }\end{array}$ & $\begin{array}{l}\text { no-canquicte } \\
\text { chinen }\end{array}$ \\
\hline \multirow[t]{3}{*}{ arrojar } & nochuñet (1) & arrojar o vomitar & $\begin{array}{l}\text { nochuñet- } \\
\text { vocoyi (25v) }\end{array}$ & $\begin{array}{l}\text { nochuñct, } \\
\text { vocoyi }\end{array}$ & $\begin{array}{l}\text { no-chuñet; } \\
\text { vocogi }\end{array}$ \\
\hline & & arrugarse & sujuijo (26) & sujuijo & sujuijo \\
\hline & & arrugas & tesue (26v) & tesue & tesue \\
\hline
\end{tabular}

\footnotetext{
${ }^{11}$ Sin duda la Copia D'Orbigny se enreda con el significado equívoco de "arco" en el español regional, que nombra tanto el -lutsej 'arco' del arco y flecha como el lewo 'arco iris/monstruo arco iris'.

12 Cf. "abrasarse con fuego".

${ }^{13}$ El uso de la $r$ en esta palabra está claro en el manuscrito y, sin embargo, es extraño en Primo, que no suele usar esa letra para escribir el wichí. En todo caso, en <orotag> reconocemos la palabra actual holotaj 'arena/arenal'.

${ }^{14}$ Cf. "cielo".
} 


\begin{tabular}{|c|c|c|c|c|c|}
\hline \multicolumn{2}{|c|}{ PrIMo (AFT, 1795) } & \multicolumn{4}{|c|}{ Copias del MANUSCRITO $D^{\prime} O_{\text {RBIGNY }}$} \\
\hline Castellano & Mataco & Castellano & O'OrBigny & LAFone 1896 & Hunt 1913 \\
\hline $\operatorname{asar}^{15}$ & $\ddot{o} \quad$ o (1) & $\operatorname{asar}(\mathrm{O}, \mathrm{L})$; asa $(\mathrm{H})$ & $\begin{array}{l}\text { labo }(24 \mathrm{v}) ; \text { o } \\
\text { otag, yoo hotg } \\
(25 \mathrm{v})\end{array}$ & otag & otag \\
\hline & & asesar & laiel (26) & laiel & laiel \\
\hline & & asomarse & yaigno (26) & yaigno & yaigno \\
\hline atar & ayit (1) & atar & ayte (25v) & aytc & aytc \\
\hline atrás & jolejute (1v) & atrás & yolejute $(24 \mathrm{v})$ & yolejuct & yolejuct \\
\hline & & atrasarse & $\begin{array}{l}\text { imaglegem } \\
(25 \mathrm{v})\end{array}$ & imaglegem & i-maglegem \\
\hline & & aullar & $\operatorname{antin}(26)$ & anlin & anlin \\
\hline & & aurora & ijualanto (26v) & yjualanle & ijualanle \\
\hline avestruz & guanlac (1) & avestruz & guanlac (24) & guanlac & guanlac \\
\hline avisar & jueno (1) & & & & \\
\hline no avisar & camag jueno (1) & & & & \\
\hline avispa & machita (1v) & avispa & machita (24) & machita & machita \\
\hline$a y^{16}$ & aquay (1) & ahí & aquay (25) & aguay & aguay \\
\hline & & ayer $^{17}$ & yonag agi (26) & yonag-agi & yonag-agi \\
\hline & & ayudar & $\begin{array}{l}\text { quiota[dañado], } \\
\text { chota }(25 \mathrm{v})\end{array}$ & quiota; chota & quiota; chota \\
\hline azadón ${ }^{18}$ & iñagquie (24) & azadón & $\begin{array}{l}\text { guatenejuani } \\
(24 \mathrm{v})\end{array}$ & ygñatguie & igñat-guie \\
\hline azotar & aitax idlin (1) & azotar & aitas idlin (25v) & aitas idlin & aitasidlin \\
\hline azotes & $\begin{array}{l}\text { notaes nates } \\
\text { (1v) }\end{array}$ & azotes & $\begin{array}{l}\text { nolaesnates } \\
\text { (25) }\end{array}$ & notaesnates & no-taesnates \\
\hline & & azuela & tainguia (26) & tainguia & tain-guia \\
\hline azul & iti pl. itictas (1) & azul & $\begin{array}{l}\text { iti pl. itietas } \\
\text { (25) }\end{array}$ & yti pl. yti-ctas & iti pl. itictas \\
\hline & & babas & guactun (27v) & guachun & guachun \\
\hline bagre & guag nole (2) & bagre & $\begin{array}{l}\text { guag-nole } \\
\text { (26v) }\end{array}$ & guag-nolc & guag-nolc \\
\hline bailar & cacchu (2) & bailar & chazchuc (27) & chazchuc & chazchuz \\
\hline & & baja lo colgado & tagquia (27) & tagquia & tagquia \\
\hline $\begin{array}{l}\text { abajar (1v); } \\
\text { bajar (2) }\end{array}$ & $\begin{array}{l}\text { nugquia (1v); } \\
\text { nonugquia (2) }\end{array}$ & bajarse & $\begin{array}{l}\text { noquias, } \\
\text { nonugquia (27) }\end{array}$ & nonugquia & no-nugquia \\
\hline bañarse & nonai; nayi (2) & bañarse o nadar & $\begin{array}{l}\text { nonai, nonaiji } \\
\text { (27) }\end{array}$ & nonai, nonaiji & no-nai; no-naiji \\
\hline barba & nouse (2) & barba & nouse (26v) & nouse & no-use \\
\hline
\end{tabular}

\footnotetext{
${ }^{15}$ En esta entrada parece haber un enredo: aparentemente los copistas confundieron "asa" del verbo "asar" con el "asa" para agarrar, es decir, no tradujeron la misma palabra. De ahí la confusión entre, por una parte, $<$ öo $\rangle,\langle 0\rangle \mathrm{y}\langle Y o 0\rangle$ donde nos parece reconocer $y^{\prime} 0$ 'quemarse', $y$, por otra parte, <otag> donde nos parece reconocer ot'ak 'mi correa/asa'. En todo caso, labo es un error, cf. "arco iris".

${ }^{16}$ Reconocemos la interyección de dolor: $a k(w) a$ ! Las copias malinterpretaron el "ay" como demostrativo.

${ }^{17}$ Cf. "por la tarde".

${ }^{18}$ No reconocemos el término de la Copia D'Orbigny, los otros sí: inhät-cha 'instrumento del barro'.
} 


\begin{tabular}{|c|c|c|c|c|c|}
\hline \multicolumn{2}{|c|}{ Primo (AFT, 1795) } & \multicolumn{4}{|c|}{ Copias del Manuscrito $D^{\prime} O_{\text {RBIGNY }}$} \\
\hline Castellano & Mataco & Castellano & O'ORBIGNY & LAFONE 1896 & Hunt 1913 \\
\hline barbas & lepàse (2) & $\begin{array}{l}\text { barbas }(L) \text {; barbas } \\
\text { (pelo) }(H)\end{array}$ & & lepaset, pase & pase \\
\hline \multirow[t]{3}{*}{ barbiquejo } & yotac (2) & barbiquejo & yotac (26v) & yotac & yotac \\
\hline & & barrenar $^{19}$ & toyen & toyen & toyen \\
\hline & & barreno & $\begin{array}{l}\text { quinagtoin } \\
(27 \mathrm{v})\end{array}$ & quinagtein & quinag-toin \\
\hline barrer & ajas (2) & barrer & ajas (27) & ajas; oubache & ajas; oubache \\
\hline barriga & noche (1v) & barriga & noche (26v) & no-che & no-che \\
\hline barrigón & chetag (2) & barrigón & chetag (26v) & chetag & chetag \\
\hline barro & igñat (2) & barro & igñat (27) & ygnat; aset & ignat; aset \\
\hline bastar de hablar & $\begin{array}{l}\text { manteg, quiet } \\
(2)\end{array}$ & $\begin{array}{l}\text { basta; basta de } \\
\text { hablar }\end{array}$ & $\begin{array}{l}\text { basta: manteg } \\
\text { (27); basta de } \\
\text { hablar: manteg } \\
\text { quiet (27) }\end{array}$ & manteg (basta) & manteg (basta) \\
\hline bastón & noca la (2v) & bastón & nocala (27) & nocala, la & Ia; no-cala \\
\hline \multirow[t]{2}{*}{ basura } & Ilamuc (20) & basura & & Ilamuc & Ilamuc \\
\hline & & batir & casoine (28) & casoini & casoini \\
\hline bautizado & pacquie leyi (2) & $\begin{array}{l}\text { bautizado o que } \\
\text { tiene nombre }\end{array}$ & $\begin{array}{l}\text { pazquie leiji } \\
(27)\end{array}$ & pazquie leije & pazquie leije \\
\hline no bautizado & $\begin{array}{l}\text { [pacquie] lei } \\
\text { ijijite (2) }\end{array}$ & no bautizado & & $\begin{array}{l}\text { pazquie } \\
\text { leijijinitc, leijijitc }\end{array}$ & $\begin{array}{l}\text { pazquie leiji-jic (o } \\
\text { jinitc) }\end{array}$ \\
\hline bautizar & $\begin{array}{l}\text { nooleya; chaipe } \\
\text { guag (2) }\end{array}$ & bautizar & & $\begin{array}{l}\text { chaipeguag; } \\
\text { nooteya; tathia }\end{array}$ & $\begin{array}{l}\text { chaipe guag; no- } \\
\text { oteya; tathia }\end{array}$ \\
\hline bayo & catuquetag (2) & bayo & $\begin{array}{l}\text { cotucuetag } \\
(26 \mathrm{v})\end{array}$ & catucuetag & catu-cuetag \\
\hline beber & $\begin{array}{l}\text { tuug; tugula; } \\
\text { quiumo (2) }\end{array}$ & beber & $\begin{array}{l}\text { tuug, tujula } \\
\text { (27) }\end{array}$ & $\begin{array}{l}\text { tuug; tujula; } \\
\text { quimo }\end{array}$ & $\begin{array}{l}\text { tuug; tujula; } \\
\text { quimo }\end{array}$ \\
\hline bejuco & $\begin{array}{l}\text { tenaca; tuscal } \\
(2 \mathrm{v})^{20}\end{array}$ & bejuco & linaca (27) & lenaca & Ienaea \\
\hline besar & noichuglin (2) & besar & $\begin{array}{l}\text { noichug- } \\
\text { lin, chuglin, } \\
\text { nisignie (27) }\end{array}$ & $\begin{array}{l}\text { noichuglin, } \\
\text { chuglin, } \\
\text { nisignée }\end{array}$ & $\begin{array}{l}\text { noi-chuglin; ni- } \\
\text { signee }\end{array}$ \\
\hline besar la mano & nonnisi neg (2) & besar la mano & $\begin{array}{l}\text { noisigneg-quici } \\
\text { (27v) }\end{array}$ & noisign-eg; quici & noi-signeg quici \\
\hline blanco & $\begin{array}{l}\text { pelag pl. pelag- } \\
\text { quietas (2) }\end{array}$ & blanco & $\begin{array}{l}\text { pelag; } \\
\text { pelagquietag } \\
\text { pl. } \\
\text { pelagquietas } \\
(27)\end{array}$ & $\begin{array}{l}\text { pelag, } \\
\text { pelagquietag } \\
\text { pl. pelaquietas; } \\
\text { peelag }\end{array}$ & $\begin{array}{l}\text { pelag; peelag; } \\
\text { muy blanco: } \\
\text { pelag-quietag; pl. } \\
\text { quietas }\end{array}$ \\
\hline boca & no laygi (2) & boca & nolagni (27) & nolagni, nolagi & no-lagni; lagi \\
\hline boca torcida & suuleg (2) & & & & \\
\hline bofes & lepujus (2) & bofes & lepujus (27) & lepujos & le-pujos \\
\hline
\end{tabular}

\footnotetext{
${ }^{19}$ Cf. "agujerear".

${ }^{20}$ Hoy t'uskal es el hiperónimo de 'bejuco/enredadera'. La otra palabra no la reconocemos.
} 


\begin{tabular}{|c|c|c|c|c|c|}
\hline \multicolumn{2}{|c|}{ Primo (AFT, 1795) } & \multicolumn{4}{|c|}{ Copias del $M_{A N u s C R I T O} D^{\prime} O_{R B I G N y}$} \\
\hline Castellano & Mataco & Castellano & O'ORBiGnY & LAFONE 1896 & Hunt 1913 \\
\hline bolsa, tabaquera & $\begin{array}{l}\text { no cagni; } \\
\text { nocaugi (2) }\end{array}$ & bolsa & noacgni (27) & nocagni & no-cagni \\
\hline borlas & nohuitac (2v) & borlas & & nohiutac & no-hiutac \\
\hline \multirow[t]{2}{*}{ borracho } & tobocoy (2) & borracho & tobocoy (27) & tobocoy & tobocoy \\
\hline & & muy borracho & techogtac (27) & techogtag & techogtag \\
\hline \multirow[t]{2}{*}{ bostezar } & $\begin{array}{l}\text { nocagquiesag } \\
\text { (2) }\end{array}$ & bostezar & $\begin{array}{l}\text { nocagquicsag } \\
\text { (27v) }\end{array}$ & nocagquiesag & no-cag-quiesag \\
\hline & & botones & noulelei (27) & noulelei & no-u-lelei \\
\hline brasas & juiñot (2) & brasa & juiño (27v) & & juiño \\
\hline bravo & juichag (2) & bravo & juichag (27v) & & juichag \\
\hline brazo & nohui (2) & brazo & nohui (27v) & & $\begin{array}{l}\text { cue; juapo; no- } \\
\text { hui }\end{array}$ \\
\hline bueno & is (2) & bueno & is $(27 \mathrm{v})$ & is & is \\
\hline \multirow[t]{2}{*}{ no está bueno } & isaya (2) & no bueno & isajia (27v) & & isaiia \\
\hline & & muy bueno & iscia $(27 v)$ & & iscia \\
\hline ¿estás bueno? & yaja is? (2) & ¿estás bueno? & quyaja is? (27v) & yaja is? & yaj ais? \\
\hline \multirow[t]{2}{*}{$\begin{array}{l}\text { bueno } \\
\text { [respondiendo] }\end{array}$} & is, istat (2) & $\begin{array}{l}\text { bueno } \\
\text { [respondiendo] }(\mathrm{O}, \\
\mathrm{L} \text { ); él es bueno }(\mathrm{H})\end{array}$ & is estat (27v) & is istat & isistat \\
\hline & & $\begin{array}{l}\text { están todos } \\
\text { buenos }\end{array}$ & & & isaay; aaysay \\
\hline $\begin{array}{l}\text { buenos días, } \\
\text { amigo }\end{array}$ & $\begin{array}{l}\text { ame negi. ala } \\
(2)^{21}\end{array}$ & $\begin{array}{l}\text { buenos días, } \\
\text { compañero }\end{array}$ & $\begin{array}{l}\text { ala anegi; } \\
\text { anne-neji (27v) }\end{array}$ & $\begin{array}{l}\text { ala annenegi, } \\
\text { anegi }\end{array}$ & $\begin{array}{l}\text { ala annenegi, } \\
\text { anegi }\end{array}$ \\
\hline $\begin{array}{l}\text { buenos días } \\
\text { [respondiendo] }\end{array}$ & antena (2) & $\begin{array}{l}\text { buenos días } \\
\text { [respondiendo] }\end{array}$ & anteña (27v) & antena & antena \\
\hline buenas noches & jonag-noig (2) & $\begin{array}{l}\text { buenas noches, } \\
\text { compañero }\end{array}$ & $\begin{array}{l}\text { ala noig is } \\
\text { jonachi (27v) }\end{array}$ & $\begin{array}{l}\text { ala, jonagnoig, } \\
\text { is jonachi }\end{array}$ & $\begin{array}{l}\text { ala jonag noig; is } \\
\text { jonachi }\end{array}$ \\
\hline \multirow[t]{2}{*}{$\begin{array}{l}\text { buenas noches } \\
\text { [respondiendo] }\end{array}$} & $\begin{array}{l}\text { camag no istat } \\
\text { (2) }\end{array}$ & $\begin{array}{l}\text { buenas noches } \\
\text { [respondiendo] }\end{array}$ & $\begin{array}{l}\text { camag noistat } \\
(27 \mathrm{v})\end{array}$ & camag noistat & camag noistag \\
\hline & & burlarse & $\begin{array}{l}\text { sumuz, ilacclin } \\
(27 v)\end{array}$ & & sumuz; ilacchin \\
\hline \multirow[t]{2}{*}{ burro } & asnò $^{* *}(2)$ & & & & \\
\hline & & buscar & uисuе (28) & & uncue \\
\hline caballo & latag (3) & caballo & letag, loy (28) & lotag; loy & lotag; loy \\
\hline caballo de paso & $\begin{array}{l}\text { latag } \\
\text { lóguequiojiji (o } \\
\text { loguequiesiji) } \\
\text { (3v) }\end{array}$ & & & & \\
\hline caballo ligero 22 & [latag] guajadlin & & & & \\
\hline caballo pesado & \begin{tabular}{|l}
{$[$ latag] } \\
choñedlin (3v)
\end{tabular} & caballo pesado & & & choneglin \\
\hline
\end{tabular}

\footnotetext{
${ }^{21}$ La $m$ está sobrescrita, podría leerse también $n n$ o an. Nos inclinamos por $m$ porque reconocemos el saludo que se usa con alguien a quien se ha visto hace poco: amnaji 'hola' (it. 'vos hace poco').

22 Cf. "ligero".
} 


\begin{tabular}{|c|c|c|c|c|c|}
\hline \multicolumn{2}{|c|}{ PrIMo (AFT, 1795) } & \multicolumn{4}{|c|}{ Copias del ManusCrIto $D^{\prime} O_{R B I G N Y}$} \\
\hline Castellano & Mataco & Castellano & O'ORBIGNY & LAFONE 1896 & Hunt 1913 \\
\hline & & caballo de Juan & & juan latag & juan latag \\
\hline caballo ensillado & abute (24) & caballo ensillado & & abutc loy & a-butc loy \\
\hline cabeza & letec $(3 \mathrm{v})$ & cabeza & litec (28) & litec & litec \\
\hline \multirow[t]{2}{*}{ cabra } & caila (3v) & cabra & caila (28) & caila & caila \\
\hline & & cada uno & $\begin{array}{l}\text { noveg yaba } \\
\text { (29) }\end{array}$ & $\begin{array}{l}\text { novegyaba, } \\
\text { chanit }\end{array}$ & $\begin{array}{l}\text { no-vegyaba } \\
\text { chanit }\end{array}$ \\
\hline cadillo & tachoc (3v) & cadillo & tachoc (28) & tachoc & tachoc \\
\hline caerse & iquiadquia (3) & caerse & equiagquia (29) & $\begin{array}{l}\text { yquiagquia; } \\
\text { thiatteen }\end{array}$ & $\begin{array}{l}\text { i-quiagquia; } \\
\text { thiatteen }\end{array}$ \\
\hline cagar $^{23}$ & Ianflin (3) & $\begin{array}{l}\text { cagar }(H) \text {; cargar } \\
(\mathrm{O}, \mathrm{L}, \mathrm{H})\end{array}$ & $\begin{array}{l}\text { cargar: Ianflin } \\
\text { (29) }\end{array}$ & cargar: Ianflin & $\begin{array}{l}\text { cagar: i-lam; } \\
\text { cargar: Ianflin }\end{array}$ \\
\hline \multirow[t]{5}{*}{ caja } & puntag (3) & caja de tocar/caja & $\begin{array}{l}\text { caja de tocar: } \\
\text { puntag }(28 \mathrm{v}) \\
\text { caja: notolile- } \\
\text { nopu }(28 \mathrm{v})^{24}\end{array}$ & $\begin{array}{l}\text { caja de tocar: } \\
\text { puutag; caja: } \\
\text { nototile, nopu }\end{array}$ & $\begin{array}{l}\text { caja de tocar: no } \\
\text { pu; caja: puntag }\end{array}$ \\
\hline & & cajita & gichuc (28v) & gichuc & gichuc \\
\hline & & calambres & yechegla (28v) & $\begin{array}{l}\text { yechegla, } \\
\text { lequilan-aitag }\end{array}$ & $\begin{array}{l}\text { yechegla, } \\
\text { lequilan aitag }\end{array}$ \\
\hline & & calentar algo & $\begin{array}{l}\text { uuni, utuni } \\
\text { (29v) }\end{array}$ & utunitigi itag & utuni tigi itag \\
\hline & & calentarse & utunlin (29v) & $\begin{array}{l}\text { utunlin; utuunlin } \\
\text { joytag }\end{array}$ & $\begin{array}{l}\text { utunlin; } \\
\text { utuunlinjo. ytag }\end{array}$ \\
\hline caldo & tobeg ii (3v) & caldo & tobebii (28) & tobobii & tobobii \\
\hline \multirow[t]{3}{*}{ caliente } & chayu (3v) & caliente & chagu (28) & chagu & cayo; chagu \\
\hline & & calor & & chingilamo & chingilamo \\
\hline & & sentir/tener calor & & chingilanno & chingilamo \\
\hline calzones & nolacpois (3) & calzones & notacpois (28v) & nolacpois & no-lacpois \\
\hline callar & obtiin (3) & callar & $\begin{array}{l}\text { obtiin (29); } \\
\text { calla: guiet (29) }\end{array}$ & $\begin{array}{l}\text { obtiin, obtheet; } \\
\text { calla: quiet, } \\
\text { nitheet }\end{array}$ & $\begin{array}{l}\text { quiet; ob- } \\
\text { theet, nitheet, } \\
\text { obtcheet, obtiin }\end{array}$ \\
\hline \multirow[t]{3}{*}{ cama } & nojoet (3) & cama & $\begin{array}{l}\text { nojoet, nouet } \\
(28 \mathrm{v})\end{array}$ & nojoet; nouet & no-joet; no-uet \\
\hline & & $\begin{array}{l}\text { cámaras de } \\
\text { sangre }\end{array}$ & & chatitagilam & chatitay ilam \\
\hline & & caminar & $\begin{array}{l}\text { nucuc naig } \\
(28 \mathrm{v})\end{array}$ & nucuenaig & nucue naig \\
\hline camino & naig (3) & camino & naig (28v) & naig & naig \\
\hline camino Ilano & naig isquie (3) & & & & \\
\hline camino no llano & naig quienas (3) & & & & \\
\hline
\end{tabular}

\footnotetext{
${ }^{23}$ En esta entrada hay un enredo. Aunque Primo y Hunt la indexan por "cagar", traducen por palabras wichís distintas, de las cuales únicamente la de Hunt se parece al actual t'alham 'defecar'. El término de Primo, que nosotros no reconocemos, es a su vez el mismo que en Lafone y Hunt traduce "cargar".

24 D'Orbigny y Lafone parecen haber confundido "caja" con "ceja": note-Ihile 'su hueso de la ceja'. Cf. "ceja”.
} 


\begin{tabular}{|c|c|c|c|c|c|}
\hline \multicolumn{2}{|c|}{ PrIMo (AFT, 1795) } & \multicolumn{4}{|c|}{ Copias del MANUSCRITO $D^{\prime} O_{\text {RBIGNY }}$} \\
\hline CAstellano & Mataco & CAstellano & O'ORBIGNY & LAFone 1896 & Hunt 1913 \\
\hline camisa & sacal (3) & camisa & sagal (28v) & sagal & sagal \\
\hline \multirow[t]{2}{*}{ camotes } & yetig $^{* * *}(3 \mathrm{v})$ & camotes & yetig $^{* * *}(28)$ & yetig $^{* * *}$ & yetig $^{* * *}$ \\
\hline & & $\begin{array}{l}\text { canar }(\mathrm{O}) \text {; } \\
\text { carrecor? }(\mathrm{L}, \mathrm{H})\end{array}$ & $\begin{array}{l}\text { tal pelagglinn } \\
(29 \mathrm{v})\end{array}$ & tab pelaglin & tabpelaglin \\
\hline canilla & nolile (3v) & canilla & notile (28) & nolile & no-lile \\
\hline cansado & yel (3) & cansado (0) & $\begin{array}{l}\text { noyel }(27 \mathrm{v}) ; n o \\
\text { iel }(28 \mathrm{v})\end{array}$ & noyel & no-yel \\
\hline cantar & cachu (3) & cantar & carchun (29) & cazchun & cazchun \\
\hline cantar las aves & ip (3) & cantar las aves & yp, yplin (29) & yp, yplin & ip; iplin \\
\hline \multirow[t]{2}{*}{ cañas } & canugiis (3v) & cañas & canujuiis (28) & canujuiis & canujuiis \\
\hline & & $\begin{array}{l}\text { capar }(\mathrm{O}, \mathrm{L}, \mathrm{H}) \text {; } \\
\text { capón }(\mathrm{H})\end{array}$ & $\begin{array}{l}\text { nag guianis, } \\
\text { nolagni ( } 29 \mathrm{v})\end{array}$ & $\begin{array}{l}\text { nag, guianis; } \\
\text { nolagni; leni } \\
\text { chianis }\end{array}$ & $\begin{array}{l}\text { no-lagni chiagnis, } \\
\text { leni; capón: nag- } \\
\text { guianis }\end{array}$ \\
\hline capitán & niat (3) & capitán & niat (28v) & niat & niat \\
\hline \multirow[t]{3}{*}{ caracol } & $\begin{array}{l}\text { lel pl. lel-lises } \\
\text { (24) }\end{array}$ & caracol & $\begin{array}{l}\text { lel pl. lelises } \\
\text { (28) }\end{array}$ & lel pl. lelises & Iel pl. lelises \\
\hline & & carancho & ajuchag (29) & ajuchag & ajuchag \\
\hline & & $\begin{array}{l}\text { cargar }(L) ; \text { carga } \\
(L) ; \text { cara }(H)^{25}\end{array}$ & $\begin{array}{l}\text { cara: tegpe } \\
\text { tepe (29v) }\end{array}$ & tigpe; tépe & tepe, tigpe \\
\hline carne & $\begin{array}{l}\text { guaseta. isan } \\
\text { (3); isam (3v) }\end{array}$ & carne & $\begin{array}{l}\text { isam, guatesa } \\
\text { (28) }\end{array}$ & ysam, guaseta & $\begin{array}{l}\text { isam; guaseta- } \\
\text { isan }\end{array}$ \\
\hline carrillo & noyalo (3) & carrillo & noyalo (28v) & noyalo & no-yalo \\
\hline \multirow[t]{2}{*}{ casa } & $\begin{array}{l}\text { lobuqùe; hoet } \\
\text { (3v) }\end{array}$ & casa & lobuque (28) & lobuque; hoet & lo buque; hoet \\
\hline & & $\begin{array}{l}\text { casarse; se ha } \\
\text { casado }(\mathrm{O}, \mathrm{L})\end{array}$ & $\begin{array}{l}\text { casarse: } \\
\text { notejuaye; se } \\
\text { ha casado: } \\
\text { tejuaye (29v) }\end{array}$ & $\begin{array}{l}\text { notejuaye; se ha } \\
\text { casado: tejuaye }\end{array}$ & no-tejuaye \\
\hline \multirow[t]{2}{*}{ cascabel } & quinag telo (24) & cascabel $(\mathrm{O}, \mathrm{L})(\mathrm{H})$ & quinagtelo (28) & quinagtelo & $\begin{array}{l}\text { campana: } \\
\text { quinag-telo }\end{array}$ \\
\hline & & castigar $^{26}$ & $\begin{array}{l}\text { aitasnin, } \\
\text { tasiglin (29v) }\end{array}$ & tasiglin, aitas & tasiglin; ai-tas \\
\hline \multirow[t]{2}{*}{ catarro } & quieltag (3) & $\begin{array}{l}\text { catarro }(\mathrm{O}, \mathrm{L}) \text {; tos, } \\
\text { catarro }(H)\end{array}$ & quieltag (28v) & quictag & quictag \\
\hline & & catorce & & alocon & alocon \\
\hline cavar & juagi gognet (3) & cavar & yuagi-gotnet & $\begin{array}{l}\text { yuagi gotnet (o } \\
\text { gonet) }\end{array}$ & $\begin{array}{l}\text { yuagi gotnet (o } \\
\text { gonet) }\end{array}$ \\
\hline cebil & $\operatorname{ajec}(18 v)$ & cebil & & & ajec \\
\hline cedro & $\begin{array}{l}\text { pagniquieteg } \\
(3 \mathrm{v})\end{array}$ & cedro & $\begin{array}{l}\text { pagniquieteg } \\
(28 \mathrm{v})\end{array}$ & pagniquieteg & pagniquieteg \\
\hline ceja & notelite (3) & ceja $(H)^{27}$ & & & no-tolile \\
\hline
\end{tabular}

\footnotetext{
${ }^{25}$ Lo indexamos como "cargar" porque reconocemos -ti'pe 'poner sObre'.

${ }^{26}$ Cf. "azotar".

${ }^{27}$ Cf. "caja".
} 


\begin{tabular}{|c|c|c|c|c|c|}
\hline \multicolumn{2}{|c|}{ Primo (AFT, 1795) } & \multicolumn{4}{|c|}{ Copias del $M_{A N u s C R I T O} D^{\prime} O_{R B I G N y}$} \\
\hline Castellano & Mataco & Castellano & O'ORBIGNY & LAFONE 1896 & Hunt 1913 \\
\hline ceniza & $\begin{array}{l}\text { lamoz, } \\
\text { macaotag (23) }\end{array}$ & ceniza & & $\begin{array}{l}\text { ytag-moc; } \\
\text { macaotag }\end{array}$ & $\begin{array}{l}\text { itag-moc; } \\
\text { macaotag }\end{array}$ \\
\hline cepo & $\begin{array}{l}\text { calagin, noponti } \\
\text { (23) }\end{array}$ & cepo & & noponte & no-ponte \\
\hline \multirow[t]{2}{*}{ cera } & sopa (3v) & cera & sopa $(28 \mathrm{v})$ & jopa & jopa \\
\hline & & cerco & nolajuce? (29v) & notajuee & no-tajuee \\
\hline cerrar & omni (3) & cerrar & ogni (29) & ogni & ogni \\
\hline cerrar la boca & nojutuec layji (3) & cerrar la boca & $\begin{array}{l}\text { nojutuec ogni } \\
\text { (29) }\end{array}$ & $\begin{array}{l}\text { no-jutuec lagni; } \\
\text { ogni lagni }\end{array}$ & $\begin{array}{l}\text { no-jutuec lagni; } \\
\text { ogni lagni }\end{array}$ \\
\hline cerrar los ojos & nomapa (3) & cerrar los ojos & $\begin{array}{l}\text { nopama tejoy } \\
\text { (29) }\end{array}$ & nomapa & no-mapa \\
\hline ciego & tenuc (3v) & ciego & tenuc $(28 \mathrm{v})$ & ténuc; aznam & tenuc; aznam \\
\hline \multirow[t]{2}{*}{ cielo } & pule (3v) & cielo & topuley (28v) & $\begin{array}{l}\text { pule; yopulei; } \\
\text { ppe-lé }\end{array}$ & $\begin{array}{l}\text { pule; puule; } \\
\text { ppele }\end{array}$ \\
\hline & & $\begin{array}{l}\text { cielo de los } \\
\text { bienaventurados }{ }^{28}\end{array}$ & & yopuley & yopuley \\
\hline ciervo & guasè (3v) & ciervo & guase (28v) & guase & guase \\
\hline cigarro & chuti (3v) & cigarro & $\begin{array}{l}\text { chuit; chuti } \\
\text { (28v) }\end{array}$ & chuti & chuti \\
\hline cinco & ipe bejacla (3v) & cinco & $\begin{array}{l}\text { ipe befagla } \\
(28 \mathrm{v})\end{array}$ & $\begin{array}{l}\text { ype befagla; } \\
\text { ypebeta; } \\
\text { ijuantesii }\end{array}$ & $\begin{array}{l}\text { ype befagla; } \\
\text { ypebeta; } \\
\text { ijuantesii }\end{array}$ \\
\hline \multirow[t]{2}{*}{ cincha } & nocachetag (3v) & $\begin{array}{l}\text { chincha }(O) \text {; } \\
\text { cincha }(L, H)\end{array}$ & $\begin{array}{l}\text { nocachetag } \\
\text { (28v) }\end{array}$ & nocachetag & no-cachetag \\
\hline & & claro & icati; isati (29) & ysati; ycati; sii & ysati; ycati; sii \\
\hline clavar & cagquia (3v) & clavar & $\begin{array}{l}\text { cagquia } \\
\text { thinenthia (29) }\end{array}$ & $\begin{array}{l}\text { cagquia; } \\
\text { thinenthia }\end{array}$ & $\begin{array}{l}\text { cagquia; } \\
\text { thinenthia }\end{array}$ \\
\hline cocido & yo (3v) & cocido $(H)^{29}$ & yo (29) & yo & yo \\
\hline cocinar & nopen (3) & cocinar & $\begin{array}{l}\text { nopenec-lac } \\
(29 \mathrm{v}) ; \text { voy } \\
\text { a cocinar: } \\
\text { nocatay (29v) }\end{array}$ & $\begin{array}{l}\text { no-penec lac; } \\
\text { voy a cocinar: } \\
\text { no-catay }\end{array}$ & $\begin{array}{l}\text { no-penec lac; voy } \\
\text { a cocinar: no- } \\
\text { catay }\end{array}$ \\
\hline codo & $\begin{array}{l}\text { nocato, } \\
\text { nocachili (3) }\end{array}$ & codo & $\begin{array}{l}\text { nocato } \\
\text { nocachile (28v) }\end{array}$ & $\begin{array}{l}\text { nocato, } \\
\text { nocachite }\end{array}$ & $\begin{array}{l}\text { no-cato; no- } \\
\text { cachite }\end{array}$ \\
\hline cojo & cala-pojo (3v) & cojo & calapojo (29) & $\begin{array}{l}\text { calapojo; } \\
\text { calavac }\end{array}$ & $\begin{array}{l}\text { cala-pojo; cala- } \\
\text { vac }\end{array}$ \\
\hline \multirow[t]{3}{*}{ cola } & lequias (3) & cola & leguias (28v) & leguias & le-guias \\
\hline & & colar & sapi (29v) & sápi & sapi \\
\hline & & colgar & $\begin{array}{l}\text { neipa; tecapa } \\
(29 \mathrm{v})\end{array}$ & $\begin{array}{l}\text { neipa; tecapa; } \\
\text { estás: yaja }\end{array}$ & neipa; tecapa \\
\hline colorado & chate (3) & colorado & $\begin{array}{l}\text { ichat; iquiat } \\
(28 \mathrm{v})\end{array}$ & ychato; yquiat & i-chato; i-quiat \\
\hline
\end{tabular}

$28<y o p u l e y>$ equivale a <yopulei $>$ de la fila anterior.

29 Las copias indexan "cosido", pero es Primo quien tiene razón, pues reconocemos y'o 'está asado/quemado'. 


\begin{tabular}{|c|c|c|c|c|c|}
\hline \multicolumn{2}{|c|}{ PrIMo (AFT, 1795) } & \multicolumn{4}{|c|}{ Copias del MANUSCRITO $D^{\prime} O_{\text {RBIGNY }}$} \\
\hline Castellano & Mataco & Castellano & O'ORBIGNY & LAFone 1896 & Hunt 1913 \\
\hline \multirow[t]{2}{*}{ collas } & juit vote $(3 \mathrm{v})^{30}$ & & & & \\
\hline & & comenzar & telajan (29v) & telepan; chiunpa & telepan; chiunpa \\
\hline \multirow[t]{2}{*}{ comer $^{31}$} & tung; tujules (3) & comer & tec $(28 \mathrm{v})$ & tec & tej; teej; tuj \\
\hline & & comezón tener & tec $(29 v)$ & tec & \\
\hline \multirow[t]{7}{*}{ comida } & lac (3) & comida & $u y e^{32} ; \operatorname{lac}(28 \mathrm{v})$ & lac; noslac; uyé & niac; niacu \\
\hline & & mi comida & & & noslac \\
\hline & & su comida & & & lac; slac \\
\hline & & $\begin{array}{l}\text { comida del } \\
\text { hombre }\end{array}$ & & & nola-lac \\
\hline & & $\begin{array}{l}\text { comida del } \\
\text { Antonio }(H) \text {; para } \\
\text { el Antonio }(L)\end{array}$ & & antonio-lac & antonio lac \\
\hline & & $\begin{array}{l}\text { ¿has comido al } \\
\text { mediodía? }\end{array}$ & & yjualai, canitug? & yjualai cani tug? \\
\hline & & compadecerse & $\begin{array}{l}\text { lelachugye } \\
(29 \mathrm{v})\end{array}$ & lelachugiji & lelachuhiji \\
\hline componer & enlin (3v) & componer & eelin (29v) & yélin, eenlin & eenlin; yelin \\
\hline $\begin{array}{l}\text { componer } \\
\text { algunos que } \\
\text { están reñidos }\end{array}$ & elilalin (3v) & $\begin{array}{l}\text { componer los } \\
\text { reñidos }\end{array}$ & & enlilalin & enlilalin \\
\hline comprar & achagle (3) & comprar & $\begin{array}{l}\text { achagle } \\
\text { cajchaja (29) }\end{array}$ & $\begin{array}{l}\text { achagle, } \\
\text { ybolejaye }\end{array}$ & $\begin{array}{l}\text { a-chag-le; } \\
\text { no-cachaja; } \\
\text { i-bolejaye }\end{array}$ \\
\hline \multirow[t]{2}{*}{$\begin{array}{l}\text { no quiero } \\
\text { comprar }\end{array}$} & $\begin{array}{l}\text { cachaja, chajite } \\
\text { (3) }\end{array}$ & no comprar (L) & & cachaja & \\
\hline & & concebir & achochan (29v) & achochan & a-chochan \\
\hline concha & $\begin{array}{l}\text { chiquita: } \\
\text { lenquietag; } \\
\text { grande: lenec } \\
\text { (24) }\end{array}$ & concha & $\begin{array}{l}\text { chiquita: } \\
\text { lenguictag; } \\
\text { grande: leñec } \\
29 \\
\end{array}$ & $\begin{array}{l}\text { chiquita: } \\
\text { lenquictag; } \\
\text { grande: leñec }\end{array}$ & $\begin{array}{l}\text { grande: le-nec; } \\
\text { chiquita: le- } \\
\text { nequictag }\end{array}$ \\
\hline \multirow[t]{3}{*}{ conejo } & maquia (3v) & conejo & macquia (29) & macquia & macquia \\
\hline & & confesarse & $\begin{array}{l}\text { tajuya padre } \\
\text { cainugias (29v) }\end{array}$ & $\begin{array}{l}\text { tapuya padre** } \\
\text { cainugias }\end{array}$ & $\begin{array}{l}\text { tapuya padre** } \\
\text { cainugias }\end{array}$ \\
\hline & & congojarse $^{33}$ & & $\begin{array}{l}\text { tiguiunquic } \\
\text { paam; } \\
\text { notichum }\end{array}$ & $\begin{array}{l}\text { tiguiunquic } \\
\text { paam; no-tichum }\end{array}$ \\
\hline $\begin{array}{l}\text { conocer (3v); } \\
\text { conozco (16) }\end{array}$ & tajueleg $(3 v, 16)$ & conocer & tajueleg (29v) & tajueleg & tajueleg \\
\hline $\begin{array}{l}\text { no conocer (3v); } \\
\text { no conozco }(16)\end{array}$ & $\begin{array}{l}\text { tajueniegte }(3 \mathrm{v}) \\
\text { tagniegte }(16)\end{array}$ & no conocer & $\begin{array}{l}\text { tajue niegte } \\
(29 \mathrm{v})\end{array}$ & tajueniegte & tajue-niegte \\
\hline
\end{tabular}

\footnotetext{
${ }^{30}$ Hunt reencontró el etnónimo de forma independientemente: "Fuiyet-wotes: los Quichuas, Koyas; Hill tribes" (1913, p. 141, también p. 36).

${ }^{31}$ Es comprensible que <tuug> figure también en "beber", pues -tujw es más bien 'ingerir'.

32 Cf. "cháguar".

33 Cf. "acordarse", "acordarse cosas tristes".
} 


\begin{tabular}{|c|c|c|c|c|c|}
\hline \multicolumn{2}{|c|}{ Primo (AFT, 1795) } & \multicolumn{4}{|c|}{ Copias del ManusCrito $D^{\prime} O_{\text {RBIGNY }}$} \\
\hline Castellano & Mataco & Castellano & O'ORBIGNY & LAFone 1896 & Hunt 1913 \\
\hline & & consolar & $\begin{array}{l}\text { ajuyeg; } \\
\text { nocagslin (29v) }\end{array}$ & $\begin{array}{l}\text { ajuyeg, } \\
\text { nocasglin }\end{array}$ & $\begin{array}{l}\text { a-juyeg; no- } \\
\text { cagslin }\end{array}$ \\
\hline & & contar [números] & $\begin{array}{l}\text { notujuantes } \\
(29 \mathrm{v})\end{array}$ & notujuantes & no-tujuantes \\
\hline & & contar [historia] & yami (29v) & yamé, yanflin & $\begin{array}{l}\text { historia: yame; } \\
\text { yanflin }\end{array}$ \\
\hline & & continuar & $\begin{array}{l}\text { telajan, ilexan } \\
\text { (29v) }\end{array}$ & telejan, ylejan & te-lejan; i-lejan \\
\hline & & contradecir & neji pate (29v) & $\begin{array}{l}\text { nejipate; siichet; } \\
\text { leche; ybuct } \\
\text { lanflin }\end{array}$ & $\begin{array}{l}\text { nejipate; } \\
\text { siichet; leche; } \\
\text { ybuctlanflin }\end{array}$ \\
\hline & & convalecer & itaguic (29v) & ylaguic & i-laguic \\
\hline conversar & tajuya (3v) & conversar & $\begin{array}{l}\text { taguisguec } \\
(29 \mathrm{v})\end{array}$ & tajuyguec & tajuyguec \\
\hline & & convidar ${ }^{34}$ & chiumien (29v) & $\begin{array}{l}\text { chiumien; } \\
\text { huewo tisla } \\
\text { yjuala }\end{array}$ & $\begin{array}{l}\text { chiumien; huewo } \\
\text { tisla ijuala }\end{array}$ \\
\hline & & convidar a todos & & huenagus & huenagus \\
\hline & & convocar & $\begin{array}{l}\text { guitearlguitcar } \\
\text { (29v) }\end{array}$ & huigui & huigui \\
\hline corazón & notogle (3v) & corazón & nototgle (29) & notogtle & no-togtle \\
\hline corral & leji (3v) & corral & leji (29) & leji & $l e-j i$ \\
\hline correr & $\begin{array}{l}\text { cayle maa, alojo } \\
\text { (3) }\end{array}$ & correr & $\begin{array}{l}\text { caile maam } \\
\text { (29) }\end{array}$ & caile, maa & caile maa \\
\hline cortar & insit (3) & cortar & insit (29) & unsit & unsit \\
\hline cortarse el pelo & $\begin{array}{l}\text { noinsit quion } \\
\text { letec (3) }\end{array}$ & $\begin{array}{l}\text { cortarse el pelo } \\
\text { de la corona }\end{array}$ & $\begin{array}{l}\text { noinsez quion } \\
\text { litec (29v) }\end{array}$ & $\begin{array}{l}\text { noinsez guion } \\
\text { litec }\end{array}$ & $\begin{array}{l}\text { no-insez guion } \\
\text { litec }\end{array}$ \\
\hline $\begin{array}{l}\text { cortarse el pelo } \\
\text { hasta la frente }\end{array}$ & $\begin{array}{l}\text { [noinsit] notap } \\
\text { (3) }\end{array}$ & $\begin{array}{l}\text { cortar hasta la } \\
\text { frente }\end{array}$ & $\begin{array}{l}\text { no insit notap } \\
(29 \mathrm{v})\end{array}$ & noinsit notap & no-insit no-tap \\
\hline $\begin{array}{l}\text { cortarse el pelo } \\
\text { hasta las orejas }\end{array}$ & \begin{tabular}{|l} 
[noinsit] no \\
tasilis (3)
\end{tabular} & $\begin{array}{l}\text { cortar hasta las } \\
\text { orejas }\end{array}$ & $\begin{array}{l}\text { no insit notap- } \\
\text { silis }(29 \mathrm{v})\end{array}$ & noinsiz notasilis & no-insiz no-tasilis \\
\hline cortarse el lazo & $\begin{array}{l}\text { yes nocabotag } \\
\text { (3) }\end{array}$ & cortarse el hilo & yes $(29 v)$ & yés & yes \\
\hline corzuela & chone (3v) & corzuela & & chowe $e^{35}$ & chowe \\
\hline coser & nochec (3) & coser & $\begin{array}{l}\text { cochec, chec, } \\
\text { nochec (29) }\end{array}$ & nochec, chec; & chec; no-chec \\
\hline cosquillas & ubalais (3v) & cosquillas & ubalais (28v) & ubalais & ubalais \\
\hline costillas & nisiglile (3v) & costillas & $\begin{array}{l}\text { nosiglile eglile } \\
(29)\end{array}$ & noisiglile & noi-siglile \\
\hline coto & nocachi (3v) & coto & nocachi (29) & nocachi & no-cachi \\
\hline cotón & nocajuquie (3v) & cotón & & nocayuquie & no-cayuquie \\
\hline
\end{tabular}

\footnotetext{
${ }^{34}$ Cf. "dar, dame". Primo no utiliza la $w$ que figura en <huewo>. Parece un error de transcripción de $n$ o $n n$, y entonces reconocemos la palabra w'enho 'da'.

35 Primo no utiliza el $w$. Acá, una vez más, es sin duda un error de transcripción por $n$ o nn, pues reconocemos tson'a 'corzuela'.
} 


\begin{tabular}{|c|c|c|c|c|c|}
\hline \multicolumn{2}{|c|}{ PrIMo (AFT, 1795) } & \multicolumn{4}{|c|}{ Copias del MANUSCRITO $D^{\prime} O_{\text {RBIGNY }}$} \\
\hline Castellano & Mataco & Castellano & O'ORBIGNY & Lafone 1896 & Hunt 1913 \\
\hline crecer & $\begin{array}{l}\text { hiclapa; hic-lapa } \\
\text { (3v) }\end{array}$ & crecer & itic lapa (29v) & hic-lapa; talac & hic-lapa; talac \\
\hline \multirow[t]{2}{*}{ crudo $^{36}$} & caset (3v) & crudo & caseg (29) & lapag & lapag \\
\hline & & $\begin{array}{l}\text { cruzar los brazos } \\
(\mathrm{O}, \mathrm{L}, \mathrm{H})\end{array}$ & $\begin{array}{l}\text { chujue lamig } \\
\text { (29v) }\end{array}$ & $\begin{array}{l}\text { chujue lamig; } \\
\text { chujuclec-acueg }\end{array}$ & $\begin{array}{l}\text { chujuelamig; } \\
\text { cruzar tus brazos: } \\
\text { chujuclec acueg }\end{array}$ \\
\hline \multirow[t]{4}{*}{ ¿cuándo? ¿qué? } & qui? (16) & ¿cuándo? & & qui? & \\
\hline & & $\begin{array}{l}\text { ¿cuándo has } \\
\text { venido? }\end{array}$ & & $\begin{array}{l}\text { quinajate- } \\
\text { lenan? }\end{array}$ & quinajate lenan? \\
\hline & & ¿cuándo irá? & & $\begin{array}{l}\text { quina atoic [no } \\
\text { es pregunta] }\end{array}$ & quinaatoic? \\
\hline & & cuando se fue & & pacchimenti & pacchi menti \\
\hline \multirow[t]{2}{*}{ ¿cuándo te vas? } & $\begin{array}{l}\text { qui lajategle } \\
\text { lec? (20) }\end{array}$ & ¿cuándo te vas? & & $\begin{array}{l}\text { ciatagateglelec? } \\
\text { chiategelapi? }\end{array}$ & $\begin{array}{l}\text { ciatagategle lec? } \\
\text { chiatege lapi? } \\
\text { chiateleg api? }\end{array}$ \\
\hline & & ¿cuándo vas? & & quiajate lecjec? & quiajate lecjec? \\
\hline \multirow[t]{2}{*}{$\begin{array}{l}\text { ¿Cuándo } \\
\text { vendrás? }\end{array}$} & $\begin{array}{l}\text { qui lajategle } \\
\text { nan? (20) }\end{array}$ & ¿cuándo vendrás? & & quilajaleglenan? & $\begin{array}{l}\text { quilajateg lenan? } \\
\text { quilateg lenan? }\end{array}$ \\
\hline & & cuanto & & quiaxati & quiaxati \\
\hline \multirow[t]{2}{*}{ ¿cuánto? } & qui jate? (16) & ¿cuánto? & & chajatac? & chajatec? \\
\hline & & cuarto & & tujuan & tujuantesiji \\
\hline cuatro & noquepoig (16) & cuatro & & $\begin{array}{l}\text { nocuepogec; } \\
\text { nocucpoigyec }\end{array}$ & $\begin{array}{l}\text { nocue-pogec; } \\
\text { nocucpoigyec }\end{array}$ \\
\hline $\begin{array}{l}\text { cubrirse o } \\
\text { ponerse el } \\
\text { sombrero }^{37}\end{array}$ & tipa letec (3) & $\begin{array}{l}\text { cubrirse o } \\
\text { ponerse el } \\
\text { sombrero }\end{array}$ & $\begin{array}{l}\text { tipa cabona } \\
(29 v)\end{array}$ & tipa cobowa & tipa cabona \\
\hline \multirow[t]{3}{*}{ cuchillo } & $\begin{array}{l}\text { chognet; catnet } \\
\text { (3) }\end{array}$ & cuchillo & chodnet (29) & chodnet & chodnet \\
\hline & & cuello & nopane $(29 v)$ & nopane & no-pane \\
\hline & & cuento & & laamet & laamet \\
\hline cuerno & quiu (2) & cuerno & quiu (29) & quin & quin \\
\hline cuero & $\operatorname{ag}(3 v)$ & cuero & ag (29) & $a g$ & $a g$ \\
\hline cuervo & $\begin{array}{l}\text { checuoo pl. } \\
\text { chequoos (3v) }\end{array}$ & cuervo & $\begin{array}{l}\text { cheguoo pl. } \\
\text { cheguos (29) }\end{array}$ & $\begin{array}{l}\text { cheguóo pl. } \\
\text { cheguos }\end{array}$ & $\begin{array}{l}\text { cheguoo pl. } \\
\text { cheguos }\end{array}$ \\
\hline \multirow[t]{2}{*}{ cuesta } & $\begin{array}{l}\text { lesug pl. lesujuis } \\
\text { (3) }\end{array}$ & cuesta & \begin{tabular}{|l} 
lesug pl. \\
lesujuis (29)
\end{tabular} & lesug pl. lesujuis & lesug pl. lesujuis \\
\hline & & cuidar & $\begin{array}{l}\text { mis cosas: huya } \\
\text { ycay (29v) }\end{array}$ & huya ycay & huya icay \\
\hline culo & logueg (3) & culo & logueg (29) & logueg & ano: lo-gueg \\
\hline cumbrera & letec (24) & cumbrera & letec (29) & letec & letec \\
\hline
\end{tabular}

\footnotetext{
${ }^{36}$ No reconocemos ninguna de las dos traducciones. Sólo vale notar que <lapag> reaparece en las traducciones de "después" de las copias de Lafone y Hunt.

${ }^{37}$ Acá quizá sea Primo el que se equivoca, pues hoy: -tiphä lakawona 'ponerse su sombrero', mientras que -tiphä Ihetek 'alzar su cabeza'.
} 


\begin{tabular}{|c|c|c|c|c|c|}
\hline \multicolumn{2}{|c|}{ PrIMo (AFT, 1795) } & \multicolumn{4}{|c|}{ Copias del MANUSCRITO $D^{\prime} O_{\text {RBIGNY }}$} \\
\hline Castellano & Mataco & Castellano & O'ORBIGNY & LAFONE 1896 & Hunt 1913 \\
\hline cuña ${ }^{38}$ & osen $(3 v)$ & cuña & $\begin{array}{l}\text { hacha: osen } \\
\text { (29) }\end{array}$ & osen & osen \\
\hline cuñada & nocatog (3v) & cuñada & nocatog (29) & nocátog & no-catog \\
\hline cuñado & nocalay (3v) & cuñado & nocalay (29) & nocalag & no-calag \\
\hline \multirow[t]{3}{*}{ curar } & tilaxan (3) & curar & $\begin{array}{l}\text { tilajan, ilageg } \\
(29 \mathrm{v})\end{array}$ & $\begin{array}{l}\text { tilanan; ylágeg; } \\
\text { ibolechaye }\end{array}$ & $\begin{array}{l}\text { tilanan; i-lageg; } \\
\text { ibolechaye }\end{array}$ \\
\hline & & $\begin{array}{l}\text { ¿cuya es esta } \\
\text { comida? de Pedro }\end{array}$ & & $\begin{array}{l}\text { achilac tage? } \\
\text { pedro lac }\end{array}$ & $\begin{array}{l}\text { achi lac tage? } \\
\text { pedro lac }\end{array}$ \\
\hline & & ¿cuyo es esto? & & achicayguet? & achi cayguet? \\
\hline chacra $^{39}$ & $\begin{array}{l}\text { ispet; lesquinas } \\
\text { tales (24) }\end{array}$ & $\begin{array}{l}\text { chacra }(\mathrm{O}) \text {; } \\
\text { chacara }(\mathrm{L}) ; \\
\text { cháchara }(\mathrm{H})\end{array}$ & $\begin{array}{l}\text { cashoit pl. } \\
\text { cashuetes (28v) }\end{array}$ & $\begin{array}{l}\text { cashoct pl. } \\
\text { cashoctes; } \\
\text { nocas }\end{array}$ & $\begin{array}{l}\text { cashoct pl. } \\
\text { cashoctes }\end{array}$ \\
\hline cháguar & niag (3v) & cháguar & $\begin{array}{l}\text { niag; niacu } \\
(28 \mathrm{v})\end{array}$ & $\begin{array}{l}\text { niag, niacu; } \\
\text { comida: uye }\end{array}$ & uye \\
\hline cháguar fruta & oyegloy (3v) & cháguar fruta & uyegloy (28v) & oyeglog & oyeglog \\
\hline chala & yspet oley $(3 \mathrm{v})^{40}$ & chala & ispa olec (28v) & yspet, oler & ispet-olec \\
\hline chaleco & $\operatorname{nouc}[\ldots]$ o $(3)^{41}$ & & & & \\
\hline chancho & $\begin{array}{l}\text { nichag; satai; } \\
\text { abuchag (3) }\end{array}$ & $\begin{array}{l}\text { cochino }(O) ; \\
\text { chancho }(L, H)\end{array}$ & $\begin{array}{l}\text { nichag, satay, } \\
\text { abuchag (28v) }\end{array}$ & $\begin{array}{l}\text { nichag; satay; } \\
\text { abuchag }\end{array}$ & $\begin{array}{l}\text { nichag; satay; } \\
\text { abuchag }\end{array}$ \\
\hline chañar & lecheni (3v) & chañar & lecheni (28v) & lechinici & lechinici \\
\hline charquear* & $\begin{array}{l}\text { novo charqui*; } \\
\text { elel chauet (3) }\end{array}$ & charquear* & $\begin{array}{l}\text { novo charqi } \\
\text { elel chanet (29) }\end{array}$ & $\begin{array}{l}\text { novocharqui*, } \\
\text { elel chauet }\end{array}$ & $\begin{array}{l}\text { no-vo charqui* } \\
\text { elel chauet }\end{array}$ \\
\hline chasque & iquien (3v) & chasque & iquien (28v) & $\begin{array}{l}\text { yquien; silat; } \\
\text { niguayac }\end{array}$ & $\begin{array}{l}\text { iquien silat } \\
\text { niguayac }\end{array}$ \\
\hline chicharrón & notuglec (3v) & chicharrón & notuglez (28v) & notuglez & notuglez \\
\hline chifles & nojlaque (3) & chifles & noglacue (28v) & $\begin{array}{l}\text { noglacuc; } \\
\text { noslacucy }\end{array}$ & $\begin{array}{l}\text { no-glacuc; no- } \\
\text { slacucy }\end{array}$ \\
\hline chilca [planta] & juichanes (24) & chilca [planta] & & yuichanes & yuichanes \\
\hline chinas [mujeres] & quileis (3v) & chinas & quileis (28v) & quileis & mujeres: quileis \\
\hline \multirow[t]{2}{*}{ chiquito } & $\operatorname{lasag}(3 \mathrm{v})$ & chiquito & $\begin{array}{l}\text { chiulite; } \\
\text { guaguita } \\
(28 \mathrm{v})^{* 42}\end{array}$ & lasáag & lassag; lasag \\
\hline & & chispa ${ }^{43}$ & tegquiel (29) & tegquiel & tegquiel \\
\hline choclos & ispet cas (3v) & choclos & espetcas (28v) & yspetcas & ispet-cas \\
\hline
\end{tabular}

\footnotetext{
${ }^{38}$ La aclaración de D'Orbigny es importante, pues hace pensar que se trata de la cuña que se usaba antiguamente para hender la madera; hoy hosan es uno de los nombres del 'hacha' de metal; la "cuña" para apoyar o apretar tiene otro nombre (cf. Montani $2017 \mathrm{a}$ ).

39 Primo anota "chacara", pero reconocemos ijpat 'maíz' y sabemos que hoy los wichis suelen llamarlo con el quechuismo chakra. La entrada además se aclara bastante si uno sabe que: <lesquinas toles> ischinhas tälhes 'brotes de plantas de zapallo' (cf. "zapallo"), <nocas > nok'äs 'su planta cultivada', <cashuetes> es -k'äs-wetes 'morada de la planta cultivada'. Cf. "choclos".

${ }^{40}$ El final de la palabra está un poco manchado, pero no nos parece una c (o una $r$, que Primo no utiliza), porque reconocemos ijpat-w'oley 'hojas de maíz'. De todos modos, debemos reconocer que en "deshojar" Primo sí anota <olec $>$ por w'oley.

41 Una o dos letras muy borrosas.

42 Del < guaguita> no hay duda. <chiulite>, asimismo, parece el criollismo "chirete". Ambos términos todavía se usan en el castellano regional.

${ }^{43}$ Reconocemos fácilmente -tech'elh 'crepitar/estallar/chisporrotear'.
} 


\begin{tabular}{|c|c|c|c|c|c|}
\hline \multicolumn{2}{|c|}{ PRIMo (AFT, 1795) } & \multicolumn{4}{|c|}{ Copias del MANusCRITo $D^{\prime} O_{\text {RBIGNy }}$} \\
\hline Castellano & Mataco & Castellano & O'ORBIGNY & LAFone 1896 & Hunt 1913 \\
\hline & & chorrear & tagloo (29v) & tagloo & tagloo \\
\hline $\begin{array}{l}\text { chucho }(3 v) \text {; } \\
\text { enfermar del } \\
\text { chucho (3) }\end{array}$ & $\begin{array}{l}\text { telag ilam (3); } \\
\text { telag (3v) }\end{array}$ & $\begin{array}{l}\text { chucho, terciana } \\
\text { (O); chucho }(L, H)\end{array}$ & telag (28v) & telag & telag \\
\hline chuña & niquiu (3v) & chuña & niguia (28v) & niguici & niguici \\
\hline chupar & nochu (3) & chupar & $\begin{array}{l}\text { nocha; noquia; } \\
\text { chule (29) }\end{array}$ & $\begin{array}{l}\text { nocha noquia- } \\
\text { chule; chugni }\end{array}$ & $\begin{array}{l}\text { chugni; nocha; } \\
\text { no-quia-chule }\end{array}$ \\
\hline \multirow[t]{2}{*}{ dar, dame } & $\begin{array}{l}\text { tis; dame: tisnoo } \\
\text { (4) }\end{array}$ & dar & $\begin{array}{l}\text { tis; avendamo } \\
\text { (30) }\end{array}$ & tis; avendamo & tis; a-vendamo \\
\hline & & dar presentando & huit gueno (30) & huit gueno & huitgueno \\
\hline darlo todo & male tuec (4) & darlo todo & maletuec (30) & maletuec & maletuec \\
\hline dedo & $\begin{array}{l}\text { nojug pl. nojus } \\
\text { (4) }\end{array}$ & dedo & $\begin{array}{l}\text { nojug pl. nojus } \\
\text { (30) }\end{array}$ & nojug pl. nojus & no-jug pl. no-jus \\
\hline dedo gordo & $\begin{array}{l}\text { nojug loquetag } \\
\text { (4) }\end{array}$ & dedo gordo & $\begin{array}{l}\text { nojug loquetag } \\
\text { (30) }\end{array}$ & nojug, loquetag & no-jug loquetag \\
\hline \multirow[t]{2}{*}{ dejar } & manteg (4) & dejar & manteg (30) & manteg & manteg \\
\hline & & de la banda & & taluechie & taluechie \\
\hline delgado & $\begin{array}{l}\text { liinsaig pl. } \\
\text { liinsas (4) }\end{array}$ & delgado & $\begin{array}{l}\text { linsag pl. linsas } \\
\text { (30) }\end{array}$ & linsag pl. linsas & linsag pl. linsas \\
\hline \multirow[t]{2}{*}{ dentera } & chipil (4) & dentera & & chipil & chipil \\
\hline & & dentudo, pescado & nijue (30) & nijuc & nijuc \\
\hline derecho & chupiquia (4) & derecho & chupingua (30) & chupinguia & chupinguia \\
\hline \multirow[t]{2}{*}{ derramar } & chaig, chai (4) & derramar & chai, chaig (30) & chai; chaig & chai; chaig \\
\hline & & derramarse & changuia (30) & changuia & changuia \\
\hline desgarrar & oglipe (4) & desgarrar la ropa & & oglipe & oglipe \\
\hline desgranar & lenquic (4) & desgranar & longuic (30) & lenguic & lenguic \\
\hline deshojar & $\begin{array}{l}\text { tognequie la } \\
\text { olec (4) }\end{array}$ & deshojar & $\begin{array}{l}\text { taguequicla } \\
\text { olec (30) }\end{array}$ & $\begin{array}{l}\text { tognequiela } \\
\text { olec }\end{array}$ & togne quiela olec \\
\hline \multirow[t]{2}{*}{ desigual hilado } & suta-nunquie (4) & desigual & $\begin{array}{l}\text { suta numquie } \\
\text { (30) }\end{array}$ & suta numquie & sutanumquie \\
\hline & & desnudarse & $\begin{array}{l}\text { nolini nohui } \\
\text { (30) }\end{array}$ & nolini nohuc & no-lini no-huc \\
\hline \multirow[t]{2}{*}{ desollar } & $\operatorname{ajec}(4)$ & desollar & ajec (30) & ajec & ajec \\
\hline & & después & camag (30) & $\begin{array}{l}\text { camag; agnis; } \\
\text { lapag }\end{array}$ & $\begin{array}{l}\text { camag; agnis; } \\
\text { lapag }\end{array}$ \\
\hline desyerbar & togne latales (4) & desyerbar & & tognela tales & togne latales \\
\hline día & iguala (4) & día & yuala (30) & yuala, iquala & ijuala; iquala \\
\hline día claro & iguala tog (4) & día claro & yuala tog (30) & yguala tog & iguala tog \\
\hline día nublado & pule inquia (4) & día nublado & & yjala pule inquia & yjala pule inquia \\
\hline diablo & ajatag (4) & diablo & $\begin{array}{l}\text { ajatag; gualac- } \\
\text { lauc (30) }\end{array}$ & $\begin{array}{l}\text { ajatag; gualac- } \\
\text { lauc }\end{array}$ & $\begin{array}{l}\text { ajatag; gualac } \\
\text { lauc }\end{array}$ \\
\hline dientes & nochote (4) & dientes & $\begin{array}{l}\text { nochote pl. } \\
\text { nochotes (30) }\end{array}$ & $\begin{array}{l}\text { nochote pl. } \\
\text { nochotes }\end{array}$ & $\begin{array}{l}\text { no-chote pl. no- } \\
\text { chotes }\end{array}$ \\
\hline
\end{tabular}




\begin{tabular}{|c|c|c|c|c|c|}
\hline \multicolumn{2}{|c|}{ Primo (AFT, 1795) } & \multicolumn{4}{|c|}{ Copias del ManusCRIto $D^{\prime} O_{\text {RbIGNy }}$} \\
\hline Castellano & Mataco & Castellano & O'ORBIGNY & LAFone 1896 & Hunt 1913 \\
\hline & & dieciseís & & opou & muchos: opou \\
\hline & & diecisiete & & loos & muchos: loos \\
\hline & & diez & & lagelapleza & lagelapleza \\
\hline \multirow[t]{2}{*}{ dios } & $\operatorname{tupa}^{\star * \star}(4)$ & dios & $\operatorname{tupa}^{\star \star \star *}(30)$ & tupa*** & tupa*** \\
\hline & & $\begin{array}{l}\text { dios se lo pague } \\
\text { (gracias) }\end{array}$ & cajli ajia (30) & & \\
\hline divieso & lechi (4) & divieso & & lechi & le-chi \\
\hline doblar & cajuel (4) & doblar la ropa & cajuel (30) & cajuel & cajuel \\
\hline \multirow[t]{2}{*}{$\begin{array}{l}\text { doblar la } \\
\text { rodilla }{ }^{44}\end{array}$} & chinen (4) & doblar la rodilla & $\begin{array}{l}\text { nocanguiete } \\
\text { renche (30) }\end{array}$ & $\begin{array}{l}\text { nocanguiete } \\
\text { nenchi }\end{array}$ & $\begin{array}{l}\text { no-canguiete } \\
\text { nenchi }\end{array}$ \\
\hline & & doce & & natujuaya-el & natujuaya-el \\
\hline doler; dolor & $\begin{array}{l}\text { doler: aytag; } \\
\text { dolor: aytag pl. } \\
\text { aytas (4) }\end{array}$ & doler; dolor & $\begin{array}{l}\text { doler: aytag } \\
\text { (30); dolor: } \\
\text { aytag pl. aytas } \\
\text { (30) }\end{array}$ & $\begin{array}{l}\text { doler: aytag; } \\
\text { dolor: aytag pl. } \\
\text { aytas }\end{array}$ & aytag pl. aytas \\
\hline \multirow[t]{3}{*}{ domar, amansar } & noyasei $(4)^{45}$ & & & & \\
\hline & & ¿dónde? & & & qui? chi? \\
\hline & & ¿de dónde? & qui? (30) & qui? & qui? \\
\hline $\begin{array}{l}\text { ¿de dónde } \\
\text { vienes? }\end{array}$ & qui-latagli? (4) & $\begin{array}{l}\text { ¿de dónde has } \\
\text { venido? }(\mathrm{O}) \text {; ¿de } \\
\text { dónde vienes? ( } \mathrm{L} \text {, } \\
\text { H) }\end{array}$ & quilatagli (30) & $\begin{array}{l}\text { quilatagli? } \\
\text { chiletagli? }\end{array}$ & $\begin{array}{l}\text { quilatagli? } \\
\text { chiletagli? }\end{array}$ \\
\hline \multirow[t]{5}{*}{ ¿en dónde? } & $\begin{array}{l}\text { qui leje? qui } \\
\text { cho? (5) }\end{array}$ & ¿en dónde? & quineg (30) & quineg? quicho? & quineg? quicho? \\
\hline & & $\begin{array}{l}\text { ¿por dónde } \\
\text { vienes? }\end{array}$ & & & quilatagli? \\
\hline & & ¿dónde está? & & quicha? & quicha? \\
\hline & & $\begin{array}{l}\text { ¿dónde está/ha } \\
\text { ido tu padre? }\end{array}$ & & chijoje asthia? & chijoje asthia? \\
\hline & & ¿por dónde? & & $\begin{array}{l}\text { quinunucuc; } \\
\text { qui ininucue? } \\
\text { quilatagli? }\end{array}$ & $\begin{array}{l}\text { quinu nucuc? } \\
\text { quiini nucue? }\end{array}$ \\
\hline dorado [pescado] & catuta (4) & dorado, pescado & catula (30) & catuta & catutu \\
\hline dormir & $\begin{array}{l}\text { nobma; lema; } \\
\text { yma; no catquia } \\
\text { (4) }\end{array}$ & dormir & $\begin{array}{l}\text { nobma; lemma } \\
\text { (30) }\end{array}$ & $\begin{array}{l}\text { nolima, lemma, } \\
\text { yma; nocanguia }\end{array}$ & $\begin{array}{l}1^{\text {a }} \text { p. noli-ma; } 2^{\mathrm{a}} \\
\text { p. lem-ma; } 3^{\mathrm{a}} \text { p. } \\
\text { i-ma; no-canguia }\end{array}$ \\
\hline \multirow[t]{2}{*}{ dos } & tacuas (4) & dos & tacuas (30) & tacuas & tacuas \\
\hline & & dulce & & acag; aconez & acag; aconez \\
\hline duro & tuum (4) & duro & tuum (30) & tuuwe & tuuwe \\
\hline echar, arrojar & $\begin{array}{l}\text { nojumeg; } \\
\text { noticadni (8) }\end{array}$ & $\begin{array}{l}\text { echar, arrojar de } \\
\text { sí }\end{array}$ & & $\begin{array}{l}\text { nojumée; } \\
\text { noticadmi }\end{array}$ & $\begin{array}{l}\text { no-jumee; no- } \\
\text { ticadmi }\end{array}$ \\
\hline
\end{tabular}

\footnotetext{
44 Pese a indicar traducciones diferentes, los distintos autores no se equivocan (cf. "Arrodillarse" y "Rodilla"): en <Chinen> reconocemos -tsinen 'doblar' y en <Nocaguiete renche> o <Nocaguiete nenchi>, nokanchete (itsi)nenche 'dobla su rodilla'.

${ }^{45}$ Quizá noyake 'ser dócil' (cf. Claesson, 2008, p. 278).
} 


\begin{tabular}{|c|c|c|c|c|c|}
\hline \multicolumn{2}{|c|}{ PRIMo (AFT, 1795) } & \multicolumn{4}{|c|}{ Copias del MANusCRITo $D^{\prime} O_{\text {RBIGNy }}$} \\
\hline Castellano & Mataco & Castellano & O'OrBigny & LAFONE 1896 & Hunt 1913 \\
\hline $\begin{array}{l}\text { echar o poner } \\
\text { alguna cosa }{ }^{46}\end{array}$ & anchijui (8) & echar o poner & & chano; chaipe & chano; chaipe \\
\hline echar sal & $\begin{array}{l}\text { chaño nisoy; } \\
\text { espolvoreando: } \\
\text { tato nisoy }(8)^{47}\end{array}$ & & & & \\
\hline \multirow[t]{2}{*}{$\begin{array}{l}\text { echar tierra al } \\
\text { agujero }\end{array}$} & $\begin{array}{l}\text { pogquie, } \\
\text { chaiquie (8) }\end{array}$ & $\begin{array}{l}\text { echar tierra o } \\
\text { tapar el agujero }\end{array}$ & & $\begin{array}{l}\text { pogquie; } \\
\text { chaigue }\end{array}$ & pogquie; chaigue \\
\hline & & él $(H)$; el otro $(L, H)$ & & jape & jape \\
\hline \multirow[t]{2}{*}{ emborracharse } & tobocoy (5) & emborracharse & & tobocoy & tobocoy \\
\hline & & $\begin{array}{l}\text { empachado; } \\
\text { empacharse }\end{array}$ & & atajuac; tujuac & tujuac; a-tajuac \\
\hline encender & lagni (5) & encender & & lagni; ugno & lagni; ugno \\
\hline encías & $\begin{array}{l}\text { nochote sanis } \\
\text { (5) }\end{array}$ & encías & & nochote sanis & no-chote-sanis \\
\hline enfermar & $\begin{array}{l}\text { aytas ilan, tug } \\
\text { (5) }\end{array}$ & enfermar & & aytasalam; tuug & aytas-alam; tuug \\
\hline $\begin{array}{l}\text { enfermedad } \\
\text { venérea }\end{array}$ & $\begin{array}{l}\text { amotag pl. } \\
\text { amotas (5) }\end{array}$ & $\begin{array}{l}\text { enfermedad } \\
\text { (O); enfermedad } \\
\text { venérea }(L, H)\end{array}$ & $\begin{array}{l}\text { amotag pl. } \\
\text { amotas (30) }\end{array}$ & $\begin{array}{l}\text { amotag pl. } \\
\text { amotas }\end{array}$ & $\begin{array}{l}\text { amotag pl. } \\
\text { amotas }\end{array}$ \\
\hline enfermo ${ }^{48}$ & yil, nisia (5) & enfermo & nisia, yel (30) & nisia; yel & nisia; yel \\
\hline \multirow[t]{2}{*}{ enfrenar } & tato; locai (5) & enfrenar & & tato locay & tato-locay \\
\hline & & engañar & & $\begin{array}{l}\text { yuecnacha; } \\
\text { yueguienglin }\end{array}$ & $\begin{array}{l}\text { yuecnacha; } \\
\text { yueguienglin }\end{array}$ \\
\hline enseñar & chajuenlin (5) & enseñar & & chujuenlin & chujuenlin \\
\hline ensillar & eng-lin (5) & ensillar & & enlin tatag & enlin latag \\
\hline entender & $\begin{array}{l}\text { nolat ama; } \\
\text { iboye (5) }\end{array}$ & entender & & nolatama & no-latama \\
\hline no entender & latita ama (5) & no entender & & latitá ama & latitaama \\
\hline \multirow[t]{3}{*}{ entrar } & noyuño (5) & entrar & & noy & noy \\
\hline & & $\begin{array}{l}\text { ¿es de Pedro } \\
\text { esto? }\end{array}$ & & $\begin{array}{l}\text { P. tagelechi? P. } \\
\text { cayguet? }\end{array}$ & $\begin{array}{l}\text { P. tagelechi? P. } \\
\text { cayguet? }\end{array}$ \\
\hline & & ese del padre & & & $\begin{array}{l}\text { pale }{ }^{* *} \text { la } \\
\text { francisco caigi }{ }^{49}\end{array}$ \\
\hline escopeta & luchetag (5) & escopeta & & luchetag & luchetag \\
\hline escribir & lesai idlin (5) & escribir & & lesairdlin & lesairdlin \\
\hline escucha & joye (5) & escuchar & & yjoye & ijoye \\
\hline eslabón & itagquie (5) & eslabón & itaguic (30) & itaguic & $i$-taguic \\
\hline espantar & ocosle (5) & espantar & & ocosa & ocosa \\
\hline
\end{tabular}

\footnotetext{
${ }^{46}$ El verbo wichí que aparece en Lafone y Hunt y en la entrada siguiente es tsäy 'derramar(se)', bajo las formas $<$ Chano $>0<$ Chaño $>$ tsähyo 'verter', y <Chaipe> tsäype 'echar sobre'. La palabra tachada no la reconocemos.

${ }^{47}$ Además de -tsähyo nisoy 'echar sal', -tatho nisoy 'poner sal' (cf. nota anterior).

48 Lafone y Hunt confunden la $i$ de <yil> y'ilh 'estar agonizante/muerto' con una $e$, y entonces traducen "enfermo" por <yel> y'elh 'estar cansado'.

${ }^{49}$ Aunque la palabra probablemente sea un préstamo de "padre", hoy päle 'pelado/sacerdote'.
} 


\begin{tabular}{|c|c|c|c|c|c|}
\hline \multicolumn{2}{|c|}{ PrIMo (AFT, 1795) } & \multicolumn{4}{|c|}{ Copias del ManusCrIto $D^{\prime} O_{R B I G N Y}$} \\
\hline Castellano & Mataco & Castellano & O'ORBIGNY & LAFONE 1896 & Hunt 1913 \\
\hline & & espantarse & & $\begin{array}{l}\text { nohag; } \\
\text { onochaya }\end{array}$ & $\begin{array}{l}\text { nohag; } \\
\text { o-nochaya }\end{array}$ \\
\hline \multirow[t]{5}{*}{ espejo } & $\begin{array}{l}\text { suulag; notuunti } \\
\text { (5) }\end{array}$ & espejo & & $\begin{array}{l}\text { souulag; } \\
\text { notuunti }\end{array}$ & $\begin{array}{l}\text { souulag; no- } \\
\text { tuunti }\end{array}$ \\
\hline & & espesar & & nigui noquioya & nigui noquioya \\
\hline & & espeso & & notonec & notonec \\
\hline & & espina & & $\begin{array}{l}\text { quitenil pl. } \\
\text { quitenis }\end{array}$ & $\begin{array}{l}\text { quitenil pl. } \\
\text { quitenis }\end{array}$ \\
\hline & & espolonear & & tato & tato \\
\hline esquina & iñat chela (5) & esquina & & chela & chela \\
\hline \multirow[t]{2}{*}{ este } & $\begin{array}{l}\text { jääpe esotao; } \\
\text { jacquite }(5)^{50}\end{array}$ & & & & \\
\hline & & estirar bien & & toone & toone \\
\hline esto & tachi; maca (5) & esto & $\begin{array}{l}\text { tajchi, atachi } \\
(30)\end{array}$ & $\begin{array}{l}\text { tagchi; atachi; } \\
\text { maca }\end{array}$ & $\begin{array}{l}\text { tagchi; a-tachi; } \\
\text { a-tagdchi; maca }\end{array}$ \\
\hline estornudar & nonachiel (5) & estornudar & & nocachien & no-cachien \\
\hline \multirow[t]{2}{*}{ estrella } & cates (5) & estrella & cates (30) & catés & cates \\
\hline & & extender & & quigni & quigni \\
\hline faja & nocaniac (6) & faja & & nocañiacu & no-cañiacu \\
\hline \multirow[t]{2}{*}{ fajarse } & noyaitlami (6) & fajarse & & $\begin{array}{l}\text { noyaitlami; } \\
\text { yuietlami }\end{array}$ & $\begin{array}{l}\text { no-yaitlami; } \\
\text { yuietlami }\end{array}$ \\
\hline & & fiar & & $\begin{array}{l}\text { quiuncata; } \\
\text { tisiapag }\end{array}$ & $\begin{array}{l}\text { quiuncata; } \\
\text { tisiapag }\end{array}$ \\
\hline fiero & $\begin{array}{l}\text { caquietag; } \\
\text { cachia (6) }\end{array}$ & fiera cosa, fiero & & $\begin{array}{l}\text { fiera cosa: } \\
\text { cachia, site; } \\
\text { "fuero": } \\
\text { caquietag; } \\
\text { cachia }\end{array}$ & $\begin{array}{l}\text { fiera cosa: site; } \\
\text { fiero: cachia; } \\
\text { caquietag }\end{array}$ \\
\hline flaco & lopen (6) & flaco & & Iompen & Iompen \\
\hline flecha & lotec (6) & flecha & & lotec & lotec \\
\hline flojo & $\begin{array}{l}\text { notacaxinite; } \\
\text { egquie (6) }\end{array}$ & flojo & & $\begin{array}{l}\text { eguie; } \\
\text { notacaxinite }\end{array}$ & $\begin{array}{l}\text { eguie; } \\
\text { notacaxinite }\end{array}$ \\
\hline $\begin{array}{l}\text { flojo, no } \\
\text { apretado }\end{array}$ & cabcaigno (6) & flojo, no apretado & & cab cayno & cabcayno \\
\hline flor & nabo (6) & $\begin{array}{l}\text { azar o flor de los } \\
\text { árboles (L); flor } \\
(L, H)\end{array}$ & & $\begin{array}{l}\text { azar o flor: labo; } \\
\text { flor: nabo }\end{array}$ & nabo; labo \\
\hline fornicar & tuug china (6) & fornicar & & $\begin{array}{l}\text { tuug, quileis; } \\
\text { gualaichag }\end{array}$ & $\begin{array}{l}\text { gualaichag; tuug } \\
\text { quileis }\end{array}$ \\
\hline forro & legi (6) & forro & & legi & le-gi \\
\hline frazada & pelatag (6) & frazada & & $\begin{array}{l}\text { pelatag; } \\
\text { poncho* }\end{array}$ & pelatag; poncho* \\
\hline freir & tuleg; otieni (6) & freir & & tuleg; otieni & tuleg; otieni \\
\hline
\end{tabular}

\footnotetext{
${ }^{50}$ Sólo nos parece reconocer el verbo cópula häpe, que tiene usos que lo asemejan a un demostrativo (cf. Claesson, 2008, p. 136). Las otras palabras no las reconocemos y no está claro si <esotao> no es un error por "estos", en español.
} 


\begin{tabular}{|c|c|c|c|c|c|}
\hline \multicolumn{2}{|c|}{ Primo (AFT, 1795) } & \multicolumn{4}{|c|}{ Copias del Manuscrito $D^{\prime} O_{\text {BbIGNy }}$} \\
\hline Castellano & Mataco & Castellano & O'Orbigny & LAFone 1896 & Hunt 1913 \\
\hline freno & locay (6) & freno & & locag & locag \\
\hline frente & notacho (6) & frente & & notachio & no-tachio \\
\hline \multirow[t]{2}{*}{ frío $^{51}$} & juiet (6) & frío & & & gochi \\
\hline & & fruta & & & $g \log ^{52}$ \\
\hline $\begin{array}{l}\text { fruto recién } \\
\text { cuajado }\end{array}$ & layjas (6) & $\begin{array}{l}\text { fruto recién } \\
\text { cuajado }\end{array}$ & & layjas & lay-jas \\
\hline fuego & itag (6) & fuego & & itag & itag \\
\hline \multirow[t]{2}{*}{ fuerte, castillo } & nojuec (6) & fuerte, castillo & & nojuec & nojuec \\
\hline & & fuerte, o duro ${ }^{53}$ & & tuum & tuum \\
\hline $\begin{array}{l}\text { galápago } \\
\text { [tortuga] }\end{array}$ & tolcag (7) & galápago [tortuga] & & tolcag & tolcag \\
\hline gallina, gallo & $\circ \circ(7)$ & gallo, gallina & & ö̈ & 00 \\
\hline ganar & $\operatorname{chag}(7)$ & ganar & & chag; nocayaan & chag; nocayaan \\
\hline garguero & nopagni (7) & garguero & & $\begin{array}{l}\text { nopagni; } \\
\text { nocachi }\end{array}$ & $\begin{array}{l}\text { no-pagni; pane; } \\
\text { no-cachi }\end{array}$ \\
\hline \multirow[t]{2}{*}{ garrapata } & juequiatag (7) & garrapata & & $\begin{array}{l}\text { yueguiatag } \mathrm{pl} . \\
\text { yueguiatas }\end{array}$ & $\begin{array}{l}\text { yueguiatag pl. } \\
\text { yueguiatas }\end{array}$ \\
\hline & & garuar & & tispetu & tispetu \\
\hline gato montés & silacai (7) & gato montés & & silacay & silacay \\
\hline \multirow[t]{2}{*}{ gavilán } & yesnag (7) & gavilán & & yesnag & yesnag \\
\hline & & gobernador & & aputag & aputag \\
\hline golondrinas & juichatas (7) & golondrina & & yuichatas & yuichatas \\
\hline gordo & yatag (7) & gordo & & yatag & yatag \\
\hline gorro & nocabona (7) & $\begin{array}{l}\text { gorro }(\mathrm{O}, \mathrm{L}) \text {; gorra } \\
(\mathrm{H})\end{array}$ & & nocabona & no-cabona \\
\hline \multirow[t]{2}{*}{ grande } & vug; talac (7) & grande & & $\begin{array}{l}\text { ucag; fem. } \\
\text { lutag }\end{array}$ & $\begin{array}{l}\text { uug; ucag; fem. } \\
\text { lutag }\end{array}$ \\
\hline & & granizo & & cataatu & cataatu \\
\hline grasa & agpè (7) & $\begin{array}{l}\text { grasa }(\mathrm{O}, \mathrm{L}) \text {; aceite } \\
(\mathrm{H})\end{array}$ & & agpe & agpe \\
\hline grillo & tichil (7) & grillo & & tichiel & tichiel \\
\hline $\begin{array}{l}\text { gualcas* }^{*} \\
\text { [collares] }\end{array}$ & $\begin{array}{l}\text { amis; laamis; } \\
\text { nachacas (7) }\end{array}$ & gualcas* [collares] & & $\begin{array}{l}\text { anis; lanis; } \\
\text { nachacaj }\end{array}$ & $\begin{array}{l}\text { a-mis; la-mis; } \\
\text { nachacaj }\end{array}$ \\
\hline $\begin{array}{l}\text { gualcas* blancas } \\
\text { de los indios }\end{array}$ & lel tages (7) & $\begin{array}{l}\text { gualcas* amarillas } \\
\text { de los indios }\end{array}$ & & leltaje & $\begin{array}{l}\text { discos de concha } \\
\text { de caracol: lel- } \\
\text { taje }\end{array}$ \\
\hline guapo & $\begin{array}{l}\text { amalay; } \\
\text { notacaji }(7)\end{array}$ & guapo & & $\begin{array}{l}\text { amalag; } \\
\text { notacagag }\end{array}$ & $\begin{array}{l}\text { amalag; } \\
\text { notacagag }\end{array}$ \\
\hline guardar & caneg (7) & guardar & & cáneg & caneg \\
\hline
\end{tabular}

\footnotetext{
51 <juiet> fwiy'et 'frío/tiempo frío'. Lo único que se nos ocurre con respecto a la otra palabra es -kalhche 'penetrar/calar' (p. ej., el frío) (cf. Claesson, 2008, p. 313).

52 Cf. "cháguar fruta".

${ }^{53}$ Corrigen lo que han anotado mal en "duro".
} 


\begin{tabular}{|c|c|c|c|c|c|}
\hline \multicolumn{2}{|c|}{ Primo (AFT, 1795) } & \multicolumn{4}{|c|}{ Copias del Manuscrito $D^{\prime} O_{\text {RBIGNy }}$} \\
\hline CAstellano & Mataco & Castellano & O'ORBIGNY & LAFONE 1896 & Hunt 1913 \\
\hline guisar & nopen (7) & guisar & & nopen, nolac & nopen nolac \\
\hline \multirow[t]{2}{*}{ gusanos } & $\operatorname{voos}(7)$ & gusanos & & ivoos & vos; ivoos \\
\hline & & hábil & & $\begin{array}{l}\text { eyab-arecar, } \\
\text { ocoz }\end{array}$ & eyab \\
\hline \multirow[t]{3}{*}{ hablar } & aboye (8) & hablar & & aboye & aboye \\
\hline & & hablar a solas & & tojuiase & tojuiase \\
\hline & & $\begin{array}{l}\text { hablar en secreto } \\
\text { o al oído }\end{array}$ & & sansameg & sansameg \\
\hline \multirow[t]{2}{*}{$\begin{array}{l}\text { ¿qué [hablas] } \\
\text { dices? }\end{array}$} & qui laboye? (8) & ¿qué hablas? & $\begin{array}{l}\text { chitaboyoe } \\
(26 \mathrm{v})\end{array}$ & quilaboye? & qui laboye? \\
\hline & & hacer & & enlin & enlin \\
\hline \multirow[t]{2}{*}{ hacha } & etetoitag (8) & hacha & & $\begin{array}{l}\text { etetoitay pl. } \\
\text { etetoitas }\end{array}$ & $\begin{array}{l}\text { etetoitay pl. } \\
\text { etetoitas }\end{array}$ \\
\hline & & hachear & & yuagi & yuagi \\
\hline hambre & chuyu (8) & hambre & & chuyu & chuyu \\
\hline hasta mañana & $\begin{array}{l}\text { iguala nilag } \\
\text { noig (8) }\end{array}$ & hasta mañana & & nilag noig & nilag noig \\
\hline \multirow[t]{2}{*}{ hermana } & quite (8) & hermana & & quite; noguita & quite; no-guita \\
\hline & & tu hermana ${ }^{54}$ & & nochila, nolas & \\
\hline \multirow[t]{2}{*}{ hermano } & quila (8) & hermano (mayor) & & $\begin{array}{l}\text { quila; noguinig; } \\
\text { tu hermano: } \\
\text { athila }\end{array}$ & $\begin{array}{l}\text { quila; a-chila; no- } \\
\text { chila; a-thila }\end{array}$ \\
\hline & & $\begin{array}{l}\text { hermano } \\
\text { pequeño/menor }\end{array}$ & & notinic & $\begin{array}{l}\text { no-guinig; no- } \\
\text { tinic }\end{array}$ \\
\hline hermoso & silentag (8) & hermoso & & silentag; ysia & silentag; isia \\
\hline hervir & naguai (8) & hervir & & naguai & naguai \\
\hline \multirow[t]{2}{*}{ no hervir } & naguainite (8) & no hervir & & naguainite & naguai-nite \\
\hline & & hierro & & & quinag \\
\hline hígado & tanec (8) & hígado & & tanec & tanec \\
\hline hija & yase (8) & hija & & yase & yasc \\
\hline hijo & yas (8) & $\begin{array}{l}\text { hijo; hijito }(\mathrm{H}) ; \\
\text { hijito mío/tuyo (L) }\end{array}$ & & $\begin{array}{l}\text { hijo: yas; hijito } \\
\text { mío: yasa; hijito } \\
\text { tuyo: aasa }\end{array}$ & yas; yasa; aasa \\
\hline hijo de puta & $\begin{array}{l}\text { nemec; juet } \\
\text { iquie }(8)^{55}\end{array}$ & hijo de puta & & yuctigue & yuctigue \\
\hline hijos & les; noles (8) & hijos & & $\begin{array}{l}\text { leles, noles; } \\
\text { mis hijos: yleés; } \\
\text { tuyos: aleés }\end{array}$ & $\begin{array}{l}\text { 1: no-lec; 2: } \\
\text { a-lees; 3: y-lee o } \\
\text { le-les }\end{array}$ \\
\hline hilado & noponec (8) & hilado & & noponec & no-ponec \\
\hline hilar & tii (8) & hilar & & tié & tie \\
\hline
\end{tabular}

54 Hoy nochila 'su hermano mayor'; la otra palabra no la reconocemos.

55 Hay un posible signo de interrogación después de <nemec>. Según Lunt (2016, p. 65), nemek es un término que se usa en la zona de Ingeniero Juárez para alguien de quien no se conoce el padre (cf. "Huérfano") y Zelda Franceschi también escuchó nemek 'huerfano' en la zona de Nueva Pompeya (com. pers.). En el otro término reconocemos (la)fwet iche 'hay corte', una expresión que podría interpretarse en el mismo sentido que nemek: se ha cortado el vínculo con el padre y su parentela. 


\begin{tabular}{|c|c|c|c|c|c|}
\hline \multicolumn{2}{|c|}{ PrIMo (AFT, 1795) } & \multicolumn{4}{|c|}{ Copias del Manuscrito $D^{\prime} O_{R B I G N Y}$} \\
\hline Castellano & Mataco & Castellano & O'ORBIGNY & LAFONE 1896 & Hunt 1913 \\
\hline hilo & $\begin{array}{l}\text { nocheg nacat } \\
\text { (8) }\end{array}$ & hilo & & nocheg-nacates & nocheg nacates \\
\hline hipo & yogle (8) & hipo & & yogle & yogle \\
\hline hojas & ole (14) & hojas & & noolcc & no-olcc \\
\hline \multirow[t]{2}{*}{ hombro } & noti (14) & hombro & & noti; nojuapo & no-juapo; no-ti \\
\hline & & honda & & nocajuti & nocajuti \\
\hline hondo & pitog (8) & hondo & & pilog & pilog \\
\hline horcón & cachute (14) & horcón & & nocachutc & nocachutc \\
\hline hormiga & $\begin{array}{l}\text { sugualac pl. } \\
\text { suguanes (8) }\end{array}$ & hormiga & & $\begin{array}{l}\text { sugulac pl. } \\
\text { suguanes }\end{array}$ & $\begin{array}{l}\text { sugulac pl. } \\
\text { suguanes }\end{array}$ \\
\hline hoy & igualane (8) & hoy & & $\begin{array}{l}\text { hijualane; } \\
\text { icualanna }\end{array}$ & $\begin{array}{l}\text { hijualane; } \\
\text { icualanna }\end{array}$ \\
\hline huérfano & penag (8) & huérfano & & ponag; nemec & ponag; nemec \\
\hline hueso & lile pl. lileta (8) & hueso & & litc pl. licta & litc pl. licta \\
\hline huevo & liquiu (8) & huevo & & liguiu & liguiu \\
\hline huir & yan (8) & huir & & yan & yan \\
\hline humareda & tuchag (8) & humareda & & tu chetag & tuchetag \\
\hline \multirow[t]{2}{*}{ humear } & nojuac (8) & humear & & nojuac & nojuac \\
\hline & & humo $^{56}$ & & tuchag & tuchag \\
\hline hurón & ilaa (20) & hurón & & ylaa & ylaa \\
\hline igual hilado & teliquiquie (9) & igual & & teliguiguic & teliguiguic \\
\hline iguana & aluche (9) & iguana & & aluche & aluche \\
\hline incordio & $\begin{array}{l}\begin{array}{l}\text { ibotia amotag } \\
(9)\end{array} \\
\end{array}$ & incordio & & ybotia amotag & ybotia amotag \\
\hline \multirow[t]{3}{*}{ indio } & \begin{tabular}{|l} 
nooln \\
[sobrescritas] (9)
\end{tabular} & indio; hombre & & $\begin{array}{l}\text { ynoon pl. } \\
\text { ynolas; noon; el } \\
\text { hombre: y noon; } \\
\text { del hombre: } \\
\text { y noon; para } \\
\text { el hombre: } y \\
\text { noon; nola-lac } \\
\text { pl. ynolas }\end{array}$ & $\begin{array}{l}\text { inoon; noon pl. } \\
\text { inolas }\end{array}$ \\
\hline & & indio bueno & & noon is & noon is \\
\hline & & indio viejo & & yuayug & yuayug \\
\hline \multirow[t]{2}{*}{ irse } & yapil; yan (9) & irse & & $\begin{array}{l}\text { yapi; lobes; } \\
\text { lobelec }\end{array}$ & $\begin{array}{l}\text { yapi; lobes; } \\
\text { lobelec }\end{array}$ \\
\hline & & no quiere ir & & yquite; netag & yquite netag \\
\hline jerga & guesag (21) & jerga & & guesag & guesag \\
\hline jugar & coij (10) & jugar & & coige & coige \\
\hline juntar & nojutuec (10) & juntarse & & nojutuec & no-jutuec \\
\hline juntos & juec (10) & juntos & & jutuec & no-jutuec \\
\hline
\end{tabular}

\footnotetext{
${ }^{56}$ Cf. "Humareda".
} 


\begin{tabular}{|c|c|c|c|c|c|}
\hline \multicolumn{2}{|c|}{ Primo (AFT, 1795) } & \multicolumn{4}{|c|}{ Copias del Manuscrito $D^{\prime} O_{\text {RBIGNy }}$} \\
\hline Castellano & Mataco & Castellano & O'ORBIGNY & LAFone 1896 & Hunt 1913 \\
\hline \multirow[t]{4}{*}{ labios } & $\begin{array}{l}\text { nopaset; } \\
\text { nopaste (11) }\end{array}$ & labios & & $\begin{array}{l}\text { nopaset; } \\
\text { nopaste }\end{array}$ & $\begin{array}{l}\text { no-paset; no- } \\
\text { paste; } 3 \text { : le-paset }\end{array}$ \\
\hline & & $\begin{array}{l}\text { la casa del padre } \\
\text { es buena }\end{array}$ & & $\begin{array}{l}\text { pale** lobucua } \\
\text { is }\end{array}$ & pale** lobucua is \\
\hline & & ladrón & & $\begin{array}{l}\text { etanchag; } \\
\text { ycaten }\end{array}$ & etanchag; ycaten \\
\hline & & lagartija & & quiala & quiala \\
\hline $\begin{array}{l}\text { lagartos de los } \\
\text { brazos (11); } \\
\text { morcillos de los } \\
\text { brazos (12v) }\end{array}$ & $\begin{array}{l}\text { no-queche (11); } \\
\text { nocueche (12v) }\end{array}$ & $\begin{array}{l}\text { morcillos de los } \\
\text { brazos (L); lagarto } \\
\text { del brazo (H) }\end{array}$ & & nochueche & no-cueehe \\
\hline lágrimas & notet-i (11v) & lágrimas & & notet-ii & no-tetii \\
\hline lana & olee; yic (11) & lana & & noolci; yic & no-olci; yic \\
\hline langosta saltona & pana (11) & langosta & & & pana \\
\hline $\begin{array}{l}\text { langosta } \\
\text { voladora }\end{array}$ & chol (11) & $\begin{array}{l}\text { langosta } \\
\text { voladora }^{57}\end{array}$ & & $\begin{array}{l}\text { chol satoma } \\
\text { pana }\end{array}$ & chol satoma \\
\hline lanza & juum (11) & lanza & & yuum & yuum \\
\hline lapacho & optac (11) & lapacho & & obtac & obtac \\
\hline largo & pitag (11) & largo & & pitag & pitag \\
\hline lavar & $\begin{array}{l}\text { lexo; noleg; leg } \\
\text { (11) }\end{array}$ & lavar & & leg; noleg: lejo & leg; no-leg; lejo \\
\hline \multirow[t]{2}{*}{ lazo } & $\begin{array}{l}\text { nocabotac, } \\
\text { chulag-quietag } \\
\text { (11) }\end{array}$ & lazo & & $\begin{array}{l}\text { nocabotag; } \\
\text { chidaguiltag }\end{array}$ & $\begin{array}{l}\text { no-cabotag; } \\
\text { chidaguiltag }\end{array}$ \\
\hline & & leche & & & cathos \\
\hline \multirow[t]{2}{*}{ lechiguana } & nobelec (11v) & lechiguana & & nobelec & nobelec \\
\hline & & lechuza & & quiliguiac & quiliguiac \\
\hline leer & noya idni (11) & leer & & noyaidni & noyaidni \\
\hline lejos & tojoe (11) & lejos & & tojoe; tojoy & tojoe; tojoy \\
\hline \multirow[t]{2}{*}{ lengua } & nocagliquiu (11) & lengua & & nocagliguiu & nocagliguiu \\
\hline & & lengua, idioma & & leine & leine \\
\hline leña & la (11) & leña & & $1 a$ & la \\
\hline león & ogualag (11) & león & & ogualag & ogualag \\
\hline $\begin{array}{l}\text { levantar alguna } \\
\text { cosa }\end{array}$ & $\begin{array}{l}\text { quieyaspa; } \\
\text { chompa (11) }\end{array}$ & $\begin{array}{l}\text { levantar arriba } \\
\text { alguna }\end{array}$ & & quicyaspa & quicyaspa \\
\hline levantarse & $\begin{array}{l}\text { nepa; nequiepa } \\
(11)\end{array}$ & levantarse & & $\begin{array}{l}\text { nipa pl. } \\
\text { neguicpa }\end{array}$ & nipa pl. neguicpa \\
\hline $\begin{array}{l}\text { librar o rescatar } \\
\text { a alguno }\end{array}$ & nolay (26) & $\begin{array}{l}\text { librar o rescatar a } \\
\text { alguno }\end{array}$ & & & nolai \\
\hline libro & nojuquiene (11) & libro & & nojuguienec & nojuguienec \\
\hline liendres $^{58}$ & g-la liquiu (11) & liendres & & ysato; obat-li & li \\
\hline
\end{tabular}

\footnotetext{
57 Las copias confunden con la línea anterior.

58 El término de Primo es claro, Iha-Ihich'u ‘huevo de piojo' (cf. "Piojo”). Los de Lafone y Hunt no los reconocemos.
} 


\begin{tabular}{|c|c|c|c|c|c|}
\hline \multicolumn{2}{|c|}{ Primo (AFT, 1795) } & \multicolumn{4}{|c|}{ Copias del $M_{A N u s C R I T O} D^{\prime} O_{R B I G N y}$} \\
\hline Castellano & Mataco & Castellano & O'ORBIGNY & LAFone 1896 & Hunt 1913 \\
\hline ligero [liviano] & guajadlin (11) & ligero [liviano] & & guajadlin & $\begin{array}{l}\text { guajalin; } \\
\text { guajadlin }\end{array}$ \\
\hline limón & $\operatorname{achag}(11 \mathrm{v})$ & limón & & $\begin{array}{l}\text { achag pl. } \\
\text { achetas }\end{array}$ & achag pl. achetas \\
\hline limpiar & isato (11) & limpiar & & isato; obat iis & isato; obatiis \\
\hline $\begin{array}{l}\text { limpio (11v); } \\
\text { está limpio (5) }\end{array}$ & $\begin{array}{l}\text { omisampa (5, } \\
11 \mathrm{v}), \text { isato (11v) }\end{array}$ & & & & \\
\hline lindo & $\begin{array}{l}\text { silentag, yojuan } \\
\text { (11) }\end{array}$ & lindo & & silentag; yojuan & silentag; yojuan \\
\hline lobo & latatag (11) & lobo & & latatag & latatag \\
\hline lomillos & quiapas (11) & lomillos & & quiapa & quiapa \\
\hline $\begin{array}{l}\text { lomillos de } \\
\text { indios }\end{array}$ & nojoguet (11) & lomillos de indios & & nojouet & no-jouet \\
\hline \multirow[t]{3}{*}{ luna } & guela (11) & luna & & guela; iguelach & guela; iguelach \\
\hline & & luna clara & & guelas & guelas \\
\hline & & luna Ilena & & guelatac poyeg & guela tacpoyeg \\
\hline \multirow[t]{2}{*}{ luna menguante } & guela tal (11) & $\begin{array}{l}\text { luna menguante; } \\
\text { luna nueva }\end{array}$ & & $\begin{array}{l}\text { menguante: } \\
\text { pagla; nueva: } \\
\text { guelatal }\end{array}$ & $\begin{array}{l}\text { menguante: } \\
\text { pagla; nueva: } \\
\text { guela tal }\end{array}$ \\
\hline & & $\operatorname{luz} z^{59}$ & & yjuala & ijuala \\
\hline luz de la vela & noxlet $(11)^{60}$ & luz de la vela & & notiet & notiet \\
\hline llamar & agnee (11) & Ilamar & & agne & agne \\
\hline te llaman & agneami (11) & $\begin{array}{l}\text { ¿cómo te llaman? } \\
\text { (L); te Ilaman }(\mathrm{H})\end{array}$ & & agne ami? & agneami \\
\hline $\begin{array}{l}\text { ¿cómo te } \\
\text { llamas? }\end{array}$ & qui voei? (3) & ¿cómo te llamas? & & qui volin? & \\
\hline $\begin{array}{l}\text { ¿cómo se } \\
\text { llama? }\end{array}$ & chioxle (11) & ¿Cómo se llama? & & quivoslen? & $\begin{array}{l}\text { quiwolin? } \\
\text { quivoslen? }\end{array}$ \\
\hline $\begin{array}{l}\text { ¿cómo se llama } \\
\text { esto? }\end{array}$ & $\begin{array}{l}\text { chioxle maca? } \\
\text { (3) }\end{array}$ & & & & \\
\hline Ilano & isquie (11v) & Ilano & & isguic & isguic \\
\hline no llano & quienas (11v) & no llano & & quienas & quienas \\
\hline llave & nopoquie (11) & Ilave & & $\begin{array}{l}\text { nopequiia; } \\
\text { nopethia }\end{array}$ & $\begin{array}{l}\text { no-pequiia; no- } \\
\text { pethia }\end{array}$ \\
\hline \multirow[t]{2}{*}{ llegar } & nam, tepil (11) & $\begin{array}{l}\text { llegar de alguna } \\
\text { parte }\end{array}$ & & naan & naan \\
\hline & & ¿ha llegado? & & yeg nan? & yeg nan? \\
\hline Ilenar & aneg (11) & llenar & & $\begin{array}{l}\text { aneg; } \\
\text { ontepoyeg }\end{array}$ & aneg; ontepoyeg \\
\hline lleno & tepoig (11) & Ileno & & tepoye & tepoye \\
\hline llorar & taglin (11) & Ilorar & & teglin & teglin \\
\hline
\end{tabular}

\footnotetext{
${ }^{59}$ Cf. "Día".

${ }^{60}$ Reconocemos nolhet 'su fuego/fogón', el sinónimo dependiente de itäj, 'fuego', que es un sustantivo independiente.

${ }^{61}$ Todos parecen grafías defectuosas de chi wolheya? ‘¿cómo se llama?’.
} 


\begin{tabular}{|c|c|c|c|c|c|}
\hline \multicolumn{2}{|c|}{ Primo (AFT, 1795) } & \multicolumn{4}{|c|}{ Copias del Manuscrito $D^{\prime} O_{\text {RBIGNy }}$} \\
\hline Castellano & Mataco & Castellano & O'ORBIGNY & LAFone 1896 & Hunt 1913 \\
\hline \multirow[t]{2}{*}{ llover } & ibonquia (11) & Ilover & & ybongutla & i-bongutla \\
\hline & & macana & & nocuenez & no-cue-nez \\
\hline madre & $\begin{array}{l}\text { yacob; lacoo } \\
(12)\end{array}$ & madre & & jacob; lacoo & la-coo; ja-cob \\
\hline madrugar & $\begin{array}{l}\text { nepa leleentag } \\
\text { (12) }\end{array}$ & madrugar & & nepa, lelentag & nepa lelentag \\
\hline aloja madura & tepei $(12 v)$ & aloja madura & & tepeigino & tepeigino \\
\hline maduro $^{62}$ & talac (12v) & maduro & & tepeinict & tepeinitc \\
\hline no maduro & laconeg (12v) & & & & \\
\hline maíz & ispet (12) & maíz & & yspet & ispet \\
\hline maíz seco & tegquiai (12) & & & & \\
\hline \multirow[t]{3}{*}{ malo } & $\begin{array}{l}\text { cachi; cachia; } \\
\text { site; nisia (12) }\end{array}$ & malo & hiel (27v) & $\begin{array}{l}\text { hiel; chache; } \\
\text { cachia; sitc, } \\
\text { nisia; nisua (15) }\end{array}$ & $\begin{array}{l}\text { chache; hiel; } \\
\text { cachia; sitc; nisia }\end{array}$ \\
\hline & & mal hombre & & & casia-nola \\
\hline & & manantial & & chijuic, junet & chijuic junet \\
\hline mandar $(12)^{63}$ & ijueno (12) & mandar (12) & & cheen & cheen \\
\hline mango & ut (12v) & mango & & lejuap-chag; ut & lejuap chag; ut \\
\hline \multirow[t]{3}{*}{ mano } & noqueis $(12 \mathrm{v})$ & mano & & noguci & no-guci \\
\hline & & mano derecha & & nochancat & no-chancat \\
\hline & & mano izquierda & & nojoncat & no-joncat \\
\hline mañana ${ }^{64}$ & iguala (12) & mañana & & yjuala; icuala & ijuala; icuala \\
\hline $\begin{array}{l}\text { de mañanita, } \\
\text { temprano }\end{array}$ & $\begin{array}{l}\text { nemitag; } \\
\text { niquianet (12) }\end{array}$ & $\begin{array}{l}\text { de mañana o muy } \\
\text { temprano }\end{array}$ & & $\begin{array}{l}\text { nemitag; } \\
\text { niguianet }\end{array}$ & $\begin{array}{l}\text { nemitag; } \\
\text { niguianet }\end{array}$ \\
\hline marido o mujer & chejua (12) & marido o mujer & & $\begin{array}{l}\text { chejua; } \\
\text { lechejuac }\end{array}$ & chejua; le-chejuaj \\
\hline mariposa & \begin{tabular}{|l|} 
chocoze \\
[sobrescrito] (12) \\
\end{tabular} & mariposa & & chocoz & chocoz \\
\hline marlo & ispet lile (12v) & marlo & & ispetlile & ispet-lile \\
\hline mataco $^{65}$ & $\begin{array}{l}\text { aanal pl. } \\
\text { aanaleis (12; } \\
12 \mathrm{v})\end{array}$ & mataco & & anal pl. analeys & anal pl. analeys \\
\hline mataguayo $^{66}$ & \begin{tabular}{|l} 
taglele pl. \\
tagleleleis (12v)
\end{tabular} & mataguayo & & $\begin{array}{l}\text { taglele pl. } \\
\text { tagleleis }\end{array}$ & $\begin{array}{l}\text { montaraz: taglele } \\
\text { pl. tagleleis }\end{array}$ \\
\hline matar & ylam ilam (12) & matar & & ylaan; laam & i-laan; laam \\
\hline matos & cochones (12) & matos & & chochones & chochones \\
\hline mear & tuul (12) & mear, orinar & & tuul & tuul \\
\hline
\end{tabular}

\footnotetext{
${ }^{62}$ Anotan cosas diferentes: Primo, thaläkw 'es adulto'; Lafone y Hunt tapayhit'e 'no es amargo' (piénsese que un fruto "no es amargo" cuando está "maduro").

${ }^{63}$ Anotan cosas diferentes: Primo, -fwenho 'comunicar/avisar a'; Lafone y Hunt, -chen 'enviar',

64 cf. "día".

${ }^{65}$ Sin duda, el nombre de parentela änäl(Ihais) 'vizcacha(s)'.

${ }^{66}$ Probablemente Hunt estaba en lo cierto, y se trata del etnónimo "ecológico" (Montani, 2017, p. 92ss) tahyi-lhele 'habitante del bosque’.
} 


\begin{tabular}{|c|c|c|c|c|c|}
\hline \multicolumn{2}{|c|}{ Primo (AFT, 1795) } & \multicolumn{4}{|c|}{ Copias del Manuscrito $D^{\prime} O_{\text {RBIGNy }}$} \\
\hline Castellano & Mataco & Castellano & O'ORBIGNY & LAFone 1896 & Hunt 1913 \\
\hline medias & $\begin{array}{l}\text { nocalapotes } \\
(12)\end{array}$ & mediar & & nocajapotes & nocajapotes \\
\hline \multirow[t]{2}{*}{ menear } & chog-lin (12) & menear & & choglin & choglin; atasin \\
\hline & & menor, el menor & & achinic & a-chinic \\
\hline mentir & $\begin{array}{l}\text { anchag-lin; } \\
\text { yanflin (12) }\end{array}$ & mentir & & $\begin{array}{l}\text { anchaglin; } \\
\text { yanflin, } \\
\text { nositabo }\end{array}$ & $\begin{array}{l}\text { anchaglin; } \\
\text { yamflin; } \\
\text { gueteanflin }\end{array}$ \\
\hline mentira & $\begin{array}{l}\text { anchag-lin; } \\
\text { yanflin (12v) }\end{array}$ & mentira & & $\begin{array}{l}\text { anchaglin; } \\
\text { gueteanflin }\end{array}$ & nositabo \\
\hline mesa & nolabquet $(12)^{67}$ & mesa & & $\begin{array}{l}\text { nolauet; } \\
\text { noueteslay }\end{array}$ & $\begin{array}{l}\text { nolauet; nouetes } \\
\text { lay }\end{array}$ \\
\hline meter & vidquie; vito (12) & meter & & vidgute; vitouit & vidgute; vitouit \\
\hline meter adentro & anchajui up (12) & meter adentro & & anchaguinp & anchaguinp \\
\hline mezquino & $\begin{array}{l}\text { juichag; } \\
\text { chognag (12v) }\end{array}$ & mezquino & & $\begin{array}{l}\text { chognag; } \\
\text { chogneteg }\end{array}$ & $\begin{array}{l}\text { chognag; } \\
\text { chogneteg }\end{array}$ \\
\hline \multirow[t]{2}{*}{ miedo } & onohaya (12v) & miedo & & noai; onohaya & noai; onohaya \\
\hline & & no miedo & & onohaya-nite & onohaya-nite \\
\hline miel & pinu (12) & miel & & pinu & pinu \\
\hline mierda & $\begin{array}{l}\text { llamuz; } a c a^{*} \\
(12)\end{array}$ & $\begin{array}{l}\text { mierda/ } \\
\text { excremento }\end{array}$ & & ramuc; $a c a^{*}$ & ramuc; $a c a^{*}$ \\
\hline mío & nocatag (12) & mío & & $\begin{array}{l}\text { nocatag; nocay, } \\
\text { ycayguet; } \\
\text { nocatagi }\end{array}$ & $\begin{array}{l}\text { nocay; nocatagi; } \\
\text { nocatag; } \\
\text { ycayguet; icaobo }\end{array}$ \\
\hline mistol & ajayag (12) & mistol & & ajayag & ajayag \\
\hline mitad & lota $(12 \mathrm{v})$ & mitad & & loota & loota \\
\hline mocos & $\begin{array}{l}\text { noca quieltag } \\
(12 \mathrm{v})\end{array}$ & mocos & & nocaguialtag & nocaguialtag \\
\hline mojarras & ajuetes (12) & mojarras & & ajuetes & ajuetes \\
\hline mojarse & \begin{tabular}{|l|} 
notacagli; \\
nocagliquie (12)
\end{tabular} & mojarse & & $\begin{array}{l}\text { notacagli; } \\
\text { nocaglien }\end{array}$ & $\begin{array}{l}\text { notacagli; } \\
\text { nocaglien }\end{array}$ \\
\hline moler & quiojuag (12) & moler & & $\begin{array}{l}\text { chojuac; } \\
\text { quionguan }\end{array}$ & $\begin{array}{l}\text { chojuac; } \\
\text { quionguan }\end{array}$ \\
\hline $\begin{array}{l}\text { montar a } \\
\text { caballo }\end{array}$ & nupa latag (12) & monta a caballo & & $\begin{array}{l}\text { nupa: latag; } \\
\text { ynupe epélatg }\end{array}$ & $\begin{array}{l}\text { nupa-latag; } \\
\text { i-nupe epe latag }\end{array}$ \\
\hline monte & teygi (12v) & monte & & teigji & teigji \\
\hline monte grande & teigitag (12v) & monte grande & & teijitag & teijitag \\
\hline morder & yocuag (12) & morder & & yocuag & yocuag \\
\hline morera & techuc (12) & morera & & techuc & techuc \\
\hline \multirow[t]{3}{*}{ morir } & il (12) & morir & & $y l$ & yel; il; hiel \\
\hline & & morirá & & inila & inila \\
\hline & & morral & & $\begin{array}{l}\text { jinag; cachitag; } \\
\text { lacuc }\end{array}$ & $\begin{array}{l}\text { jinag; cachitag; } \\
\text { lacuc }\end{array}$ \\
\hline
\end{tabular}

${ }^{67}$ Las letras que tachamos en el menuscrito están sobrescritas. Ambas tienen sentido: nolhäk-wet 'su morada del alimento/mesa'. 


\begin{tabular}{|c|c|c|c|c|c|}
\hline \multicolumn{2}{|c|}{ Primo (AFT, 1795) } & \multicolumn{4}{|c|}{ Copias del ManusCRITO $D^{\prime} O_{\text {RBIGNY }}$} \\
\hline Castellano & Mataco & Castellano & O'Orbigny & LAFONE 1896 & Hunt 1913 \\
\hline mortero & juelec (12v) & mortero & & yuelic & yuelic \\
\hline mosca & \begin{tabular}{|l} 
atac pl. atas \\
$(12)$
\end{tabular} & mosca & & atac pl. atas & atac pl. atas \\
\hline \multirow[t]{2}{*}{ mosquitos } & juinetes (12) & mosquitos & & yuinetes & yuinetes \\
\hline & & $\begin{array}{l}\text { mostrar alguna } \\
\text { cosa }(L, H) ; \\
\text { mostrar }(H)\end{array}$ & & $\begin{array}{l}\text { paina; pina; } \\
\text { tigigi }\end{array}$ & $\begin{array}{l}\text { paina; mostrar } \\
\text { alguna cosa: } \\
\text { pina; mostrar: } \\
\text { tigigi }\end{array}$ \\
\hline mote & nopenec (12) & mote & & noponec & no-ponec \\
\hline moza & lucha (12v) & moza & & lucha & lucha \\
\hline mozo & $\begin{array}{l}\text { magse pl. } \\
\text { magses (12v) }\end{array}$ & mozo & & $\begin{array}{l}\text { magse; magses; } \\
\text { mansi }\end{array}$ & $\begin{array}{l}\text { magse; magses; } \\
\text { mansi }\end{array}$ \\
\hline muchachos & naches (12) & muchachos & & naches & naches \\
\hline muchos & $\operatorname{loos}(12)$ & muchos & & 1005 & \\
\hline \multirow[t]{3}{*}{ muerto } & $\begin{array}{l}\text { il (12) pl. ineen } \\
(12 \mathrm{v})\end{array}$ & $\begin{array}{l}\text { se ha muerto }(\mathrm{L}) \text {; } \\
\text { muerto o difunto } \\
(\mathrm{L})\end{array}$ & & yil; ylneen & yil; ilneen \\
\hline & & han muerto & & ylaan & ilaan \\
\hline & & muerto o difunto & & ajaat & ajaat \\
\hline $\begin{array}{l}\text { todavía no ha } \\
\text { muerto }^{68}\end{array}$ & camag (12) & & & & \\
\hline muñeca & noquevo $(12 \mathrm{v})$ & muñeca & & nocucbo & no-cucbo \\
\hline murciélago & asus (12) & murciélago & & asus & asus \\
\hline muslo & $\begin{array}{l}\text { nolaguie; } \\
\text { nolequie (12v) }\end{array}$ & muslo & & leche; noleguic & leche; noleguic \\
\hline \multirow[t]{2}{*}{ nacer } & ezlin; tagle (13) & nacer (planta) & & talg & talg \\
\hline & & $\begin{array}{l}\text { nacer (gente, } \\
\text { animal) }\end{array}$ & & capuchan & capuchan \\
\hline nada & mahic (13) & nada & & maic & maic \\
\hline nadar & $\begin{array}{l}\text { nonai; nonayi } \\
\text { (13) }\end{array}$ & nadar & & $\begin{array}{l}\text { naay; nonaig; } \\
\text { nonaigi }\end{array}$ & $\begin{array}{l}\text { naay; nonaig; } \\
\text { nonaigi }\end{array}$ \\
\hline nalgas & $\begin{array}{l}\text { laguez chalos } \\
\text { (13) }\end{array}$ & nalgas & & logueg-chalos & lo-gueg-chalos \\
\hline $\begin{array}{l}\text { naranjo y } \\
\text { naranjas }\end{array}$ & $\begin{array}{l}\text { acheta pl. } \\
\text { achetas (13) }\end{array}$ & naranja & & $\begin{array}{l}\text { achetag pl. } \\
\text { achetas }\end{array}$ & $\begin{array}{l}\text { achetaj pl. } \\
\text { achetas }\end{array}$ \\
\hline narices & nonus (13) & narices; nariz & & nonus & no-nus \\
\hline navaja & najuel (13) & navaja & & najucl & najucl \\
\hline negro & $\begin{array}{l}\text { chalag; } \\
\text { chalagita pl. } \\
\text { chalagquietas } \\
\text { (13) }\end{array}$ & negro & & $\begin{array}{l}\text { chalag; } \\
\text { chalagita; } \\
\text { chelgag }\end{array}$ & $\begin{array}{l}\text { chalag; chelag; } \\
\text { no negro: } \\
\text { chalagita }\end{array}$ \\
\hline niebla & $\begin{array}{l}\text { tuchag; } \\
\text { tuchetag (13) }\end{array}$ & niebla & & $\begin{array}{l}\text { tuchag; } \\
\text { tuchetag }\end{array}$ & tuchag; tuchetag \\
\hline
\end{tabular}

${ }^{68}$ No parece tratarse de "todavía no ha muerto", sino de kamaj 'todavía/todavía no', cf. "después". 


\begin{tabular}{|c|c|c|c|c|c|}
\hline \multicolumn{2}{|c|}{ Primo (AFT, 1795) } & \multicolumn{4}{|c|}{ Copias del $M_{A N u s C R I T O} D^{\prime} O_{R B I G N y}$} \\
\hline Castellano & Mataco & Castellano & O'ORBIGNY & LAFone 1896 & Hunt 1913 \\
\hline nieta & noquiaya (13) & nieta & & yguiaya & yguiaya \\
\hline nieto & quiayas (13) & nieto & & $\begin{array}{l}\text { yuiayas; } \\
\text { ychayas; } \\
\text { nouaela }\end{array}$ & yuiayas; ychayas \\
\hline no & $c a(13)$ & no & & $c a ; a m a ; k a ́$ & $c a ; a m a$ \\
\hline noche & jonachi (13) & noche & & yonaachi & yonaachi \\
\hline \multirow[t]{4}{*}{ no hay } & novainita (13) & no hay & & novainita & novainita \\
\hline & & nombre & & noley & no-ley \\
\hline & & nosotros & & namil; lemeil & namil; lemeil \\
\hline & & nosotros somos & & janoslemeil & janoslemeil \\
\hline nubes & $\begin{array}{l}\text { calatu; pute } \\
(13)^{69}\end{array}$ & nubes & & pulc; calatu & pulc; calatu \\
\hline \multirow[t]{2}{*}{ nublado } & juichez (13) & nublado & & yuicheec & yuicheec \\
\hline & & nudos & & nocochoim & no-cochoim \\
\hline \multirow[t]{4}{*}{$\begin{array}{l}\text { nudos de los } \\
\text { dedos }\end{array}$} & nojus cocho (13) & $\begin{array}{l}\text { nudos de los } \\
\text { dedos }\end{array}$ & & najuscocho & na-jus-cocho \\
\hline & & nuestro & & $\begin{array}{l}\text { nemil; } \\
\text { yacaguet; } \\
\text { nocayguet }\end{array}$ & $\begin{array}{l}\text { nemil; nocayguet; } \\
\text { icaguet; icaiguet }\end{array}$ \\
\hline & & $\begin{array}{l}\text { nuestro, de } \\
\text { nosotros, no } \\
\text { ajeno }\end{array}$ & & & cata \\
\hline & & nueve & & naya & naya \\
\hline nuevo & nequiahic (13) & nuevo & & $\begin{array}{l}\text { neguiachic; } \\
\text { nethaec }\end{array}$ & $\begin{array}{l}\text { neguiachic; } \\
\text { nethaec }\end{array}$ \\
\hline nutria & analatag (13) & nutria & & analatag & analatag \\
\hline \multirow[t]{3}{*}{ ñato } & $\begin{array}{l}\text { nonus cho; } \\
\text { choguag (13) }\end{array}$ & ñato & & $\begin{array}{l}\text { nonus-cho; } \\
\text { nonus choguiag }\end{array}$ & $\begin{array}{l}\text { no-nuscho; no- } \\
\text { nuschoguiag }\end{array}$ \\
\hline & & ocioso está & & tetaijua & tetaijua \\
\hline & & ocho & & najaela & najaela \\
\hline \multirow[t]{2}{*}{ oír } & latne ama (14) & oír & & latne-ama; lata & lata; latneama \\
\hline & & ¡ojalá! & & jaa! yajay! & jaa! yajay! \\
\hline ojo & notelo (14) & ojo & & notelo & no-telo \\
\hline oler & isineg (14) & oler & & ysineg & isineg \\
\hline olvidar & nopetet la (14) & olvidar & & $\begin{array}{l}\text { nopetula; } \\
\text { chovalia }\end{array}$ & $\begin{array}{l}\text { no-petula; } \\
\text { chovalia }\end{array}$ \\
\hline olla & tobag (14) & olla & & tobcg & tobcg \\
\hline \multirow[t]{2}{*}{ ombligo } & nochac (14) & ombligo & & nochac & no-chac \\
\hline & & once & & yjuantesii & yjuantesii \\
\hline orejas & noqiote (14) & orejas & & noguiotc & no-guiotc \\
\hline oscuro & jonachi (14) & oscuro & & yonachi, vuu & yonachi vuu \\
\hline
\end{tabular}

\footnotetext{
${ }^{69}$ No se entiende por qué está tachado, hoy pule es 'cielo' (cf. "cielo") y 'nube'. En cuanto al otro término, por el contrario, hay quizá un error, porque kalatu es 'granizo' (cf. "granizo").
} 


\begin{tabular}{|c|c|c|c|c|c|}
\hline \multicolumn{2}{|c|}{ Primo (AFT, 1795) } & \multicolumn{4}{|c|}{ Copias del ManusCRITO $D^{\prime} O_{\text {RBIGNY }}$} \\
\hline Castellano & Mataco & Castellano & O'Orbigny & LAFONE 1896 & Hunt 1913 \\
\hline muy oscuro & $\begin{array}{l}\text { jonachi ugia } \\
\text { (14) }\end{array}$ & muy oscuro & & yonachi ugia & yonachi ugia \\
\hline oso hormiguero & suulag (14) & oso hormiguero & & suulag & suulag \\
\hline otra vez & achag quie (14) & otra vez & & achugquic & $\begin{array}{l}\text { achugquie; } \\
\text { achagquie }\end{array}$ \\
\hline \multirow[t]{3}{*}{ otro } & el (14) & $\begin{array}{l}\text { otro, otra }(\mathrm{L}) \text {; otro } \\
(\mathrm{H})\end{array}$ & & el & el \\
\hline & & otro, del otro & & atalechi & atalechi \\
\hline & & los otros & & naam & naam \\
\hline oveja & choneta (14) & oveja & & chonetag & chonetag \\
\hline ovillo de hilo ${ }^{70}$ & $\begin{array}{l}\text { noponec pl. } \\
\text { noponcay (14) }\end{array}$ & & & & \\
\hline pacará [árbol] & guatog (15v) & pacará [árbol] & & guatog & guatog \\
\hline pacú & juctac (15v) & pacú & & yuctac & yuctac \\
\hline padre & igquia (15) & $\begin{array}{l}\text { padre }(\mathrm{L}) ; \mathbf{m i} \\
\text { padre }(\mathrm{H})\end{array}$ & & $\begin{array}{l}\text { ycquia; ysquia; } \\
\text { ysthia }\end{array}$ & $\begin{array}{l}\text { ycquia; ysquia; } \\
\text { ysthia }\end{array}$ \\
\hline pagará $^{71}$ & $\begin{array}{l}\text { olajaya; ibonla } \\
\text { lajaig (15) }\end{array}$ & pagar & & $\begin{array}{l}\text { olajaya; } \\
\text { ybonlalajaya }\end{array}$ & $\begin{array}{l}\text { olajaya; } \\
\text { ibonlalajaya }\end{array}$ \\
\hline paja & up (15v) & paja & & vup & vup \\
\hline pala & latag ag (15) & pala & & lat-ag & latag \\
\hline palma [árbol] & juichuc (15v) & palma [árbol] & & yuichue & yuichue \\
\hline $\begin{array}{l}\text { palma de la } \\
\text { mano }\end{array}$ & \begin{tabular}{|l|} 
nectueqio \\
[sobrescrito] \\
(15); nocuequio \\
(15v)
\end{tabular} & palma de la mano & & nocuccho & no-cuccho \\
\hline palmar & juichucue (15v) & palmar & & yuichucue & yuichuc-ue \\
\hline \multirow[t]{2}{*}{ palo } & la (15) & palo & & la & la \\
\hline & & palo borracho & & chenlac $=$ chile & chenlac; chile \\
\hline palo santo & joc (15) & palo santo & & yooc & yooc \\
\hline \multirow[t]{4}{*}{ paloma } & cachitag (15) & paloma & & cachitag & cachitag \\
\hline & & paloma chiquita & & chipup & chipup \\
\hline & & $\begin{array}{l}\text { paloma del } \\
\text { campo }\end{array}$ & & chulu & chulu \\
\hline & & paloma grande & & poperi & poperi \\
\hline pampas & alotas (15) & pampa & & alotag & alotag \\
\hline pan & tantan $^{*}(15)$ & pan & & tantan $^{*}$; tenten ${ }^{*}$ & tantan $^{*}$; tenten ${ }^{*}$ \\
\hline pantorrilla & nocala che (15v) & pantorrilla & & nocaleche & no-cale-che \\
\hline panza & noche (15) & panza & & noche; leche & no-che; le-che \\
\hline
\end{tabular}

\footnotetext{
70 <noponec $>$ también aparece en "hilado", y ambas traducciones parecen correctas. A pesar de que hoy -p'onek hoy significa fundamentalmente 'ovillo', lit. es 'cosa enrrolada' (del verbo -p'on 'enrollar').

71 En el original dice "pagara", sin tilde, pero en la expresión wichí reconocemos el futuro: <ibonla lajaig> iwohlalahayej 'recompensará/pagará por'. Lafone y Hunt anotan "pagar", en infinitivo, pero <ibonlalajaya> está también en futuro: iwohlalahaya 'pagará'.
} 


\begin{tabular}{|c|c|c|c|c|c|}
\hline \multicolumn{2}{|c|}{ Primo (AFT, 1795) } & \multicolumn{4}{|c|}{ Copias del $M_{A N u s C R I T O} D^{\prime} O_{R B I G N y}$} \\
\hline Castellano & Mataco & Castellano & O'ORBIGNY & LAFone 1896 & Hunt 1913 \\
\hline pañuelo & $\begin{array}{l}\text { noca quieltag } \\
\text { quia (15v) }\end{array}$ & pañuelo & & $\begin{array}{l}\text { nocaguiectag } \\
\text { quia }\end{array}$ & nocaguiectagquia \\
\hline papas & nasuz (15) & papas & & nasuc & nasuc \\
\hline papas del monte & lenac (15) & papas del monte & & lenac & lenac \\
\hline papel & noyape (15) & papel & & $\begin{array}{l}\text { noyape; } \\
\text { nojuquienec }\end{array}$ & $\begin{array}{l}\text { noyape; } \\
\text { nojuquienec }\end{array}$ \\
\hline $\begin{array}{l}\text { pararse o estar } \\
\text { en pie }\end{array}$ & casit (15) & $\begin{array}{l}\text { pararse o estar } \\
\text { en pie }\end{array}$ & & casit & casit \\
\hline parco & $\begin{array}{l}\text { nagquiuyaja } \\
\text { (15v) }\end{array}$ & parco & & nagquiuyaja & nagquiuyaja \\
\hline \multirow[t]{2}{*}{ pared } & igñat (15) & pared & & ygñat & ygñat \\
\hline & & mis/tus parientes & & $\begin{array}{l}\text { mis parientes: } \\
\text { iaaiñac; tus } \\
\text { parientes: } \\
\text { aaiñac }\end{array}$ & $\begin{array}{l}\text { 1. ia-aiñac; } 2 . \\
\text { a-aiñac }\end{array}$ \\
\hline \multirow[t]{2}{*}{ parir } & рии (15) & parir & & puu; capuchan & puu; capuchan \\
\hline & & pasado mañana & & yjuala eb & ijual eb \\
\hline pasear & $\begin{array}{l}\text { obelec; obes; } \\
\text { nolenlin (15) }\end{array}$ & pasear & & $\begin{array}{l}\text { obes; obelek; } \\
\text { nolenlin }\end{array}$ & $\begin{array}{l}\text { o-bes; obelek; } \\
\text { nolenlin }\end{array}$ \\
\hline pata & nocala (15) & $\begin{array}{l}\text { pata }(\mathrm{L}) \text {; pata de } \\
\text { ave }(\mathrm{H})\end{array}$ & & nocala & nocala \\
\hline pato blanco & joquietag (24v) & pato blanco & & yoquictag & yoquictag \\
\hline $\begin{array}{l}\text { pato negro } \\
\text { grande } \\
\text { [cormorán] }\end{array}$ & $\operatorname{ascan}(24 v)$ & $\begin{array}{l}\text { pato negro } \\
\text { [cormorán] }\end{array}$ & & ascan & ascan \\
\hline \multirow{2}{*}{$\begin{array}{l}\text { patos negros } \\
\text { chiquitos }\end{array}$} & yeleni $(24 \mathrm{v})$ & pato chiquito & & ycleni & ycleni \\
\hline & & patrón & & ybuc & ybuc \\
\hline pava del monte & estajuetag (24v) & pava del monte & & estajuctag & estajuc-tag \\
\hline \multirow[t]{2}{*}{ pecho } & notoque (15) & pecho & & $\begin{array}{l}\text { notoque; } \\
\text { notuguc }\end{array}$ & $\begin{array}{l}\text { no-toque; no- } \\
\text { tuguc }\end{array}$ \\
\hline & & pedir & & $\begin{array}{l}\text { asla; notala; } \\
\text { noslla }\end{array}$ & $\begin{array}{l}\text { asla; notala; } \\
\text { noslla }\end{array}$ \\
\hline pedir licencia & vosilote (15) & $\begin{array}{l}\text { pedir licencia o } \\
\text { avisar }\end{array}$ & & vasilotc & vasilotc \\
\hline pedo & $\begin{array}{l}\text { notugcaz; } \\
\text { juegquio (15v) }\end{array}$ & pedo & & notugcaz & notugcaz \\
\hline \multirow[t]{2}{*}{ peer } & agtui (15) & peer & & agtuc & agtuc \\
\hline & & pegarse & & seteg & seteg \\
\hline peinarse & nosit (15) & peinarse & & nosit, leteg & nosit leteg \\
\hline peine & chonig (15v) & peine & & chonig & chonig \\
\hline pelar 72 & locat (15) & & & & \\
\hline
\end{tabular}

\footnotetext{
${ }^{72}$ Se trata al parecer de un error de Primo en la entrada castellana, "pelar" por "pelear": este <locat> se correspondería con el <licat> de las copias (cf. "pelear").
} 


\begin{tabular}{|c|c|c|c|c|c|}
\hline \multicolumn{2}{|c|}{ Primo (AFT, 1795) } & \multicolumn{4}{|c|}{ Copias del $M_{A N u s C R I T O} D^{\prime} O_{R B I G N y}$} \\
\hline Castellano & Mataco & Castellano & O'ORBIGNY & Lafone 1896 & Hunt 1913 \\
\hline pelar fruta & $\begin{array}{l}\text { nolenquie tajes } \\
\text { (15) }\end{array}$ & $\begin{array}{l}\text { pelar o quitar la } \\
\text { cáscara }\end{array}$ & & yenguietajes & yenguie tajes \\
\hline pelear & $\begin{array}{l}\text { notaglin; taccle } \\
\text { (15) }\end{array}$ & pelear & & $\begin{array}{l}\text { notaglo; licat } \\
\text { titi hium }\end{array}$ & $\begin{array}{l}\text { notaglo; licat titi } \\
\text { hium }\end{array}$ \\
\hline pelo & no olee (15) & pelo & & noolee & no-olee \\
\hline pendiente & $\begin{array}{l}\text { noquio tele } \\
(15 \mathrm{v})\end{array}$ & pendiente & & noguiotele & no-guiote-le \\
\hline $\begin{array}{l}\text { [pene] } \\
\text { "miembro" }\end{array}$ & $100(3)$ & [pene] "miembro" & & 100 & 100 \\
\hline peones & $\begin{array}{l}\text { nochumienei } \\
\text { (15v) }\end{array}$ & $\begin{array}{l}\text { peones }(L) \text {; peón } \\
(H)\end{array}$ & & $\begin{array}{l}\text { nochumienec; } \\
\text { nocainom }\end{array}$ & $\begin{array}{l}\text { no-chumyenec; } \\
\text { noca-inom }\end{array}$ \\
\hline pequeño & $\operatorname{lasag}(15 \mathrm{v})$ & pequeño & & lasag & lasag \\
\hline perderse & $\begin{array}{l}\text { tetaig pl. } \\
\text { tetaiglin (15) }\end{array}$ & $\begin{array}{l}\text { perderse alguna } \\
\text { cosa }\end{array}$ & & $\begin{array}{l}\text { tetaig pl. } \\
\text { tetaiglin; } \\
\text { nogueti }\end{array}$ & $\begin{array}{l}\text { tetaig pl. } \\
\text { tetaiglin; "casa": } \\
\text { nogueti }\end{array}$ \\
\hline \multirow[t]{2}{*}{ perro } & $\begin{array}{l}\text { sinag; signata } \\
\text { pl. sinas; } \\
\text { signatas (15) }\end{array}$ & perro & & signag pl. sinas & $\begin{array}{l}\text { sinag; signag pl. } \\
\text { sinas }\end{array}$ \\
\hline & & perro ligero & & snag, guajalin & sinag guajalin \\
\hline \multirow[t]{2}{*}{ pesado } & tilag-pa (15v) & $\begin{array}{l}\text { pesado }(\mathrm{L}) \\
\text { pesado, pesar }(\mathrm{H})\end{array}$ & & tilagpa & tilagpa; tiglapa \\
\hline & & $\begin{array}{l}\text { pesado o no } \\
\text { ligero }\end{array}$ & & & choneglin \\
\hline pesar & tilagpa (15) & pesar & & tiglapa; ytitnum & ytitnum \\
\hline pescado & $\begin{array}{l}\text { yagset } \mathrm{pl} . \\
\text { yasetes (15v) }\end{array}$ & pescado & & $\begin{array}{l}\text { yagset } \mathrm{pl} . \\
\text { yagsetes }\end{array}$ & $\begin{array}{l}\text { yagset } \mathrm{pl} . \\
\text { yagsetes }\end{array}$ \\
\hline pescar con red & abocoi (15) & pescar con red & & abocoy & abocoy \\
\hline $\begin{array}{l}\text { pescar con } \\
\text { flecha }\end{array}$ & tiajan (15) & pescar con flecha & & tiacan & tiacan \\
\hline pescuezo & labo (24v) & pescuezo & & $\begin{array}{l}\text { nabo; nabotes; } \\
\text { pagni }\end{array}$ & $\begin{array}{l}\text { na-bo; na-botes; } \\
\text { pagni }\end{array}$ \\
\hline petaca & nocagni (15v) & petaca & & $\begin{array}{l}\text { nocagni; } \\
\text { nocluuc }\end{array}$ & nocagni; nocluuc \\
\hline $\begin{array}{l}\text { pezón del ají o } \\
\text { de otra cosa }\end{array}$ & $a c(24 \mathrm{v})$ & pezón & & $a c$ & $a c$ \\
\hline pícaro $^{73}$ & obtitag (15v) & pícaro & & ytayeg & itayeg \\
\hline pico de las aves & paset (15v) & pico de las aves & & paset & paset \\
\hline piedra & tuunte (15) & piedra & & tuunte & tuunte \\
\hline \multirow[t]{3}{*}{ pies } & nopachio (15v) & pies & & nopachio & $\begin{array}{l}\text { pie: no-cala; } \\
\text { planta del pie: } \\
\text { no-pachio }\end{array}$ \\
\hline & & pintarse & & ylen, hoaytag & ilen hoaytag \\
\hline & & pintura (achiote) & & & hoaytag \\
\hline piojo & gla (15v) & & & & \\
\hline
\end{tabular}

${ }^{73}$ Sólo reconocemos fácilmente el término de las copias: itäyaj 'pícaro/malhechor'. 


\begin{tabular}{|c|c|c|c|c|c|}
\hline \multicolumn{2}{|c|}{ Primo (AFT, 1795) } & \multicolumn{4}{|c|}{ Copias del $M_{A N u s C R I T O} D^{\prime} O_{R B I G N y}$} \\
\hline Castellano & Mataco & Castellano & O'ORBIGNY & LAFONE 1896 & Hunt 1913 \\
\hline pisar & aspè (15) & pisar & & aso; aspe & aso; aspe \\
\hline $\begin{array}{l}\text { pisar o apretar } \\
\text { la tierra }\end{array}$ & $\begin{array}{l}\text { chojuagquie } \\
\text { godnet (15) }\end{array}$ & $\begin{array}{l}\text { pisar o apretar la } \\
\text { tierra }\end{array}$ & & $\begin{array}{l}\text { choguegguie } \\
\text { gognet }\end{array}$ & $\begin{array}{l}\text { choguegguie } \\
\text { gognet }\end{array}$ \\
\hline plata & colque $^{*}(15 \mathrm{v})$ & plata & & colque* & colque* \\
\hline plato & quinag (15) & plato & & $\begin{array}{l}\text { aset; quinag; } \\
\text { chapel }\end{array}$ & $\begin{array}{l}\text { barro: aset; } \\
\text { hierro: quinag; } \\
\text { chapel }\end{array}$ \\
\hline \multirow[t]{2}{*}{ pluma $^{74}$} & lejo (15v) & & & & \\
\hline & & $\begin{array}{l}\text { plumar }(L) ; \\
\text { plumar? }(H)\end{array}$ & & $\begin{array}{l}\text { chiguititas, } \\
\text { lejuya }\end{array}$ & chiguititas, lejuya \\
\hline pobre & lichag (15) & pobre & & lichag & lichag \\
\hline \multirow[t]{3}{*}{ pobrecito } & lichajajuu (15) & & & & \\
\hline & & muy pobre & & jajucim & jajucim \\
\hline & & poco a poco & & $\begin{array}{l}\text { atagnan; } \\
\text { atagnanflin }\end{array}$ & $\begin{array}{l}\text { atagnan; } \\
\text { atagnanflin }\end{array}$ \\
\hline podrido & najut (15v) & podrido & & najut & najut \\
\hline podrirse & najut (15) & podrirse & & nojuti & nojuti \\
\hline poner & tinacachi (15) & $\begin{array}{l}\text { poner/poner en } \\
\text { algún lugar }\end{array}$ & & $\begin{array}{l}\text { pon: tigi; aigi; } \\
\text { poner en algún } \\
\text { lugar: tinacachi }\end{array}$ & $\begin{array}{l}\text { poner: tigi; aigi; } \\
\text { poner en algún } \\
\text { lugar: tinacachi }\end{array}$ \\
\hline $\begin{array}{l}\text { ponerse } \\
\text { adelante }\end{array}$ & ajoye (15) & poner adelante & & $\begin{array}{l}\text { ajoye; majoye; } \\
\text { letagiig }\end{array}$ & $\begin{array}{l}\text { ajoye; majoye; } \\
\text { letagiig }\end{array}$ \\
\hline ponerse atrás & jolejute (15) & ponerse atrás & & jolejutc & jolejutc \\
\hline \multirow[t]{2}{*}{ poquito } & $\begin{array}{l}\text { quiesag; } \\
\text { quinsag (15v) }\end{array}$ & poquito & & quinsag & quinsag \\
\hline & & pon al fuego & & & agua \\
\hline porongo & bochotag (15v) & porongo & & bochotag & bochotag \\
\hline $\begin{array}{l}\text { porongo de } \\
\text { abejas }\end{array}$ & yeclag $(24 \mathrm{v})$ & $\begin{array}{l}\text { porongo de } \\
\text { abejas }\end{array}$ & & yeclag & yeclag \\
\hline \multirow[t]{2}{*}{ porotos } & $\operatorname{anietag}(15)$ & porotos & & anictag & anictag \\
\hline & & porque & & ziquiac & ziquiac \\
\hline está preñada & $\begin{array}{l}\text { ahochan; } \\
\text { choochan (15) }\end{array}$ & $\begin{array}{l}\text { estar preñada }(L) \\
\text { preñada }(H)\end{array}$ & & $\begin{array}{l}\text { ahochan; } \\
\text { chohochan }\end{array}$ & $\begin{array}{l}\text { achochan; } \\
\text { ahochan; } \\
\text { chochochan }\end{array}$ \\
\hline $\begin{array}{l}\text { presentar } \\
\text { alguna cosa }\end{array}$ & $\begin{array}{l}\text { huit nogueno } \\
\text { (15) }\end{array}$ & $\begin{array}{l}\text { prestar, dar } \\
\text { gratuitamente } \\
(\mathrm{L}) ; \text { presentar, dar } \\
\text { gratuitamente }(\mathrm{H})\end{array}$ & no-gueno & & no-gueno \\
\hline prestar & $\begin{array}{l}\text { noquie janeg } \\
\text { (15) }\end{array}$ & prestar & & $\begin{array}{l}\text { chojantieg; } \\
\text { noquiejaneg }\end{array}$ & $\begin{array}{l}\text { chojantieg; } \\
\text { noquiejaneg }\end{array}$ \\
\hline \multirow[t]{2}{*}{ presto } & $\begin{array}{l}\text { guatana; cayle; } \\
\text { alojo (15) }\end{array}$ & presto & & $\begin{array}{l}\text { guatana; caile; } \\
\text { aloxa }\end{array}$ & guatana; caile \\
\hline & & primero & & nequela & nequela \\
\hline
\end{tabular}

\footnotetext{
${ }^{74}$ Parece estar anotando /hefw 'su ala'.
} 


\begin{tabular}{|c|c|c|c|c|c|}
\hline \multicolumn{2}{|c|}{ Primo (AFT, 1795) } & \multicolumn{4}{|c|}{ Copias del $M_{\text {ANUSCRITO }} D^{\prime} O_{\text {BbIGNY }}$} \\
\hline CAstellano & Mataco & CAstellano & O'ORBIGNY & LAFone 1896 & Hunt 1913 \\
\hline puerta & no-peot (15v) & puerta & & nope-ot & nope; nopeot \\
\hline pulga & sinag vos (15v) & pulga & & signagvos & signag-vos \\
\hline pulsera & $\begin{array}{l}\text { noque-ojuat } \\
(24 \mathrm{v})\end{array}$ & pulsera & & nocuc, ojuata & no-cucojuata \\
\hline punta & lepes (15v) & punta & & lepes & lepes \\
\hline \multirow[t]{2}{*}{ ¿qué? } & qui? (16) & ¿qué? & & qui? & qui? chi? \\
\hline & & ¿qué es lo que? & & achimayeg? & achimayeg? \\
\hline ¿qué es eso? & achumachi? (16) & ¿qué es eso? & & $\begin{array}{l}\text { achumagchi? } \\
\text { quiapajac? }\end{array}$ & $\begin{array}{l}\text { achumagchi? } \\
\text { quiapajac? } \\
\text { quiapajate? }\end{array}$ \\
\hline ¿qué más? ${ }^{75}$ & qui voel? (16) & ¿qué más? & & chiel? quiina? & $\begin{array}{l}\text { chiel? chieel? } \\
\text { quiinac? }\end{array}$ \\
\hline ¿qué quieres? & $\begin{array}{l}\text { atagla jumen? } \\
\text { (16) }\end{array}$ & & & & \\
\hline ¿qué traes? & $\begin{array}{l}\text { atagle chag? } \\
\text { (16) }\end{array}$ & ¿qué traes? & & ataglechag & atagle chag? \\
\hline quebrado & $\begin{array}{l}\text { poxo pl. } \\
\text { poxotas (16) }\end{array}$ & $\begin{array}{l}\text { quebrado (L)/ } \\
\text { quebrado, } \\
\text { quebrarse (H) }\end{array}$ & & poxo; poxotas & poxo; poxotas \\
\hline \multirow[t]{2}{*}{ quebrar } & $\begin{array}{l}\text { nonacas; non- } \\
\text { nacas (16) }\end{array}$ & quebrar & & $\begin{array}{l}\text { non-macas; } \\
\text { echa }\end{array}$ & nonmacas; echa \\
\hline & & quebrarse $^{76}$ & & poxo; sayec & sayec \\
\hline quemar & $\begin{array}{l}\text { itag tuug; no-yo } \\
\text { (16) }\end{array}$ & quemar & & $\begin{array}{l}\text { tiag-tuug; } \\
\text { nooyo; labag }\end{array}$ & $\begin{array}{l}\text { tiag-tuug; nooyo; } \\
\text { labag }\end{array}$ \\
\hline querer & $\begin{array}{l}\text { jumen; ajumen; } \\
\text { ijumen (16) }\end{array}$ & querer & & $\begin{array}{l}\text { junin; yjumin; } \\
\text { ajuminatage }\end{array}$ & $\begin{array}{l}\text { junin; yjumin; } \\
\text { ajuminatage }\end{array}$ \\
\hline queso & cachos (16) & queso & & guasetacathos & guaseta-cathos \\
\hline no quiero & $\begin{array}{l}\text { ijumennità; } \\
\text { nujitate (16) }\end{array}$ & no querer & & $\begin{array}{l}\text { yjuminite; } \\
\text { nujunitc }\end{array}$ & $\begin{array}{l}\text { yjuminite; } \\
\text { nujunitc }\end{array}$ \\
\hline \multirow[t]{2}{*}{ no quiero nada } & $\begin{array}{l}\text { nojumnite; } \\
\text { ijumennite- } \\
\text { mahic (16) }\end{array}$ & & & & \\
\hline & & ¿quién? & & achitagehi? & achitagehi? \\
\hline \multirow[t]{2}{*}{$\begin{array}{l}\text { ¿de quién es } \\
\text { eso? }\end{array}$} & $\begin{array}{l}\text { achine tagj? } \\
\text { achaicatage } \\
\text { taj? (4) }\end{array}$ & ¿de quién es eso? & achine tag (30) & $\begin{array}{l}\text { achine tag? } \\
\text { achitagge? }\end{array}$ & $\begin{array}{l}\text { achinetag? } \\
\text { achitagge? }\end{array}$ \\
\hline & & ¿quién es ese? & & $\begin{array}{l}\text { achinag- } \\
\text { chitagchi? } \\
\text { achipi? } \\
\text { achitape? }\end{array}$ & $\begin{array}{l}\text { achinag } \\
\text { chitagchi? achipi? } \\
\text { achitape? }\end{array}$ \\
\hline \multirow[t]{2}{*}{ ¿quién es aquel? } & $\begin{array}{l}\text { achi tag lechi? } \\
\text { (16) }\end{array}$ & ¿quién es aquel? & & achitaglechi? & achitaglechi? \\
\hline & & ¿quién esto trae? & & achitag-pa? & achitagpa? \\
\hline
\end{tabular}

\footnotetext{
75 Podemos transliterar dos de estas expresiones y arriesgar una traducción literal, aunque no las hemos escuchado: <Qui voel?> Chi wo elh? '¿Qué hace otro? y <Chiel> Chi elh? ¿Qué otro?'

76 Cf. "quebrado".
} 


\begin{tabular}{|c|c|c|c|c|c|}
\hline \multicolumn{2}{|c|}{ Primo (AFT, 1795) } & \multicolumn{4}{|c|}{ Copias del MANusCRITO $D^{\prime} O_{\text {BbIGNY }}$} \\
\hline Castellano & Mataco & Castellano & O'ORBIGNY & LAFone 1896 & Hunt 1913 \\
\hline & & quinto & & yjuantesi & yjuantesi \\
\hline & & quince & & naya & naya \\
\hline $\begin{array}{l}\text { quirquincho } \\
\text { [armadillo] }\end{array}$ & $\begin{array}{l}\text { oguanag; } \\
\text { teletag (16) }\end{array}$ & $\begin{array}{l}\text { quirquincho } \\
\text { [armadillo] }\end{array}$ & & $\begin{array}{l}\text { telatag; } \\
\text { oguanag }\end{array}$ & telatag; oguanag \\
\hline quitar & $\begin{array}{l}\text { iscat pl. iscaten } \\
\text { (16) }\end{array}$ & quitar & & $\begin{array}{l}\text { yscat; etanchag } \\
\text { pl. ycaten }\end{array}$ & $\begin{array}{l}\text { yscat; ycaten; } \\
\text { etanchag }\end{array}$ \\
\hline no quitar & cama iscat (16) & no quitar & & camaiscat & cama iscat \\
\hline \multirow[t]{3}{*}{$\begin{array}{l}\text { quítate el } \\
\text { sombrero }\end{array}$} & $\begin{array}{l}\text { tacquia cabona } \\
\text { (16) }\end{array}$ & $\begin{array}{l}\text { quitarse el } \\
\text { sombrero }\end{array}$ & & tacguiacabona & tacguia cabona \\
\hline & & quitataco [planta] & & natal & natal \\
\hline & & quijada & & nochaloslie & no-chalos-lie \\
\hline rabón & chopo (17) & rabón & & chopo & chopo \\
\hline \multirow[t]{2}{*}{ rajan } & acquie (17) & rajar & & yuagquie & yuagquie \\
\hline & & rajarse $^{77}$ & & poxo & poxo \\
\hline rana & gualegte (17) & & & & \\
\hline \multirow[t]{2}{*}{ rascarse } & chiasma (17) & rascarse & & chiasma & chiasma \\
\hline & & raspar & & ajas & ajas \\
\hline ratón & amat (17) & ratón & & amat & amat \\
\hline raya, pescado & pogni (17) & raya, pescado & & pogni, taajan & pogni taajan \\
\hline rayo & juichec iag (17) & rayo & & yuichecyag & yuichecyag \\
\hline recoger & notueq (17) & & & & \\
\hline \multirow[t]{2}{*}{ red } & otanag (17) & red & & otama & o-tama \\
\hline & & redondo & & letoig; tonlaglin & letoig; tonlaglin \\
\hline regar & chaipi guag (17) & & & & \\
\hline regalar & $\begin{array}{l}\text { huit nogueno } \\
\text { (17) }\end{array}$ & regalar & & huitnoguem & $\begin{array}{l}\text { no-guen; } \\
\text { huitnoguem }\end{array}$ \\
\hline regoldar & $\begin{array}{l}\text { nopat; atujuac } \\
\text { (17) }\end{array}$ & regoldar & & $\begin{array}{l}\text { nopat; atujuac; } \\
\text { cojuc; coujua }\end{array}$ & $\begin{array}{l}\text { no-pat; atujuac; } \\
\text { cojuc; coujua }\end{array}$ \\
\hline reír & esquiei (17) & reír & & esguieili & esguieili \\
\hline \multirow[t]{4}{*}{ relámpago } & yoclep (17) & relámpago & & yoclep & yoclep \\
\hline & & remedio caliente & & nocathia & no-cathia \\
\hline & & remendar & & toy, cheec & toy cheec \\
\hline & & remolino & & guc, saiontag & gucsaiontag \\
\hline rempujar & nunquie (17) & rempujar & & yomec; nugguic & yomec; nugguic \\
\hline reñir & yglin (17) & reñir & & yglin & yglin \\
\hline reventar & poxo (17) & reventar & & poxo & poxo \\
\hline rincón & lacaucu (17) & rincón & & lacaucu & letoig; lacaucu \\
\hline río & tecta (16) & río & & tecta & tecta \\
\hline río corriente & $\begin{array}{l}\text { tecta ilajuelquie } \\
\text { (17) }\end{array}$ & río corriente & & tecta ilajucche & tecta ilajucche \\
\hline
\end{tabular}

\footnotetext{
77 Cf. "quebrado".
} 


\begin{tabular}{|c|c|c|c|c|c|}
\hline \multicolumn{2}{|c|}{ Primo (AFT, 1795) } & \multicolumn{4}{|c|}{ Copias del Manuscrito $D^{\prime} O_{\text {RBIGNY }}$} \\
\hline Castellano & Mataco & Castellano & O'ORBIGNY & LAFONE 1896 & Hunt 1913 \\
\hline río crecido & tecta poig (17) & río crecido & & $\begin{array}{l}\text { tetacuug; } \\
\text { tectapoig }\end{array}$ & $\begin{array}{l}\text { tetac ung; tecta } \\
\text { poig }\end{array}$ \\
\hline río manso & $\begin{array}{l}\text { tecta lajue } \\
\text { niquiete (17) }\end{array}$ & río manso & & $\begin{array}{l}\text { tecta } \\
\text { ilajucnijuctic; } \\
\text { tectac-iin }\end{array}$ & $\begin{array}{l}\text { tecta ilajuc } \\
\text { nijuctic; tectac iin }\end{array}$ \\
\hline robar & $\begin{array}{l}\text { iscat; etanchag } \\
\text { (17) }\end{array}$ & robar & & yscat; etanchag & yscat; etanchag \\
\hline robal, pescado & tachucuita (17) & $\begin{array}{l}\text { robal/roba, } \\
\text { pescado }\end{array}$ & & tachucuita & tachucuita \\
\hline rocío & $\begin{array}{l}\text { ayas; mucho: } \\
\text { ayasas (17) }\end{array}$ & rocío & & ajas; yas & ajas; yas \\
\hline rodilla & $\begin{array}{l}\text { nocanquiete } \\
\text { (17) }\end{array}$ & rodilla & & nocanguicte & no-canguiete \\
\hline romper & $\begin{array}{l}\text { quiesag; lequies } \\
\text { (17) }\end{array}$ & romper & & $\begin{array}{l}\text { queisag; } \\
\text { lequies; } \\
\text { chesaag }\end{array}$ & $\begin{array}{l}\text { queisag; lequies; } \\
\text { chesaag }\end{array}$ \\
\hline $\begin{array}{l}\text { ropa } \\
\text { cualquiera }\end{array}$ & guesag (17) & ropa & & & no-huc; $u$; o \\
\hline sábalo & cheiñat (18) & sábalo & & cheinat & cheinat \\
\hline saber & janeg (18) & saber & & $\begin{array}{l}\text { yaneg; } \\
\text { nijaneyec; taig; } \\
\text { tetag }\end{array}$ & $\begin{array}{l}\text { yaneg; ni- } \\
\text { janeyec; taig; } \\
\text { tetag }\end{array}$ \\
\hline no saber & \begin{tabular}{|l} 
tayeg, taig, \\
ijaniegte (18)
\end{tabular} & no saber & & yjanicte & yjanicte \\
\hline sacar & leni (18) & sacar & & leni & Ieni \\
\hline no sacar & leni ijite (18) & no sacar & & leniijijinite & leni-ijijinite \\
\hline sacudir & siquiat (18) & sacudir & & siquiat & siquiat \\
\hline sal & nisoy (18) & sal & & & nisoi \\
\hline salir & nupa (18) & sal $(\mathrm{L})$; salir $(\mathrm{H})$ & & nupa & nupa \\
\hline saliva & laquil (18) & saliva & & laguiel; nolachil & laguiel; no-lachil \\
\hline salivar & $\begin{array}{l}\text { nojuachug; } \\
\text { nolaquil (18) }\end{array}$ & salivar & & najuachug & na-juachug \\
\hline sandía & suvelac (18) & sandía & & suvelac & suvelac \\
\hline \multirow[t]{2}{*}{ sangre } & vois (18) & sangre & & voys & voys \\
\hline & & $\operatorname{sano}^{79}$ & nolag (27v) & nolag; is & is; no-lag \\
\hline \multirow[t]{2}{*}{ sapo } & tagna (18) & sapo & & tagna & tagna \\
\hline & & sarna & & quiesag & quiesag \\
\hline sebo & ag-la (18v) & sebo & & & agla \\
\hline secar & tecquiai (18) & secarse & & tecnhiac & tecnhiac \\
\hline $\begin{array}{l}\text { secarse o } \\
\text { cortarse el agua }\end{array}$ & $\begin{array}{l}\text { inaguag; im } \\
\text { guag (18) }\end{array}$ & $\begin{array}{l}\text { secarse o cortarse } \\
\text { el agua }\end{array}$ & & ynguag & ynguag \\
\hline
\end{tabular}

\footnotetext{
${ }^{78}$ Reconocemos fácilmente el término de Primo: wesaj 'algodón/tela/trapo' (cf. "jerga"). En las copias quizá el primero sea un error por nowuy 'su ropa'.

${ }^{79}$ Quizá nälej is 'parece estar bien'.
} 


\begin{tabular}{|c|c|c|c|c|c|}
\hline \multicolumn{2}{|c|}{ Primo (AFT, 1795) } & \multicolumn{4}{|c|}{ Copias del $M_{A N u s C R I T O} D^{\prime} O_{R B I G N y}$} \\
\hline Castellano & Mataco & Castellano & O'Orbigny & LAFONe 1896 & Hunt 1913 \\
\hline $\begin{array}{l}\text { tener sed (18); } \\
\text { sed (18v); tener } \\
\text { sed (19) }\end{array}$ & $\begin{array}{l}\text { noquim (18); } \\
\text { noquin (18v); } \\
\text { noquin; negelan } \\
\text { ilan (19) }\end{array}$ & tener sed & & $\begin{array}{l}\text { noquiin; } \\
\text { negelan; yctun; } \\
\text { negelanpillan; } \\
\text { nogtlin }\end{array}$ & $\begin{array}{l}\text { quimo; no-quiin; } \\
\text { negelan; negelan } \\
\text { pillan; nogtlin; } \\
\text { yctun }\end{array}$ \\
\hline \multirow[t]{3}{*}{ seguir a otro } & moque (18) & seguir a otro & & moquel; yjuic & moquel; yjuic \\
\hline & & segundo 80 & & eel & eel \\
\hline & & seis & & todajinta & todajinta \\
\hline sembrar & tuudquie (18) & sembrar & & tuudguic & tuutguic \\
\hline ya sembré & $\begin{array}{l}\text { pacquie notud } \\
\text { quie (18) }\end{array}$ & ya sembré & & $\begin{array}{l}\text { pacquic } \\
\text { notudguic }\end{array}$ & $\begin{array}{l}\text { pacquic } \\
\text { notudguic }\end{array}$ \\
\hline semilla & càs; loy (18) & $\begin{array}{l}\text { semilla }(O, L, H) \text {; } \\
\text { cogollo }(H)\end{array}$ & & $\begin{array}{l}\text { nocas, looy, } \\
\text { nocaslooy }\end{array}$ & $\begin{array}{l}\text { looy (semilla); } \\
\text { no-cas (cogollo) }\end{array}$ \\
\hline sentado & pajiempa (18) & sentado & & рара; рајіетра & рара; рајіeтра \\
\hline sesos & letigla (q8v) & sesos & & letigla & letigla \\
\hline sí & $e e(18)$ & sí & & ic & ic \\
\hline \multirow[t]{2}{*}{ sidras } & achetatas (18v) & sidras & & achetatas & acheta-tas \\
\hline & & siete & & loosi & loosi \\
\hline silbar & yoc (18) & silbar & & yoc piin & yocpiin \\
\hline silla & nohuet (18v) & silla & & nohueghuet & no-hueghuet \\
\hline sobaco & nubilis cho (18) & sobaco & & nubilicho & nu-bilicho \\
\hline $\begin{array}{l}\text { sobremesa de } \\
\text { cháguar }\end{array}$ & siquiet (18) & $\begin{array}{l}\text { sobremesa de } \\
\text { cháguar }\end{array}$ & & siguiet & siguiet \\
\hline sobrina & $\begin{array}{l}\text { lenig; lenijua } \\
\text { (18) }\end{array}$ & sobrina & & lenig; lenijua & lenig; lenijua \\
\hline sobrino & nohagla (18) & sobrino & & nohacla & $\begin{array}{l}\text { no-hacla; no- } \\
\text { uaela }\end{array}$ \\
\hline sol & ijuala (18) & sol & & $\begin{array}{l}\text { yjuala; yjuaba; } \\
\text { iqua'a }\end{array}$ & $\begin{array}{l}\text { ijuala; ijuaba; } \\
\text { iqua'a }\end{array}$ \\
\hline $\begin{array}{l}\text { soldado, } \\
\text { cristiano }\end{array}$ & ajatay (18) & soldado, cristiano & & ajalag & ajalag \\
\hline \multirow[t]{2}{*}{ solo ${ }^{81}$} & befacla (18) & solo & & tangua & tangua \\
\hline & & sombra & & nupel; na & nupel; na \\
\hline sombrero & nocabona (18) & sombrero & & nocabona & no cabona \\
\hline sonsera & cainujia (18) & sonsera & & cainogia & cainogia \\
\hline sonso & $\begin{array}{l}\text { suc; isuc pl. } \\
\text { sucuis (18) }\end{array}$ & sonso & & $\begin{array}{l}\text { ysuc; suuc pl. } \\
\text { sucuis }\end{array}$ & $\begin{array}{l}\text { ysuc; suuc pl. } \\
\text { sucuis }\end{array}$ \\
\hline soplar & ajut (18) & soplar & & ajuthi & ajuthi \\
\hline sordo & chotequio (18) & sordo & & chototoio & choto-toio \\
\hline
\end{tabular}

\footnotetext{
${ }^{80}$ Cf. "otro".

81 Reconocemos la palabra de Primo: iwehyalha 'uno(número)/único' (cf. "uno"); las de las copias, no.
} 


\begin{tabular}{|c|c|c|c|c|c|}
\hline \multicolumn{2}{|c|}{ Primo (AFT, 1795) } & \multicolumn{4}{|c|}{ Copias del ManusCRITO $D^{\prime} O_{\text {RBIGNY }}$} \\
\hline Castellano & Mataco & Castellano & O'ORBIGNY & LAFone 1896 & Hunt 1913 \\
\hline sortija & nojugni (18) & sortija & & $\begin{array}{l}\text { nojugni; nojugi; } \\
\text { mío: icaobo; } \\
\text { tuyo: acabona; } \\
\text { del otro: } \\
\text { atalechi }\end{array}$ & $\begin{array}{l}\text { no-jugi; no-jugni; } \\
\text { 1. icaobo; } 2 \text {. } \\
\text { acabona }\end{array}$ \\
\hline subir $^{82}$ & nohul (18) & subir & & nuсa-puca & nucapuca \\
\hline sucio & $\begin{array}{l}\text { iquioño; } \\
\text { iquiodlin (18v) }\end{array}$ & sucio & & $\begin{array}{l}\text { yguiono; } \\
\text { yguiodlin }\end{array}$ & $\begin{array}{l}\text { yguiono; } \\
\text { yguiodlin }\end{array}$ \\
\hline \multirow[t]{2}{*}{ sudor } & $\begin{array}{l}\text { tacagli; chiug } \\
\text { (18) }\end{array}$ & sudor & & $\begin{array}{l}\text { chiug; } \\
\text { chuugaitag; } \\
\text { tacagli }\end{array}$ & $\begin{array}{l}\text { chiug; chuug- } \\
\text { aitag; tacagli }\end{array}$ \\
\hline & & suegro & & nocachati & no-cachati \\
\hline suelo & setay (18) & suelo & & setag; siteg & setag; siteg \\
\hline sueño & nogeti (18) & sueño & & negeti & negeti \\
\hline surubí & quiuncacu (18) & surubí & & quiuncacu & quiuncacu \\
\hline suspirar & no litag (18) & suspirar & & $\begin{array}{l}\text { leyalebompa; } \\
\text { aloblitag }\end{array}$ & $\begin{array}{l}\text { leyalebompa; } \\
\text { aloblitag }\end{array}$ \\
\hline $\begin{array}{l}\text { suyo, cuando } \\
\text { viviente }\end{array}$ & la pl. lay (18v) & $\begin{array}{l}\text { suyo (cuando la } \\
\text { cosa es viviente) }\end{array}$ & & la pl. lay & la pl. lay \\
\hline $\begin{array}{l}\text { suyo, cuando no } \\
\text { es viviente }\end{array}$ & $\begin{array}{l}\text { cai pl. caigies } \\
\text { (18v) }\end{array}$ & $\begin{array}{l}\text { suyo (cuando no } \\
\text { viviente) (L); suyo } \\
\text { (H) }\end{array}$ & & cay pl. caigies & cay pl. caigies \\
\hline tabaco & $\begin{array}{l}\text { yocos; yocuas } \\
\text { (19) }\end{array}$ & tabaco & & yocos; yocuas & yocos; yocuos \\
\hline tábano & lacas (19) & tábano & & lacas & lacas \\
\hline talega & nihilud (19) & talega de cháguar & & nihilud & nihilud \\
\hline \multirow[t]{2}{*}{ taparse } & ope (19) & taparse & & ope & ope \\
\hline & & tapón & & lopet & lopet \\
\hline por la tarde & jonag (19) & tarde & & yonag & yonag \\
\hline $\operatorname{tases}^{\star 83}$ & gualaup (19) & tases & & gualaup & gualaup \\
\hline tejer & nohic (19) & tejer & & nohuc; tii & tie; tii; no-huc tii \\
\hline telaraña & chiojoc sac (19) & telaraña & & chiojocsac & chiojoc-sac \\
\hline tender ${ }^{84}$ & atiji (19) & tender & & quicgni & quicgni \\
\hline \multirow[t]{2}{*}{ tener } & $\begin{array}{l}y_{g}^{u} \text { en; noguen; } \\
\text { not ala maic } \\
\text { (19) }\end{array}$ & tener & & $\begin{array}{l}\text { yguen; noguen; } \\
\text { nuhun ho }\end{array}$ & $\begin{array}{l}\text { yguen; noguen; } \\
\text { nuhunho }\end{array}$ \\
\hline & & no tener & & $\begin{array}{l}\text { novainita; nota; } \\
\text { hueni tde; } \\
\text { nouho }\end{array}$ & $\begin{array}{l}\text { novainita; nota; } \\
\text { huenitde; nouho }\end{array}$ \\
\hline $\begin{array}{l}\text { tener de alguna } \\
\text { cosa [agarrar] }\end{array}$ & choc (19) & $\begin{array}{l}\text { tener de alguna } \\
\text { cosa }\end{array}$ & & choc & choc \\
\hline tener frío & juiet ilan no (19) & tener frío & & yuletilanno & yulet-ilanno \\
\hline
\end{tabular}

82 Quizá Primo anotó notwulh 'trepa'. La palabra de las copias no la reconocemos.

83 Se trata sin duda de la enredadera Morrenia odorata, tasi en quechua y jwalawukw en wichí.

84 Reconocemos dos verbos wichís diferentes: <atiji> -tihi 'poner en' y <quicgni>, -ch'enhi 'abrir/tender' (como en 'tender algo al sol'). 


\begin{tabular}{|c|c|c|c|c|c|}
\hline \multicolumn{2}{|c|}{ Primo (AFT, 1795) } & \multicolumn{4}{|c|}{ Copias del $M_{A N u s C R I T O} D^{\prime} O_{R B I G N y}$} \\
\hline Castellano & Mataco & Castellano & O'Orbigny & LAFONE 1896 & Hunt 1913 \\
\hline tener miedo & onohaya (19) & tener miedo & & onohaga & o-nohaga \\
\hline no tener miedo & $\begin{array}{l}\text { onohaynicte } \\
\text { (19) }\end{array}$ & no tener miedo & & ohonohagnietc & ohonohag-nietec \\
\hline & & tener vergüenza ${ }^{85}$ & & nojucl & nojucl \\
\hline & & $\begin{array}{l}\text { tercera }(\mathrm{L}) \text {; tercero } \\
(\mathrm{H})\end{array}$ & & eeltaxe & eel taxe \\
\hline $\begin{array}{l}\text { [testículos] "las } \\
\text { partes" }\end{array}$ & $\begin{array}{l}\text { chanciles; } \\
\text { chanes (3) }\end{array}$ & $\begin{array}{l}\text { C... las partes del } \\
\text { hombre }(O) \text {; las } \\
\text { partes de la cola } \\
(\mathrm{L}, \mathrm{H})\end{array}$ & $\begin{array}{l}\text { chanchiles } \\
(28 \mathrm{v})\end{array}$ & $\begin{array}{l}\text { chanchiles; } \\
\text { chawe (p. 47); } \\
\text { chauc }\end{array}$ & $\begin{array}{l}\text { chianis; guianis; } \\
\text { chauc; chanchiles }\end{array}$ \\
\hline tetas & notate (19) & tetas & & notate & notate \\
\hline $\begin{array}{l}\text { poquitito } \\
\text { tiempo }\end{array}$ & teijua (1v) & & & & \\
\hline tierra & gognet (19) & tierra & & gognet & gognet \\
\hline tigre & yag (19) & tigre & & yag & yag \\
\hline tijeras & aintacui (19) & tijeras & & aintacuy & aintacui \\
\hline tinaja & yate (19) & tinaja & & yatc & yatc \\
\hline tío carnal & lay (19) & $\begin{array}{l}\text { tío }(\mathrm{L}, \mathrm{H}) ; \mathbf{m i} / \mathrm{tu} \\
\text { tío }(\mathrm{L})\end{array}$ & & $\begin{array}{l}\text { mi tío: leey; tío: } \\
\text { lay; tu tío: éléy }\end{array}$ & lay; leey; eley \\
\hline tirar & jumeg (19) & $\begin{array}{l}\text { tirar o botar } \\
\text { alguna cosa }\end{array}$ & & yumeg & yumeg \\
\hline tirar la flecha & tiag lotec (19) & $\begin{array}{l}\text { tirar o disparar } \\
\text { alguna cosa }\end{array}$ & & tiag & tiag \\
\hline $\begin{array}{l}\text { tirar de alguna } \\
\text { cosa }\end{array}$ & togne; ton (19) & $\begin{array}{l}\text { tirar de alguna } \\
\text { cosa }\end{array}$ & & togne; toan & togne; toan \\
\hline toba & guanlay (19) & toba & & guanlag & guanlag \\
\hline tobillo & nocasopa (19) & tobillo & & nocasopa & no-casopa \\
\hline toca la campana & ag quinag (19) & & & & \\
\hline tocar & $\begin{array}{l}\text { ag; agi; calajai } \\
\text { (19) }\end{array}$ & tocar & & aag; calagay & aag; calagay \\
\hline voy a tocar & agla (19) & & & & \\
\hline todos & $\begin{array}{l}\text { o-ague-nequieg } \\
\text { (19) }\end{array}$ & todos & & \begin{tabular}{|l|}
$\begin{array}{l}\text { aaguc nequicg, } \\
\text { oenec }\end{array}$ \\
\end{tabular} & $\begin{array}{l}\text { aaguc nequicg } \\
\text { oenec }\end{array}$ \\
\hline tomar & chuma (19) & tomar & & chuma; choc & chuma; choc \\
\hline torcido & choqueglin (19) & torcido & & choqueglin & choqueglin \\
\hline tordillo negro & chagquie (19) & tordillo & & chagquic & chagquic \\
\hline $\begin{array}{l}\text { toser (19), estar } \\
\text { acatarrado (5) }\end{array}$ & $\begin{array}{l}\text { quieltag ilam } \\
\text { (5); quieltag- } \\
\text { ilam (19) }\end{array}$ & toser & & quicltagilan & quicltag-ilan \\
\hline toser & $\begin{array}{l}\text { noyobogquie } \\
\text { nopagni (19) }\end{array}$ & & & & \\
\hline $\begin{array}{l}\text { trabajador } \\
\text { bueno }\end{array}$ & notacajui (19) & trabajador bueno & & nota, cajui & notacajui \\
\hline
\end{tabular}

${ }^{85}$ n'äfwelh 'tiene vergüenza'. 


\begin{tabular}{|c|c|c|c|c|c|}
\hline \multicolumn{2}{|c|}{ PrIMo (AFT, 1795) } & \multicolumn{4}{|c|}{ Copias del MANUSCRITO $D^{\prime} O_{\text {RBIGNY }}$} \\
\hline Castellano & Mataco & Castellano & O'OrBigny & LAFONE 1896 & Hunt 1913 \\
\hline trabajar & chunglin (19) & trabajar & & chuglin & chuglin \\
\hline tragón & yalcaltag (19) & tragón & & yalcaltag & yalcaltag \\
\hline \multirow[t]{3}{*}{ traer } & $\begin{array}{l}\text { mihe; chag; } \\
\text { achag; legchitla } \\
\text { (19) }\end{array}$ & traer & & chag; achag & chag; a-chag \\
\hline & & trampa & & lainlele & lainlele \\
\hline & & trece & & yacpe & yacpe \\
\hline trenzarse el pelo & pachin quie (19) & trenzar & & pachinquic & pachinguic \\
\hline tres & tacuiya (19) & tres & & tacuya & tacuya \\
\hline tripas & casle (19) & tripas & & casle & casle \\
\hline triste & obligtag (19) & triste & & oblitag & oblitag \\
\hline no triste & obligtagite (19) & no triste & & oblitagjite & oblitag-jite \\
\hline tropezar & napam (19) & tropezar & & napan & napan \\
\hline \multirow[t]{4}{*}{ trueno } & yplin (19) & $\begin{array}{l}\text { bramar }(\mathrm{O}) \text {; } \\
\text { trueno }(\mathrm{L}) \text {; bramar } \\
\text { trueno, tronar }(\mathrm{H})\end{array}$ & iplin (28) & yplin & ip-lin; iplin \\
\hline & & tú & & $\begin{array}{l}\text { aam; apam; } \\
\text { japeem }\end{array}$ & $\begin{array}{l}\text { aam; eem; apam; } \\
\text { japeem }\end{array}$ \\
\hline & & tú eres & & japenage eem & jape nage eem \\
\hline & & tuyo & & $\begin{array}{l}\text { ya; acaiguet; } \\
\text { acatag }\end{array}$ & $\begin{array}{l}\text { ya; aca; acatag; } \\
\text { acaiguet }\end{array}$ \\
\hline \multirow[t]{2}{*}{ ubres } & cachos (20) & ubres & & chachos & chachos \\
\hline & & último & & lajoo & Iajoo \\
\hline uno & befacla (20) & uno & & befagla & befagla \\
\hline untar & ilageg (20) & untar & & ylegeg & ylegeg \\
\hline uña & $\begin{array}{l}\text { nojug tag pl. } \\
\text { nojus tages (20) }\end{array}$ & uña & & $\begin{array}{l}\text { nojugtag pl. } \\
\text { nojustajes }\end{array}$ & $\begin{array}{l}\text { no-jug-tag pl. no- } \\
\text { jus-tajes }\end{array}$ \\
\hline urundel & antac (20) & urundel & & antac & antac \\
\hline vaca & guaseta (2) & vaca & $\begin{array}{l}\text { guasita, isan } \\
\text { (26v) } \\
\end{array}$ & guaseta, ysan & guaseta \\
\hline vaho & nojuac (20) & vaho & & nojuac & no-juac \\
\hline vaina & legi (2) & vaina & leji (26v) & legi & legi \\
\hline vamos & nec; aquila (20) & vamos & & $\begin{array}{l}\text { neec; todos } \\
\text { vamos: } \\
\text { mayaneec }\end{array}$ & $\begin{array}{l}\text { neec; vamos } \\
\text { todos: maya neec }\end{array}$ \\
\hline vaso & noglati (20) & vaso & & noglati & noglati \\
\hline no te vayas ${ }^{86}$ & $\begin{array}{l}\text { camahec; ma- } \\
\text { titeg (20) }\end{array}$ & no te vayas & & matitc; mathitc & matitc; mathitc \\
\hline vejiga & utluni (2) & vejiga & ultuni (27) & utuni & utuni \\
\hline [vejoz] bejoso & $\begin{array}{l}\text { tacho pl. } \\
\text { tachones (2) }\end{array}$ & $\begin{array}{l}\text { bejoso }(\mathrm{O}) \text {; vejoso } \\
(\mathrm{L}, \mathrm{H})\end{array}$ & \begin{tabular}{|l|} 
tatho pl. \\
tactones (27) \\
\end{tabular} & $\begin{array}{l}\text { tatho pl. } \\
\text { tactunes }\end{array}$ & $\begin{array}{l}\text { tatho pl. } \\
\text { tactunes }\end{array}$ \\
\hline vela & notlet (2) & vela & nolet (27) & nolet & no-let \\
\hline
\end{tabular}

${ }^{86}$ Cf. "anda". 


\begin{tabular}{|c|c|c|c|c|c|}
\hline \multicolumn{2}{|c|}{ PRIMo (AFT, 1795) } & \multicolumn{4}{|c|}{ Copias del MANusCRITo $D^{\prime} O_{\text {RBIGNy }}$} \\
\hline Castellano & Mataco & Castellano & O'ORBIGNY & LAFone 1896 & Hunt 1913 \\
\hline vena & nosat (20) & vena & & nosat & nosat \\
\hline \multirow[t]{4}{*}{ ven acá } & $\begin{array}{l}\text { aco caana; } \\
\text { luum; niquiei } \\
\text { (20) }\end{array}$ & ven acá & & $\begin{array}{l}\text { acocana; luum; } \\
\text { nitié }\end{array}$ & $\begin{array}{l}\text { acocana; } \\
\text { acacona; luu; } \\
\text { luum; nitie }\end{array}$ \\
\hline & & venir & & $\begin{array}{l}\text { niet; noye; atha; } \\
\text { achina }\end{array}$ & $\begin{array}{l}\text { niet; noye; atha; } \\
\text { achina }\end{array}$ \\
\hline & & $\begin{array}{l}\text { venir, a las que } \\
\text { vengan }\end{array}$ & & ocaja & ocaja \\
\hline & & $\begin{array}{l}\text { venir, a los } \\
\text { hombres }\end{array}$ & & ynonijocana & ynonijocana \\
\hline no quiere venir & $\begin{array}{l}\text { netag; nequitag; } \\
\text { neiquite (20) }\end{array}$ & no quiere venir & & $\begin{array}{l}\text { netag; } \\
\text { nequitag; } \\
\text { neiquite }\end{array}$ & $\begin{array}{l}\text { netag; nequitag; } \\
\text { neiquite; yquite } \\
\text { netag }\end{array}$ \\
\hline ver & $\begin{array}{l}\text { yo: yama guen; } \\
\text { aquel ha visto: } \\
\text { iven; todos han } \\
\text { visto: noguen } \\
\text { (20) }\end{array}$ & ver & & yjuen & yjuen \\
\hline $\begin{array}{l}\text { verdaderamente, } \\
\text { cierto }\end{array}$ & itmet; met (20) & verdad, cierto & & $\begin{array}{l}\text { mat; meet; } \\
\text { achun }\end{array}$ & mat; meet \\
\hline $\begin{array}{l}\text { no } \\
\text { verdaderamente }\end{array}$ & metite (20) & no verdad, falso & & $\begin{array}{l}\text { matti-tde; } \\
\text { meetite }\end{array}$ & mattitde; meetite \\
\hline $\begin{array}{l}\text { verde o no seco; } \\
\text { verde, yerba o } \\
\text { planta }\end{array}$ & $\begin{array}{l}\text { achuc; guachan } \\
\text { (20) }\end{array}$ & $\begin{array}{l}\text { verde yerba o } \\
\text { planta }\end{array}$ & & guachan & guachan \\
\hline verdolaga & anec (20) & & & & \\
\hline vestirse & odlaienlin (20) & vestirse & & odla-ienlin & odla; ienlin \\
\hline víbora & $\operatorname{anlag}(20)$ & víbora & & anlag; ylai ile & anlag \\
\hline viejo & chiut (20) & viejo & & chiut & chiut \\
\hline vieja, pescado & chiguitag (20) & vieja, pescado & & $\begin{array}{l}\text { chiguitag; } \\
\text { chiutag }\end{array}$ & chiguitag \\
\hline \multirow[t]{2}{*}{ viento } & ijuac (20) & viento & & ynjuac & ynjuac \\
\hline & & mucho viento & & ynguacuetag & ynguacuetag \\
\hline \multirow[t]{3}{*}{ viruelas } & chiutadquie (20) & viruelas & & $\begin{array}{l}\text { chiutagquic; } \\
\text { chiutagchic }\end{array}$ & $\begin{array}{l}\text { chiutag-quic (o } \\
\text { chic) }\end{array}$ \\
\hline & & viuda & & tesa pl. tesales & tesa pl. tesales \\
\hline & & viudo & & nate pl. nateles & nate pl. nateles \\
\hline \multirow[t]{4}{*}{$\operatorname{vivos}^{87}$} & caninia (20) & vivir, vivo & & & ylai; Ile \\
\hline & & volar & luumpa (27v) & luumpa & luumpa \\
\hline & & volver & & & laame \\
\hline & & $\begin{array}{l}\text { volver o venir } \\
\text { adonde se sale }\end{array}$ & $\begin{array}{l}\text { tepil-nan; tepil- } \\
\text { la }(27 \mathrm{v})\end{array}$ & $\begin{array}{l}\text { tepil; tepil-la; } \\
\text { nan }\end{array}$ & tepil; tepil-la; nan \\
\hline
\end{tabular}

\footnotetext{
${ }^{87}$ En <ylais reconocemos iläy 'está vivo/vive' y en <caninia>, quizá, -känyaj 'buena presencia' o ikanhän 'vivir allá'. El otro término no lo reconocemos.
} 


\begin{tabular}{|c|c|c|c|c|c|}
\hline \multicolumn{2}{|c|}{ Primo (AFT, 1795) } & \multicolumn{4}{|c|}{ Copias del ManusCRIto $D^{\prime} O_{\text {RbIGNy }}$} \\
\hline Castellano & Mataco & Castellano & O'ORBIGNY & LAFONE 1896 & Hunt 1913 \\
\hline $\begin{array}{l}\text { volver del otro } \\
\text { lado }\end{array}$ & tilagquia (2) & $\begin{array}{l}\text { volver del otro } \\
\text { lado }(O) \text {; volver } \\
\text { del otro lado } \\
\text { alguna cosa }(L, H)\end{array}$ & tilaglipeel (27v) & tilaglipeel & tilag lipeel \\
\hline $\begin{array}{l}\text { vuelve o repite } \\
\text { otra vez }\end{array}$ & achag-quie (2) & $\begin{array}{l}\text { volver a repetir } \\
(\mathrm{O}) \text {; volver o } \\
\text { repetir }(L, H)\end{array}$ & $\begin{array}{l}\text { achagguic } \\
\text { (27v) }\end{array}$ & achagguic & achagguic \\
\hline \multirow[t]{2}{*}{ dar vueltas } & noluclin (2) & $\begin{array}{l}\text { volver a todo } \\
\text { lados o dar } \\
\text { vueltas }\end{array}$ & noluclin $(27 v)$ & notuclin & no-tuclin \\
\hline & & volveré ahorita & $\begin{array}{l}\text { nanmel[...]a } \\
\text { [tachado] (27v) }\end{array}$ & & \\
\hline \multirow[t]{3}{*}{ vomitar } & nochuñet (20) & vomitar & & nochuñet & no-chuñet \\
\hline & & vosotros & & amey; yehi & $\begin{array}{l}\text { amey; emey } \\
\text { (?yehi) }\end{array}$ \\
\hline & & vosotros sois & & japemeyu & japemeyu \\
\hline me voy & $\begin{array}{l}\text { yapi; hic; obees } \\
\text { aquila (20) }\end{array}$ & voy & & yapi; hic & yapi; hic \\
\hline vueltas & nolunaglin (2) & vueltas & noluglin $(27 \mathrm{v})$ & & \\
\hline \multirow[t]{2}{*}{ vuelve pronto } & caile laama (2) & $\begin{array}{l}\text { vuelve pronto }(\mathrm{O}) \text {; } \\
\text { vuelve presto }(\mathrm{L} \text {, } \\
\text { H) }\end{array}$ & $\begin{array}{l}\text { caile laama } \\
(27 \mathrm{v})\end{array}$ & caile laame & caile laame \\
\hline & & ya & & & $\begin{array}{l}\text { pacquic; pazquie; } \\
\text { pacchi }\end{array}$ \\
\hline yacaré & alutag (22) & yacaré & & alutag & alutag \\
\hline \multirow[t]{2}{*}{ yerbas } & la-tales (22) & yerbas & & latales & la-tales \\
\hline & & yerro & & $z$ & nojayenec \\
\hline yesquero, yesca & $\begin{array}{l}\text { yesquero: } \\
\text { nocaitagi; } \\
\text { yesca: nocaitag, } \\
\text { lac (22) }\end{array}$ & yesquero & & nocaitaglac & noca-itag-lac \\
\hline yo & yam (22) & yo & & yaan; yapian & yaan \\
\hline yo soy & yam me (22) & yo soy & & japian & $\begin{array}{l}\text { yapian; japian; } \\
\text { yamme jaapian; } \\
\text { jamo apian }\end{array}$ \\
\hline zancudos & yapina (23) & zancudos & & yapina & yapina \\
\hline \multirow[t]{2}{*}{ zapallo } & $\begin{array}{l}\text { esquin pl. } \\
\text { esquinas (23) }\end{array}$ & zapallo & & $\begin{array}{l}\text { esguin pl. } \\
\text { esquinas }\end{array}$ & $\begin{array}{l}\text { esguin pl. } \\
\text { esquinas }\end{array}$ \\
\hline & & zapallo negro & & aniotag & aniotag \\
\hline zapato & $\begin{array}{l}\text { nisa pl. nisas } \\
(23)\end{array}$ & zapato & & nisa pl. nisas & nisa pl. nisas \\
\hline Zenta & Iupui (23) & zenta & & Iupuc & lupuc \\
\hline zorro & mau, tasloc (23) & zorro & & mau; tasloc & mau; tasloc \\
\hline
\end{tabular}

